$=239$

$\sqrt{28}$

opy 1

\title{
Van Pelt's
}

Cow Demonstration

By HUGH G. VAN PELT

Published by

Kimball's Dairy Farmer

Waterloo, Iowa 



\section{Van Pelt's}

\section{Cow Demonstration}

\section{By}

\section{HUGH G. VAN PELT}

Iowa Dairy Expert

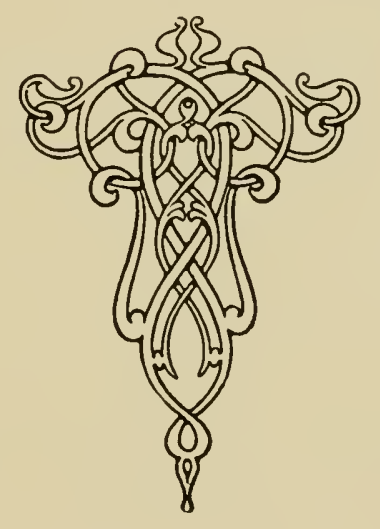

PUBLISHED BY

\section{KIMBALL'S DAIRY FARMER}

WATERLOO,'IOWA 


\section{CONTENTS}

PAGE

List of illustrations ..................... 5

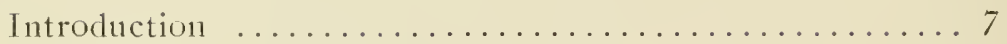

CHAPTER I.

Five essential points of a productive cow............11

CHAP'TER II.

Constitution of the cow ........................ 19

CHAPTER III.

Capacity . . . . . . . . . . . . . . . . . . .

CHAPTER IV.

Nervous temperament

CHAPTER V.

Blood circulation

CHAPTER VI.

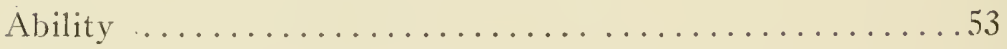

CHAPTER VII.

Other desirable points $\ldots \ldots \ldots \ldots \ldots \ldots \ldots \ldots \ldots \ldots .63$

CHAPTÉR VIII.

How to secure cows combining the five essential points...67

CHAPTER IX.

The accurate proof of the cow's value............. 81 


\section{LIST OF ILLUSTRATIONS}

Parthenia Hengerveld-A many times champion Holstein cow in the largest shows of America. Owned by W. B. Barney

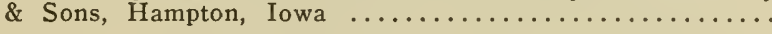

Page

Frontispiece

BosnIANA'S ANNA-Champion Jersey cow Iowa and National Dairy Shows, 1910. Owned by C. I. Hudson, East Norwich,

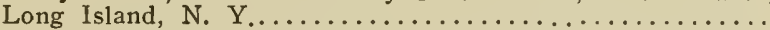

12 and 56

Auchenbrain's White Beauty 2nd-A champion Ayrshire cow,

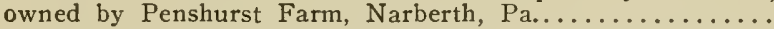

Colantha 4th's Johanna-Champion cow of the world. Record 1247.95 pounds butter, 80 per cent fat in one year. Owned

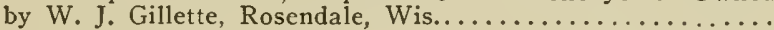

First and second prize Ayrshire cows at the Iowa and National Dairy Shows, 1910. Owned by L. A. Reyman Estate, Wheeling, W. Va., and Ryanogue Farm, Brewster, N. Y., re-

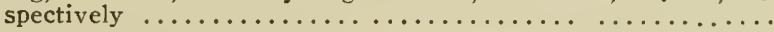

BoghaLL's SNOWDROP-Champion Ayrshire cow at the Iowa and National Dairy Shows, 1910. Owned by L. A. Reyman Est.,

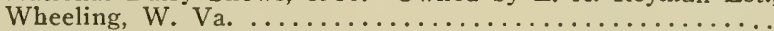

DAIRY MAID of PINEHURST-Champion 3-year-old cow of the world. Record 1012.07 pounds butter, 80 per cent fat, in one year. Owned by W. W. Marsh, Waterloo, Iowa......18, 20, 24, 26

JACOBA IRENE-Champion long distance cow of the world. 2053 pounds, 15.3 ounces butter, 85 per cent fat in two years. Owned by F. B. Keeney, Warsaw, N. Y......28, 34, 46, 50, 54, 58, 62

LORD MAR-An undefeated Guernsey bull. Owned by W. W.

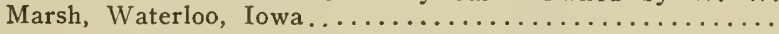

The bead of a champion Guernsey bull................

HowiE's Fizzaway-Ayrshire bull, Champion winner at National Dairy Show, 1909. Owned by J. F. Converse \& Son,

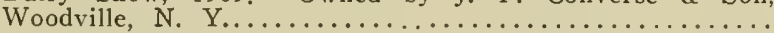

Netherhall Brownie IX.-Champion Ayrshire cow. Record 1025.11 pounds butter, 80 per cent fat, in one year. Owned

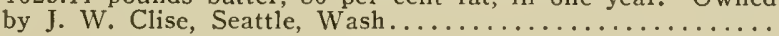

Noble of OAKlands-Many times a champion. Sold for $\$ 15,000$, highest price ever paid at auction for a Jersey bull. Owned by Elmendorf Farm, Lexington, Ky................

Glencoe's Bopeep-Champion Guernsey cow at the Iowa and National Dairy Shows, 1910. Owned by W. W. Marsh,

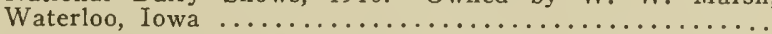

Sir Beets Cornucopia Netherland-Champion Holstein bull at the Iowa and National Dairy Shows, 1910. Owned by W. S. Moscrip, St. Paul, Minn..................... 72, 74, 78

Financial Countess-Ex. champion Jersey cow. Record 935 pounds, 10 ounces of butter in one year. Owned by C. E.

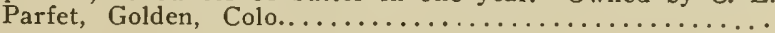

A pair of great cows from the Island of Jersey ..............

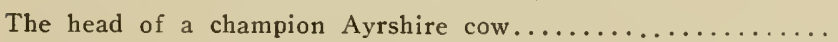

MaUser's Queen-Champion Jersey cow Illinois State Fair, 1909. Owned by H. V. Prentice, Worcester, Mass.............

Pietertje Maid Ormsiy-Champion 30-day cow of the world. Record 145.66 pounds butter, 80 per cent fat. Owned by John B. Irwin, Minneapolis, Minn.......... 


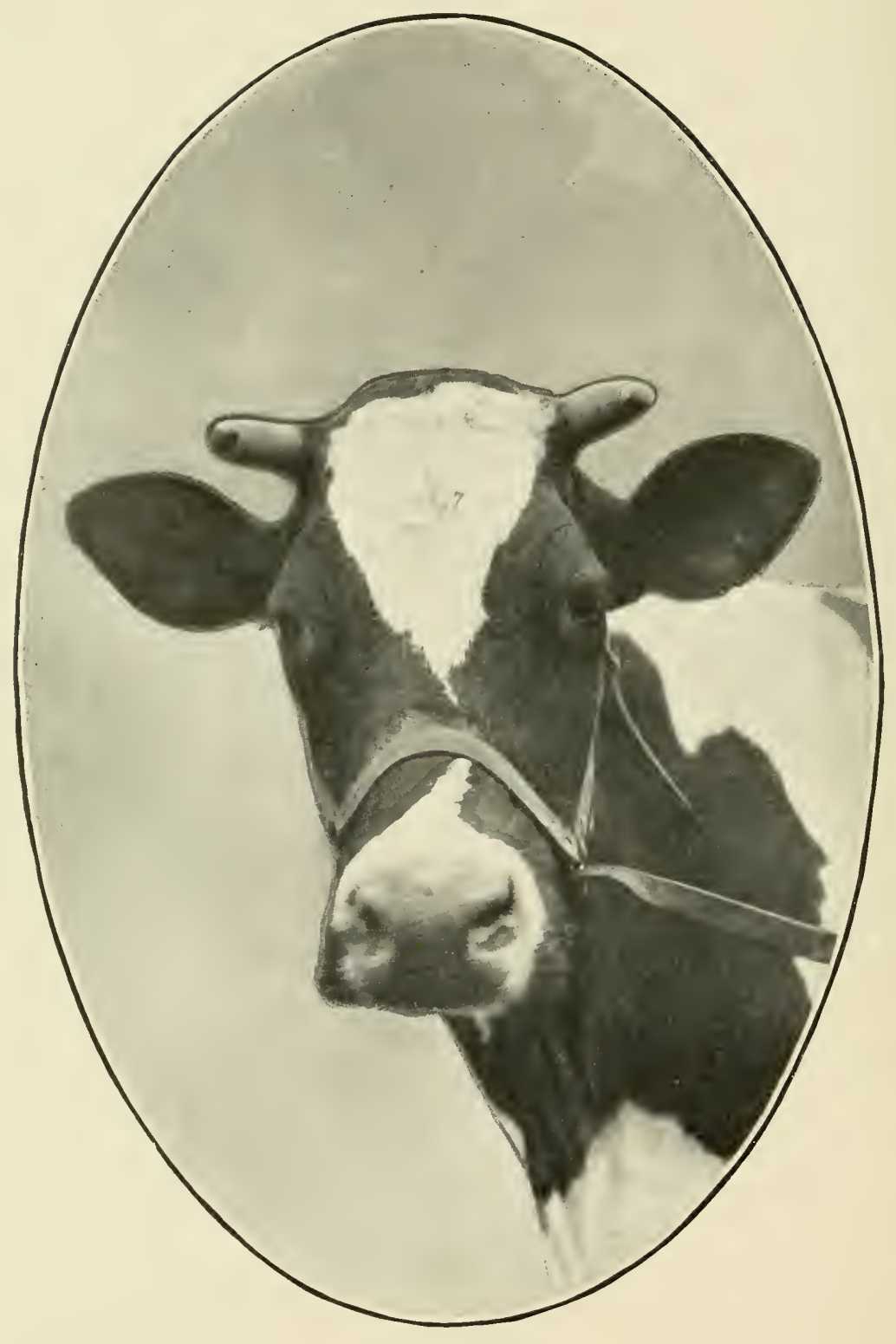




\section{INTRODUCTION}

Present day competition has placed all industries on a commercial basis. The successful merchant is the one who can sell his wares at the lowest price and still make as large as or a larger percentage of profit than his competitors. The successful professional man is the one who receives the greatest remuneration because of the value of his services to his clients. The successful manufacturer is the one whose methods enable him to produce an article and sell it at a price as low as or lower than that asked by other manufacturers and still make as great a profit. The farmer who produces products on his farm for the least possible cost, quality considered, is the one who is successful.

There has never been a time when the farmer could not boast that of all humanity he alone is really independent. To so great an extent has this been true and so well has it generally become known among agriculturists that there is a likelihood that the farmer has grown careless to a degree and in his strife for higher prices has overlooked a very important point; namely, that a dollar saved in the cost of producing 100 pounds of any commodity is in reality, a dollar made and probably the easiest dollar that possibly could be made upon the farm.

This is especially true of the dairy farmer or the man on the farm who milks cows. There is a general complaint all over the land that the dairy business is very confining and where one farmer or farmer's son is found who likes to milk there are 50 who would rather do any other farm labor. Why? Because so many of the cows are not worth milking. The conditions under which they are milked are repelling. There are few farms on which there are not from 10 to 75 per cent of the cows that are absolutely making no profit whatever and many that are a source of loss to their owners. In the days when butter-fat was selling for 10 or 12 rents a pound, and a drug on the market at that, there might have been some excuse for the manufacturer of dairy products losing money on some of his cows, yet undoubtedly a larger percentage of the cows in those days were making net profits for their owners than are at the present time. When cows are kept upon land worth from $\$ 25$ to $\$ 50$ an acre and can be fed corn worth from 10 to 12 cents a bushel, oats from 8 to 10 cents, bran from $\$ 10$ to $\$ 12$ per ton, oil meal $\$ 10$ to $\$ 20$ per ton, hay from 
$\$ 3$ to $\$ 5$ a ton, it is a mighty poor cow that will not pay for her feed and make for her owner some sort of a net profit to remunerate him for his labor. Farmers complained bitterly in those times because it was impossible to secure more for the butter-fat. Today the farmer is, in many localities, receiving an average of more than 30 cents a pound the year around for butter-fat. If. however, lie will look the proposition squarely in the face he will find that with corn worth 50 cents or more a bushel, oats from 32 to 40 cents a bushel, bran from $\$ 25$ to $\$ 28$ a ton, oil meal from $\$ 30$ to $\$ 40$ per ton, hay from $\$ 10$ to $\$ 20$ per ton and other foods proportionately high that he is making less real profit in feeding cows on land worth from $\$ 100$ to $\$ 300$ per acre than he did during those times which he called hard. This statement is made advisedly and refers to that class of cows which are to be found on the average farm.

Farm conditions have changed so radically and yet so gradually that few are the farmers who realize that they really are milking a number of cows over 700 times each year merely for the fun of doing so, and yet statistics determined by considering the number of cows milked in the United States and the number of farms upon which they are milked, will bear out the statement that on the average farm someone is wasting annually 27.2 days every year milking cows that return no profit whatever.

There are two reasons why there are so many profitless cows. First, on the average farm cows are not cared for properly. They do not receive feed in the proper amounts or of the proper character. The barns in which they are kept are often lark, damp, cold and poorly ventilated. The cows are milked, fed and watered at irregular intervals and as a matter of fact they are not seriously considered from the standpoint of farm profits.. Cows cared for under conditions such as these are rictims of misfortune and it matters little how well bred they may be or how excellent their individuality, it is out of the question to expect that they will make for their owner any great amount of profit.

Secondly, there are being kept on the farms of the United States a vast number of cows so lacking in breeding individuality and ability that it is impossible for them to produce profitably. It makes no difference whether they are found on the common farm under adverse conditions or in the high class dairy where they receive every possible opportunity by way of feed, care and treatment. they will 


\section{VAN PELT'S COW DEMONSTRATION}

never return a cent of profit over and above the cost of the feed they consume. It is estimated that out of the 22,000,000 cows that are being milked on farms in the United States there are $14,000,000$ of them that are entirely unproductive of profits. Half of these, would make a profit were they properly fed and cared for. The other half, or $7,000,000$ cows, are unprofitable because they belong to one of two classes of cows-either poorly bred or miserable individuals.

In dealing with a description of cows and the building up of the herd to more profitable proportions, the subject must be confined largely to the same economic, commercial and businesslike basis that the manufacturer uses in selecting machines for his factory. True, the dairy cow is more than a machine. She is a living. highly nervous and rather sentimental being and in a great degree governed by the force of habit. These traits she possesses and in addition. if a good cow, all the qualities of an efficient, durable and capacious machine. It is therefore significant that the manufacturer of dairy products has a task even greater than the manufacturer of any other class of commodities. He must not only commercialize his efforts as do other manufacturers but in addition he must cater to the individual traits of each living machine on his farm factory.

When the farmer finally realizes that in reality the farms of this country are its greatest factories and that every animal is there for the same purpose as the machine in any other factory and that every machine must do its part well if the factory is to be a source of gratification and large dividends to its owner, then and not until then will all cows milked on the farm be a source of profit to their owners and not until then will the farm boy lose his desire to move to town and work in factories of another sort for a few cents per hour. Both the farmer and his son will then realize that of all factories the greatest dividends and interest on investments are returned by the factory, the roof of which is the sky and the walls the horizon. Because of this and because of the human interest in commercialism this book will deal with the cow more largely from the standpoint of a machine in the factory than from that of breed characteristics. 


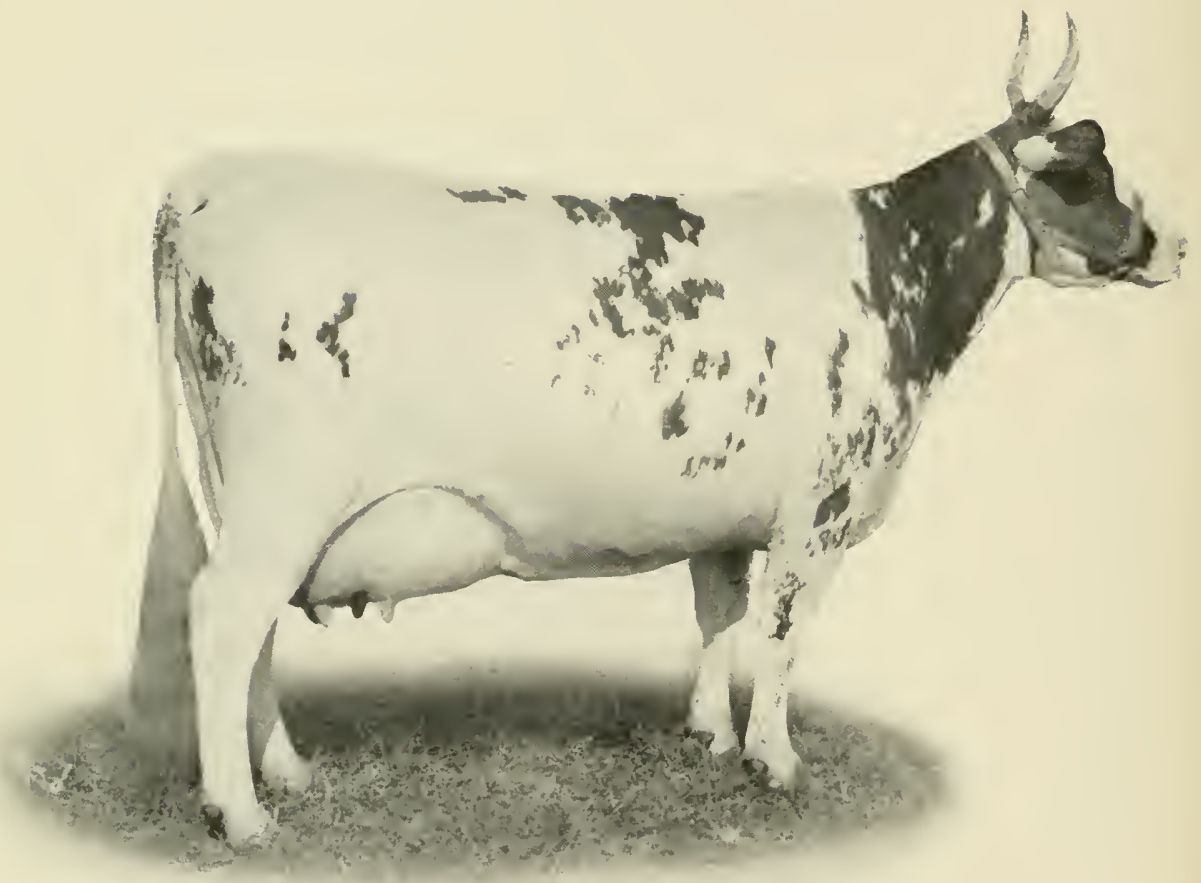

Form and beauty 


\section{Five Essentials of a Productive Cow}

The fundamental functions of the cow are production and reproduction. Her intrinsic value depends upon the efficiency with which she accomplishes these duties.

A careful study of any great producing cow reveals the manner in which she accomplishes her purpose. Viewed from the standpoint of production she must eat and digest food, she must breathe, her blood must circulate and she must yield milk and butter-fat, all of which is work.

If her efforts along these lines are effective certain portions of her body and certain characteristics assert themselves accordingly and may be termed the essential points that indicate great and economical production. There are five of these essential points that must be present and well developed in the external form of a cow if she proves herself a profitable producer of milk and butter-fat under present conditions. These are the indications of constitution, capacity, nervous temperament, blood circulation and ability.

If all of these points are present it may safely be considered that the cow will be highly productive if she is given the proper care and the treatment to which she is entitled.

\section{Each Point Is Vital}

So vital is each to great, economical and persistent performance that it is difficult to classify them in order of importance. Each is dependent upon the other and if any one is lacking in development the machinery is incomplete and he who milks such a beast does not milk a cow-only a part of a cow. She is like a gasoline engine with a corroded spark plug, a leaky gasoline tank, weak batteries. an undersized piston or an inefficient governor. Satisfactory results cannot reasonably be expected.

It often occurs that breeders in their eager desire to breed cows of phenomenal ability overlook the importance of the other points and when it seems they have succeeded in their achievements and most excellent results appear to be secured it is found that their animals lack constitution and although they yield almost abnomally for a short period they do not have the strength to contunue with the heavy work; some of them dic and others revert to the state of 


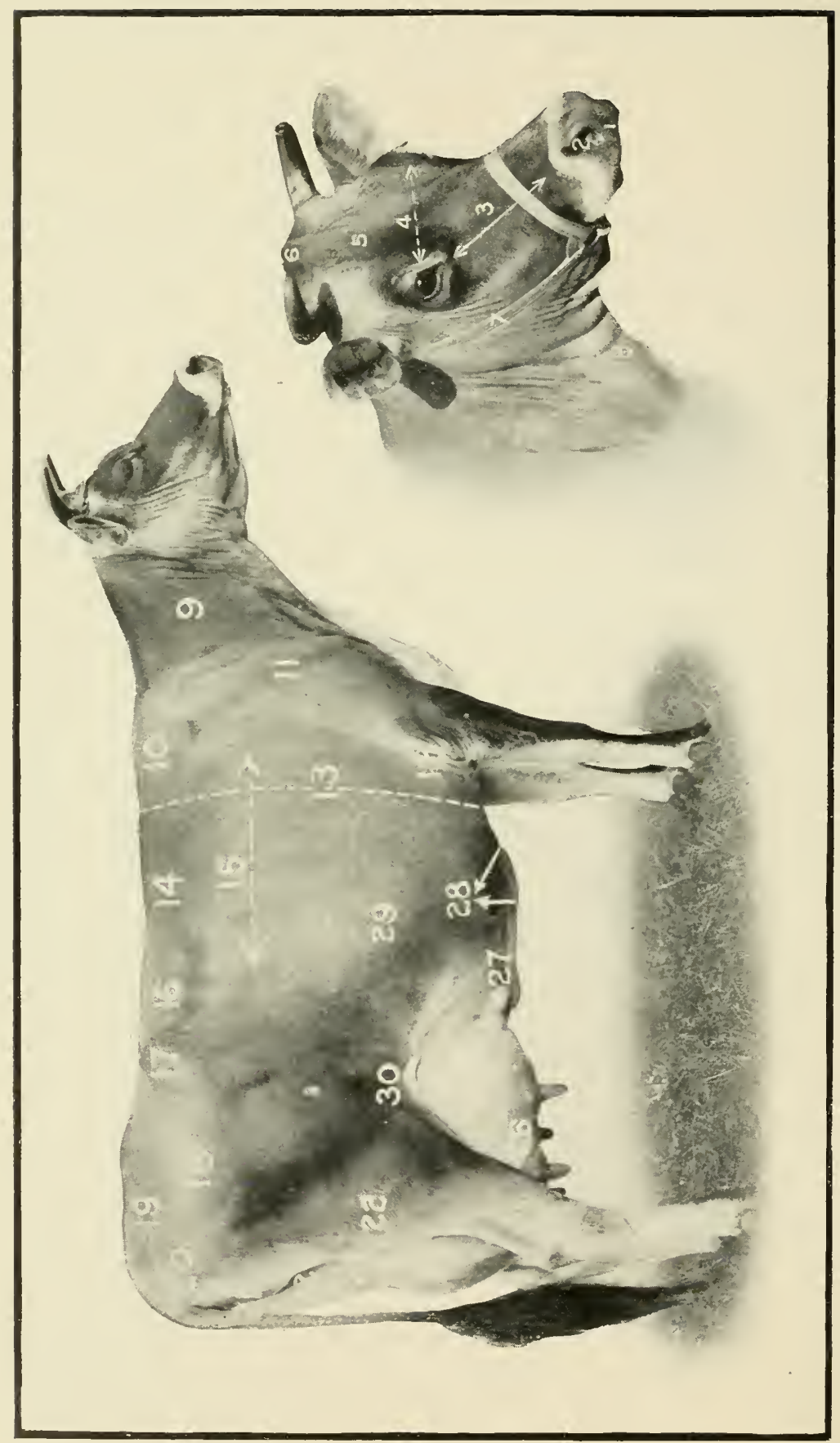

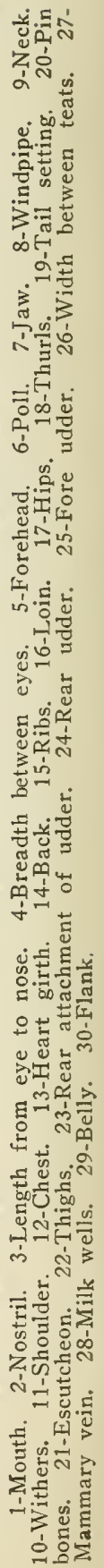


the loafer. Or it may be capacity that has been orerlooked and consequences equally as discouraging occur. So long as the animal may draw 11jon the stored up tissues of the body wonderful production continues but when this has become exhausted the animal is not capable of consuming a sufficient amount of food to keep up the work and she declines rapidly in her milk flow and is retired to the ranks of those that lack persistency. Such cows are difficult for even the most expert feeder to manage. When they freshen and he gradually increases their daily rations they respond readily and continue to do so reassuring the feeder every time a small amount of feed is added to their ration. Not expecting that the limit of capacity is so near when response to increased feed is so marked, the cow is overfed before her weakness is recognized.

Great as may be the development of all other parts if the significance of the nervons temperament is overlooked the cow will simply loaf and there will be neither greatness of production nor persistency. And in the same manner a circulatory system of the right sort dove-tails with the other essentials.

When this system is sluggish or developed in such a way that it carries the blood to other parts of the body" than the udder there will be a rapidly decreasing milk flow as soon as the maternal instincts of the cow have passed their state of greatest stimulation.

\section{No Point Can Be Overlooked}

Therefore in selecting and breeding cows it must be borne in mind that as important as any four of the essential points may be they are to a great degree worthless unless accompanied by the fifth.

Careful consideration of all the characteristics indicative of these essentials will by experience in their use aid greatly in selecting and breeding cattle of the useful sort and many connterfeits that might otherwise find their way into the herd may be discovered before it is too late.

To avoid confusion and the overlooking of one or more of the significant indices of development or the lack of it in any part it is well to acquire a systematic method of examinino the animal.

\section{Examining the Animal}

It is always advisable to take in the general appearance of the animal first for in many instances this is all that is necessary. To the experienced eye the first impression 


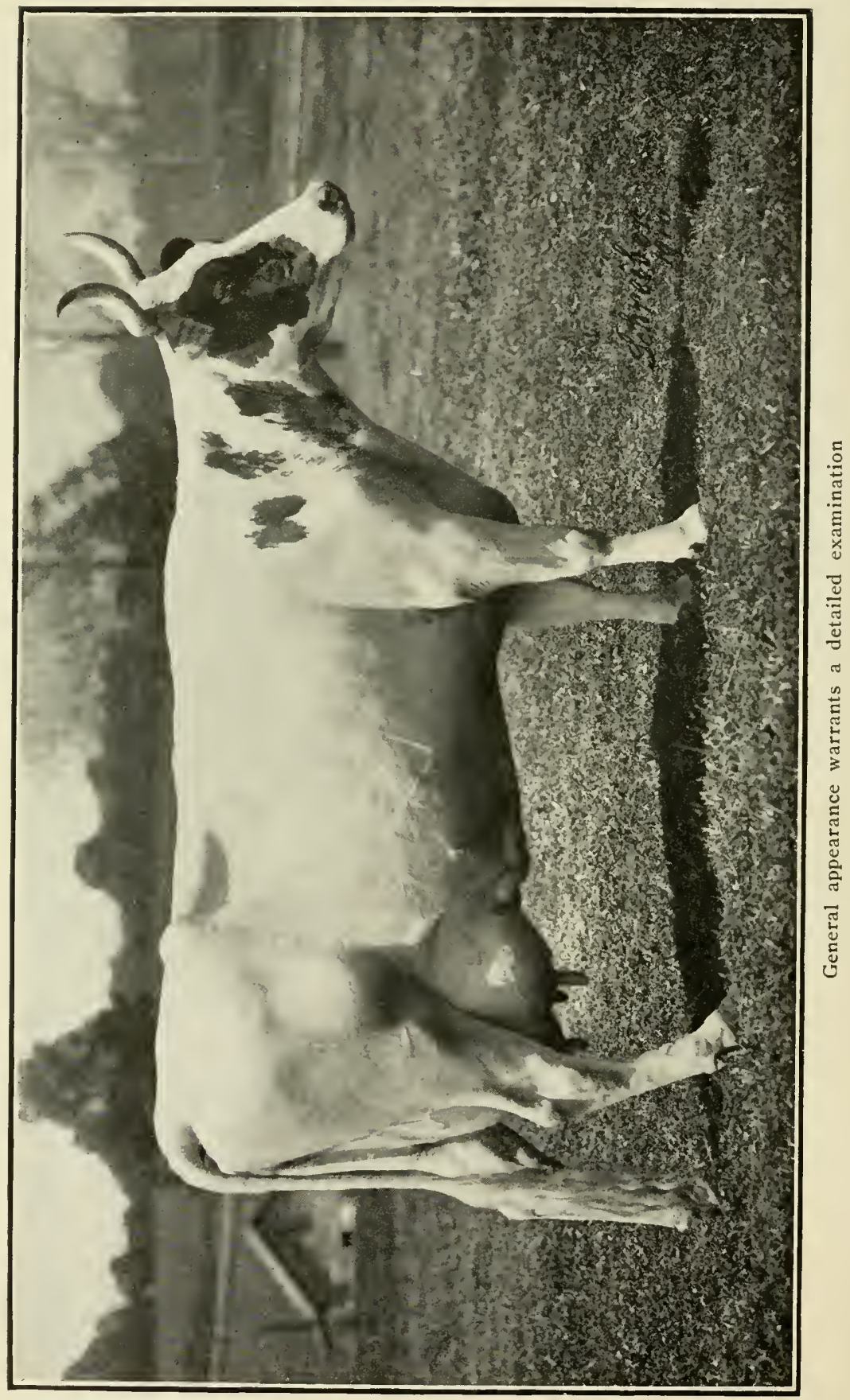


shows it to be faulty in one or more of the essential qualities. 'This first impression is always gained with greatest accuracy from a reasonable distance while the animal is standing or walking broadside to the observer. It is at this time that constitution and capacity are most plainly revealed, and never will a skillful judge decide between the comparative excellence of two animals that are closely matched until he has observed them in this manner. As a rule if the first impression is favorable it is well to walk slowly around the animal studying it in the same manner on all sides remembering that all animals do not present the same appearance on both sides. This examination requires but a very short time and if it has proven satisfactory and a further study of the animal is desirable it is well to step quietly to the head. After noting all indications presented there the observer may walk slowly along the side and, as he goes by, noting the form of the neck and by passing the hand firmly along the shoulder and backward along the spinal column he learns the character of these regions. With the other hand he can lift the hide and at once there will be conveyed to his mind the condition that obtains and after no great amount of experience he will find that different animals leave with him varying impressions as to quality in this respect.

\section{Hips and Rump}

The comparative width across the hips and length in the rump is usually apparent enough so it may be determined by the eye rather than by measurement with the arms although in cases where animals are nearly the same in these parts the latter procedure is sometimes advisable. By standing immediately behind the animal an impression of the conformation of the hind quarters is obtained and all necessary information relating to the length and quality of the tail can at this time be quickly gathered.

\section{Mammary System}

The examination of the mammary system should now take place and if possible should be made in detail by the use of both the senses of sight and touch for many are the indications of ability that escape the eye and as a rule enough mistakes occur where both faculties are put to work. In completing the examination of a cow it is always advisable to milk or see some one else milk her in order to determine certainly that there are no defects that are not apparent when the udder is full. 


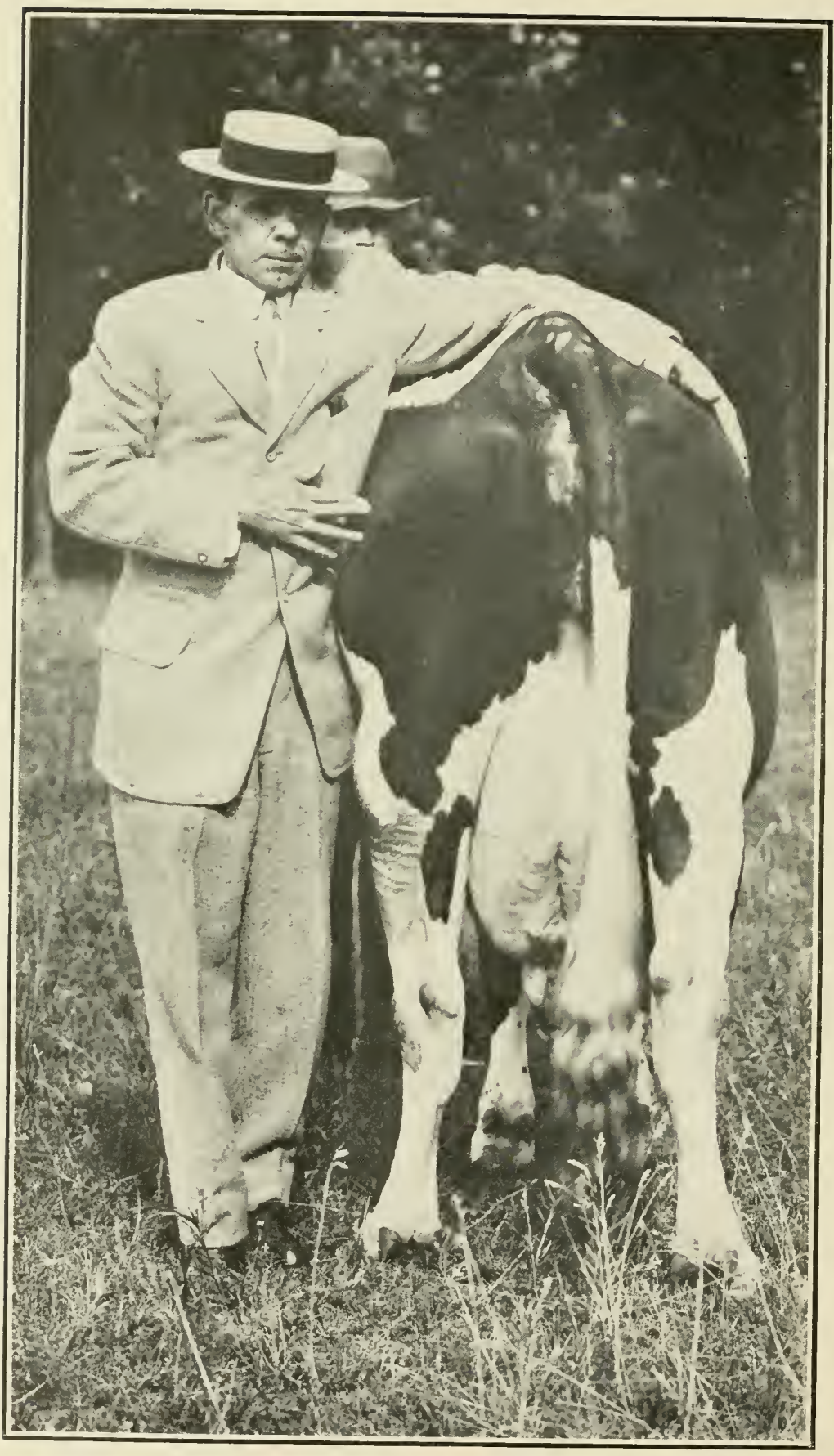

Width across the hips and through the thu:ls 


\section{VAN PELT'S COW DEMONSTRATION}

\section{Milk the Cow}

More than one judge of wide reputation has given first and championship prizes to cows of very inferior merit because he was so confident of his knowledge that he believed it useless to have them milked before completing the examination. Many a man has purchased a cow and never discovered her worthlessness in one or more quarters of her udder until she has been paid for and no recourse remained.

During the examination the observer should proceed promptly but he should not hurry. Although alert to discover the lesson told by each part he should go about his work in a manner so careful and quiet that at no time will he disturb the animal under consideration.

After considerable experience has been obtained little time is consumed in the process and it is well to accuire the habit of learning with certainty all that is to be known of the animal in the shortest possible time and to decide upon its merits without too much cleliberation for there is a danger of the judgment tiring. When this is the case wonder and guessing enter into all decisions rendering them either questionable or faulty. 


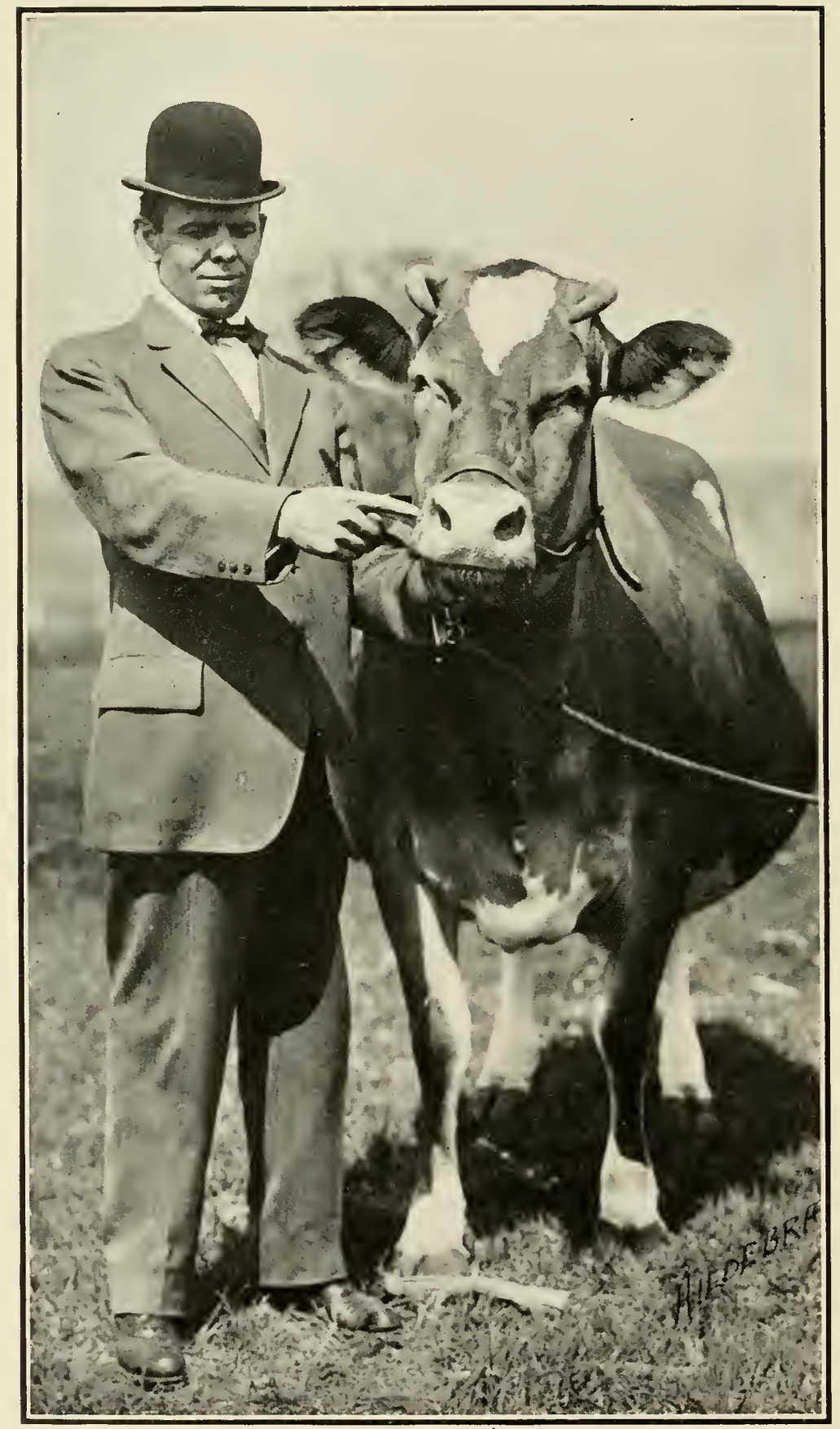

An open well distended nostril 


\section{CHAPTER II \\ Constitution of the Cow}

Of all farm animals the dairy cow is the hardest worked. She labors night and day gathering, consuming, digesting and assimilating food and converting the nutrients into milk and butter-fat. Morning and night she returns to her owner an amount of finished product which accounts for all the nutrients contained in the food she has eaten minus those that have been absolutely required to keep her body in a healthy and thrifty working condition and to nourish the unborn calf that she may be developing to perpetuate her kind. From the standpoint of restults, if she be a truly productive cow she will yield greater returns to her owner measured in food values than any other animal he may keep.

\section{Cow Compared With Steer}

A noticeable example of this fact is cited by Prof. Eckles of the Missouri experiment station. Princess Carlotta, a Holstein cow under his supervision, produced in one year 18,405 pounds of milk which was found to contain more human food than is contained in the complete carcasses of four steers weighing 1,250 pounds each. The following table gives the comparative composition of the substances found in the cow's volume of milk and the steer's carcass:

18,405 lbs. milk.

Proteid ..........552 lbs.

Fat ............6. 618 lbs.

Sugar ...........920 lbs.

Ash ...............128 lbs.

Total ........2,218 lbs.
1,250 -lb. steer

172 Ibs.

333 lbs.

... 1bs.

43 lbs.

The whole of the milk solids was digestible but this was not true with the solid material in the steer's carcass, for the 548 pounds is the record of the dry matter and includes hair and hide, bones and tendons, organs of digestion and respiration : in fact the entire animal, a large portion of which is not edible.

Quoting Prof. Eckles: “The analysis of the steer's carcass was made from samples taken after grinding up together one half of the complete carcass and is not in any sense an estimation of the composition of the carcass. 


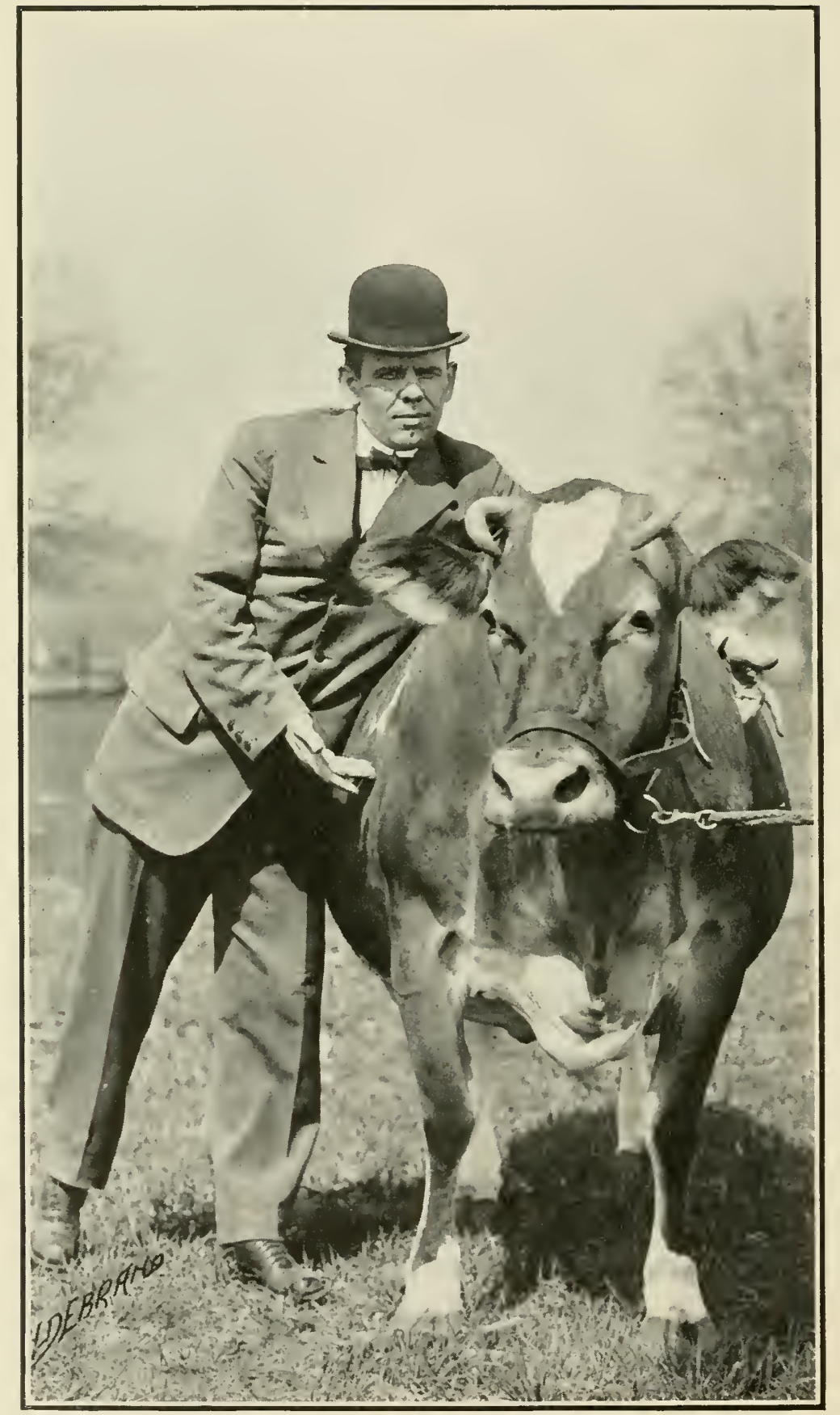

A well sprung front rib 
"Princess Carlotta produced proteids sufficient for more than three steers; nearly fat enough for two; ash enough to build the skeleton for three, and in addition, produced 920 pounds of milk sugar worth as much per pound for food as ordinary stigar.

"These figures show the remarkable efficiency of the cow as a producer of human food. It is because of this economical use of food that the dairy cow and not the steer is kept on high priced lands. When land is cheap and feed abundant the meat producing animals predominate, but when the land becomes high in value and feed expensive the farmer turns to the dairy cow."

\section{Continual Production Demands Vitality}

To accomplish such enormous results and to continue year after year for 10 or 15 years, which represents the working lifetime of a good cow, necessitates that she have a most rugged constitution and much vitality.

But, great production is not the only tax upon the constitution that is required to keep her in working condition throughout a busy lifetime. Nearly half of the time if she lives north of the fortieth degree of latitude she is stabled and in the majority of cases her home is far from being a healthful place. Oftentimes her stall is in the basement of a barn that years ago was built for other purposes and invariably her quarters are devoid of windows, rendering them dark, damp and poorly ventilated. From one year to the other no sun light penetrates the air in which she is compelled to exist during the winter.

Germ life flourishes. Only the cows with the greatest constitutions are able to resist the germs of tuberculosis, contagions abortion, pnemmonia, garget and other diseases with which dairy herds suffer.

\section{Large and Small Cows Equally Susceptible}

Very often the dairyman discriminates against one breed or another because he believes that particular breed to be more susceptible to tuberculosis than others. His belief is based largely upon the fact that the breed in question is small in size. Nothing conld be farther from logic for were it true that large cows had greater constitutions than small ones then it would be likewise true that large men are stronger in constitution than small men. It makes little difference how large a cow is, if she be housed in a 


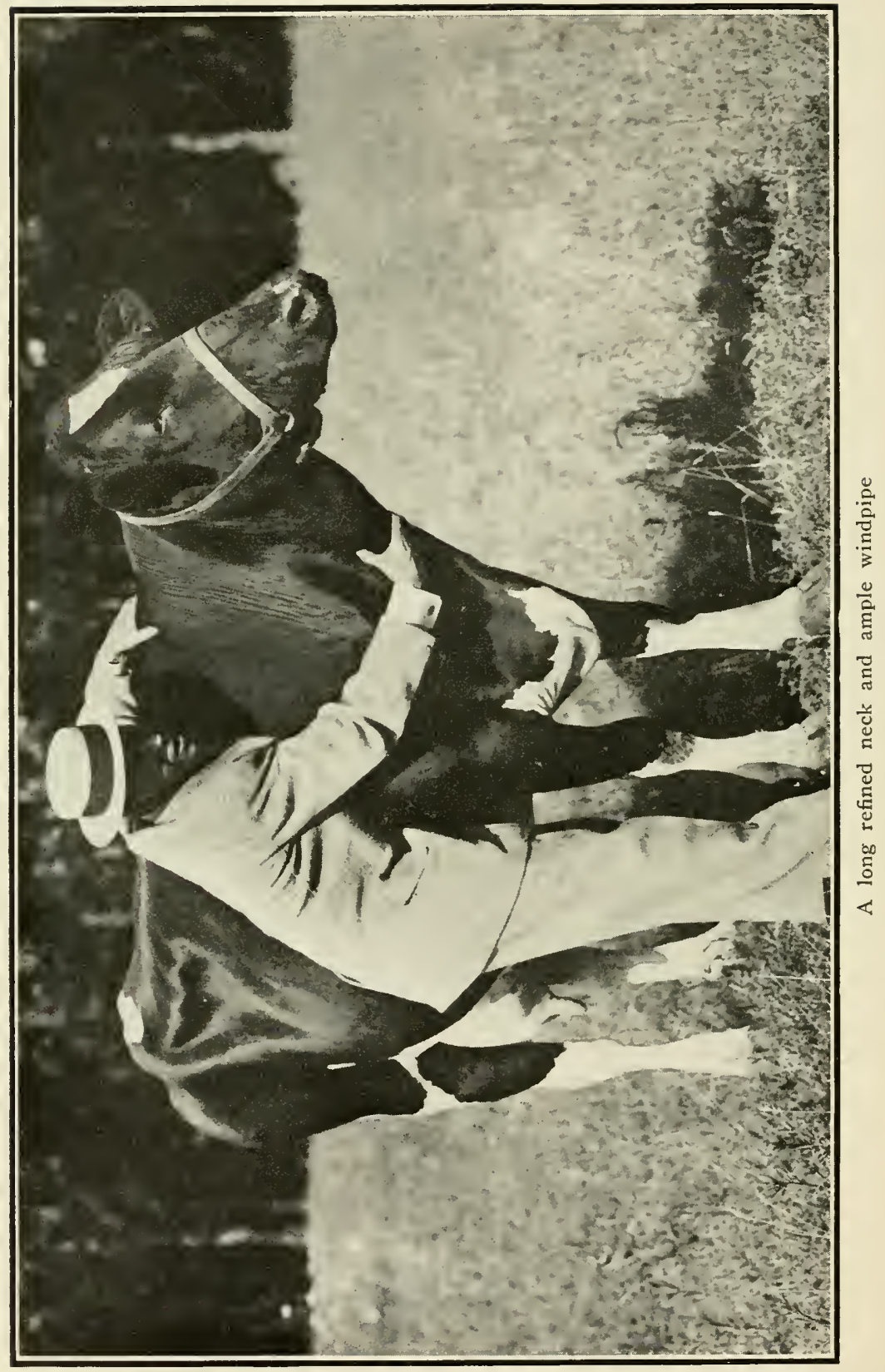


dark, damp, poorly ventilated barn where the sun never enters she is just as liable to become diseased as a small cow for the disease germs are without doubt present in great numbers. Likewise it may be true that it matters little how small the cow is if the organs vital to constitution are greatly developed in proportion to the other parts of the body she will more likely resist disease than a larger cow weaker proportionately in these constitutional parts.

\section{Large Volume of Air Essential}

Strength of constitution depends primarily upon the amount of pure fresh air that enters the body and the manner in which it is utilized by the lungs in purifying the blood.

If the nostrils, the trachea, or windpipe, and other chambers through which the air travels on its way to the lungs are large, open and well distended the volume of air entering the body will be large and thus far the indications will point to healthfulness.

Oxygen alone purifies blood, and fresh air is the only medium in which it is conveyed to the blood. Every particle of air that reaches the lungs and comes in contact with the blood passes first through the nostrils and later through the wind pipe. If these channels are small one of two things happens; either a small volume of air enters or the cow must breathe more rapidly than the cow with a large nostril. Observation teaches, however, that the respiration. of one cow is not perceptibly more rapid than that of another. Therefore the conclusion may properly be drawn that the cow with the small nostril does not take into her lungs the great amount of air that the cow with the large, open and dilated nostrils and windpipe does.

\section{Capacity of Thorax}

Quite as important as an indication of vigorous constitution is the size and capacionsness of the thorax or the chamber in which the heart and lungs are located. Smallness or lack of development in this part of the body prohibits greatness of heart and lung development resulting in limited stamina, vigor and ruggedness. To insure ample room for the fullest growth of the heart and lungs the cow should be extremely deep from the top of the shoulder to the floor of the chest, fairly broad in the chest, deep in the region of the heart girth and well sprung in the fore rib. Cows that are at once narrow and shallow in the chest cavity, tucked up and pinched in the space occupied by the 


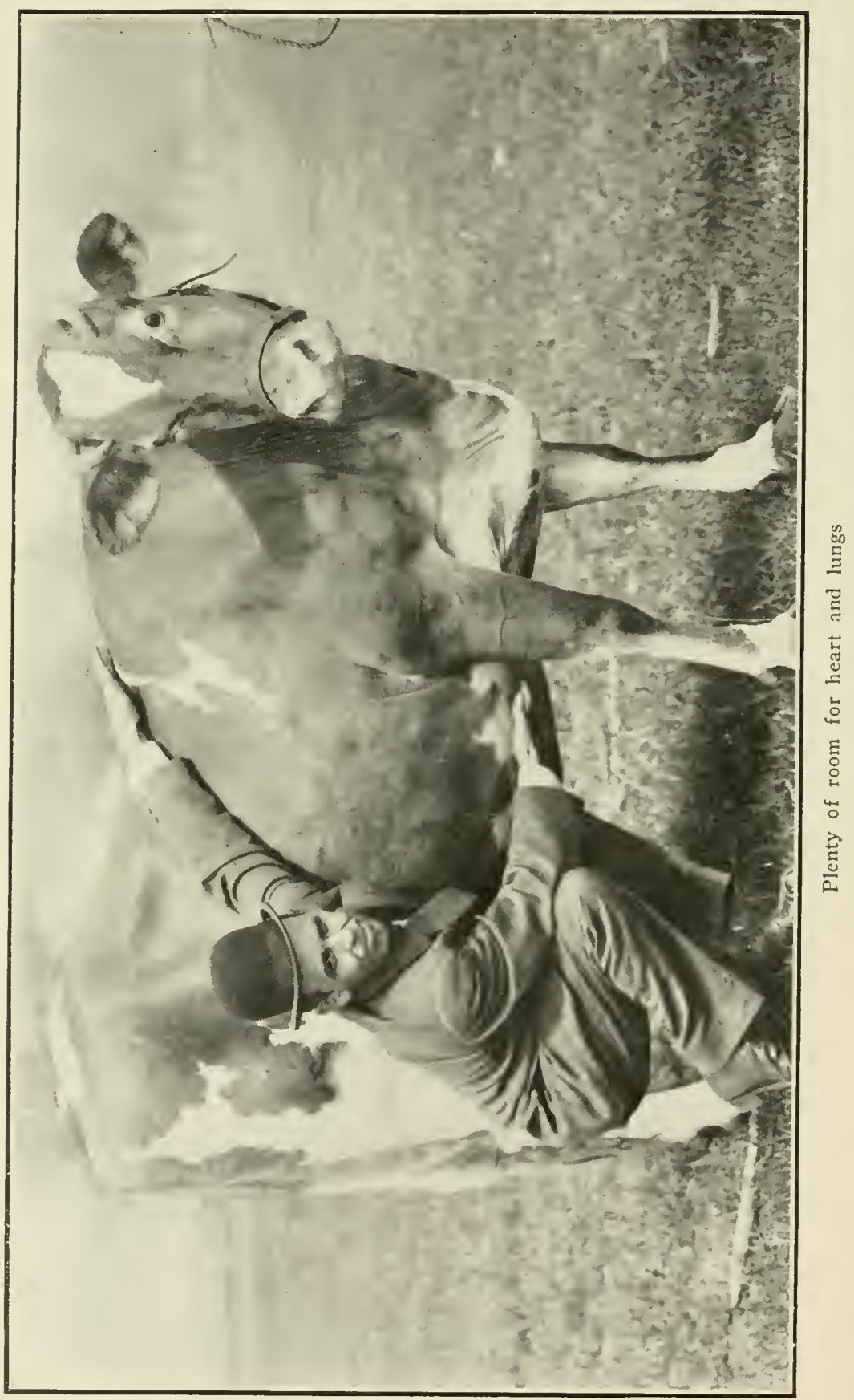


heart are always troublesome and never persistent feeders or producers.

Although reasonable breadth of chest is to be desired the mistake is sometimes made in laying too much stress upon its value and, to attain breadth, other more necessary requirements are sacrificed.

It shonld be remembered that although the beef animal and draft horse gain their constitution in breadth of chest to a greater extent than by depth the opposite is true of the running horse and the dairy cow and just as truly as the horse bred for speed is endowed with constitution as great as or greater than the larger and heavier draft horse so does the dairy cow compare with the beef animal.

In fact no less authority than Gov. W. D. Hoard makes the statement that upon following fifty head of animals to the block he found that the heart and lungs of the dairy cow were larger and weighed more than did those of beef animals with which they were compared.

\section{Eyes and Horns}

Although of less importance than the considerations already discussed it may be said that usually the cow with eyes that are bright, prominent and clear and horns that are rather heavy at the base and tapering gradually to a point is more vigorous than the one with the dull sunken eyes and horns that are almost as small at their base as near the point. Certainly it is true that diseases of the heart and lungs in advanced stages are accompanied by dull, expressionless and oftentimes sunken eyes and to the careful observer the first symptoms of weakness and disease become apparent in the appearance of the eyes. On the other hand the character of the horns and eves may be and as a rule is a truer indication of other conditions obtaining and does not denote constitution with the same infallibility as do the organs of respiration.

One may rest assured that if the vital parts are large as compared with other parts of the body and the animal has been permitted to breathe fresh pure air not infected with disease germs during her whole life it is quite perfect in one of the essential requirements. 


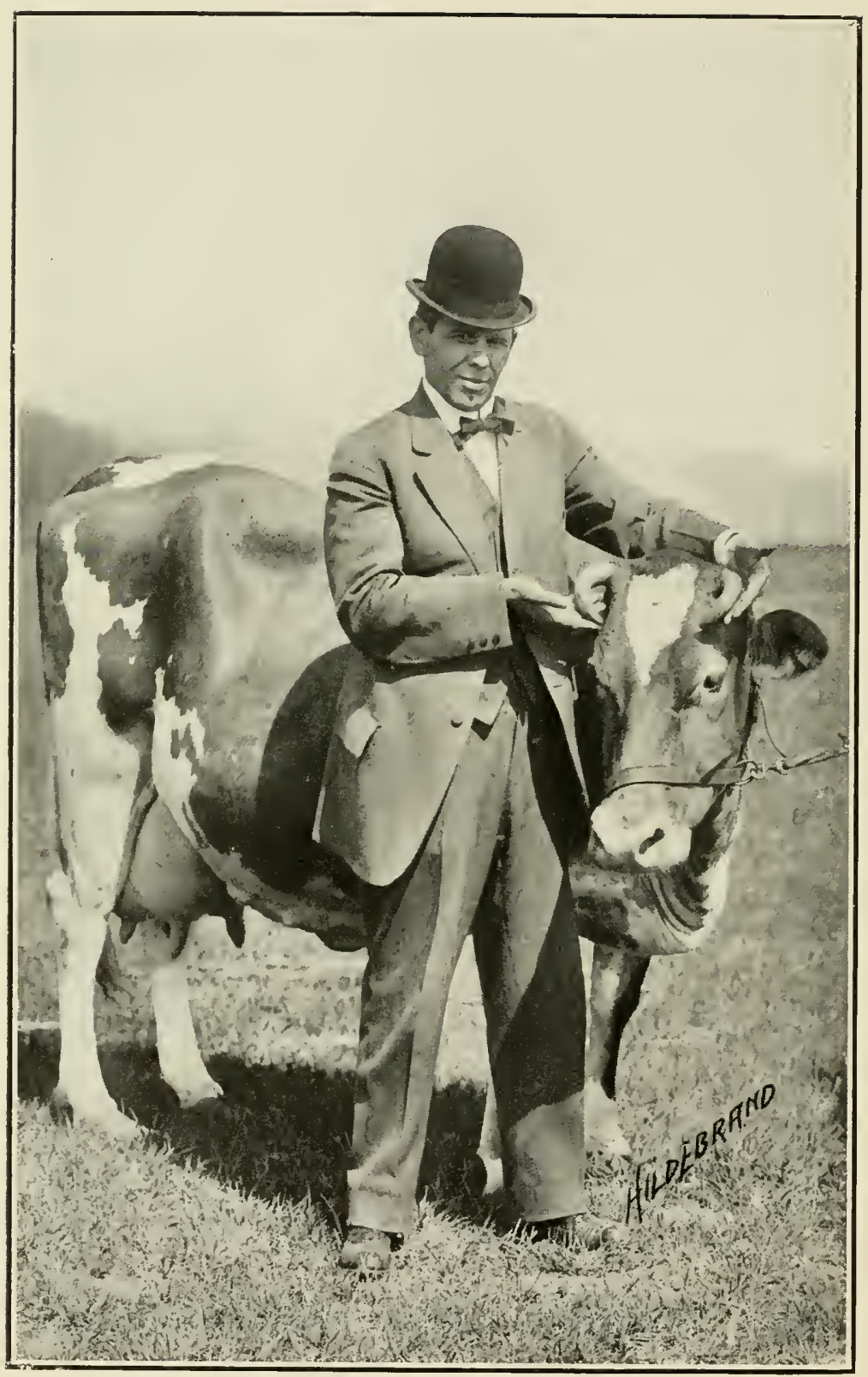

Medium sized incurving horns 


\section{CHAPTER III}

\section{Capacity}

The capacity of the dairy cow refers to the total amount of food she can consume and digest in a given time without injuring her future usefulness. It depends upon the size and strength of her organs of prehension, mastication and digestion.

According to Prof. Henry 60 per cent of all the cow can eat is required to sustain her body and only after this amount is provided can there be any return to the feeder. This being true it is evident that the greater the capacity of the cow the greater will be the amount of return represented by the 40 per cent.

Capacions cows are always more ravenons feeders than cows lacking in the development of this characteristic and for this reason less difficult to feed. It is seldom that the feeder who uses julgment experiences trouble from such animals "going off feed" or sickening from the effects of heavy feeding, but cows that are limited in the amount of food they can hancle are a continual source of worry when one attempts to tax them to the limit of their powers of pro duction. Furthermore the cow with great capacity according to her size is a more economical producer than the less capacious cow who as a rule is a more dainty feeder, for she former will eat foods rougher in character and these are often cheaper.

\section{The Heavily Taxed Organs}

More apparent still becomes the importance of greatness and strength of feeding and digestive capacity when the fact is recalled that of all parts of the body these organs are most heavily taxed when the animal undergoes heavy feeding and as a rule they are the parts that first give way under the strain of hard work of long duration such as is demanded of the cow when her efforts are commercialized.

In this respect she differs greatly from the beef steer which enters the feed-lot. He undergoes heavy feeding for a period of from four months to a year at the most and is sent to the shambles but the cow to be a desirable individual must feed on and put to profitable use her food year after year throughout a long life time without taking time to rest 


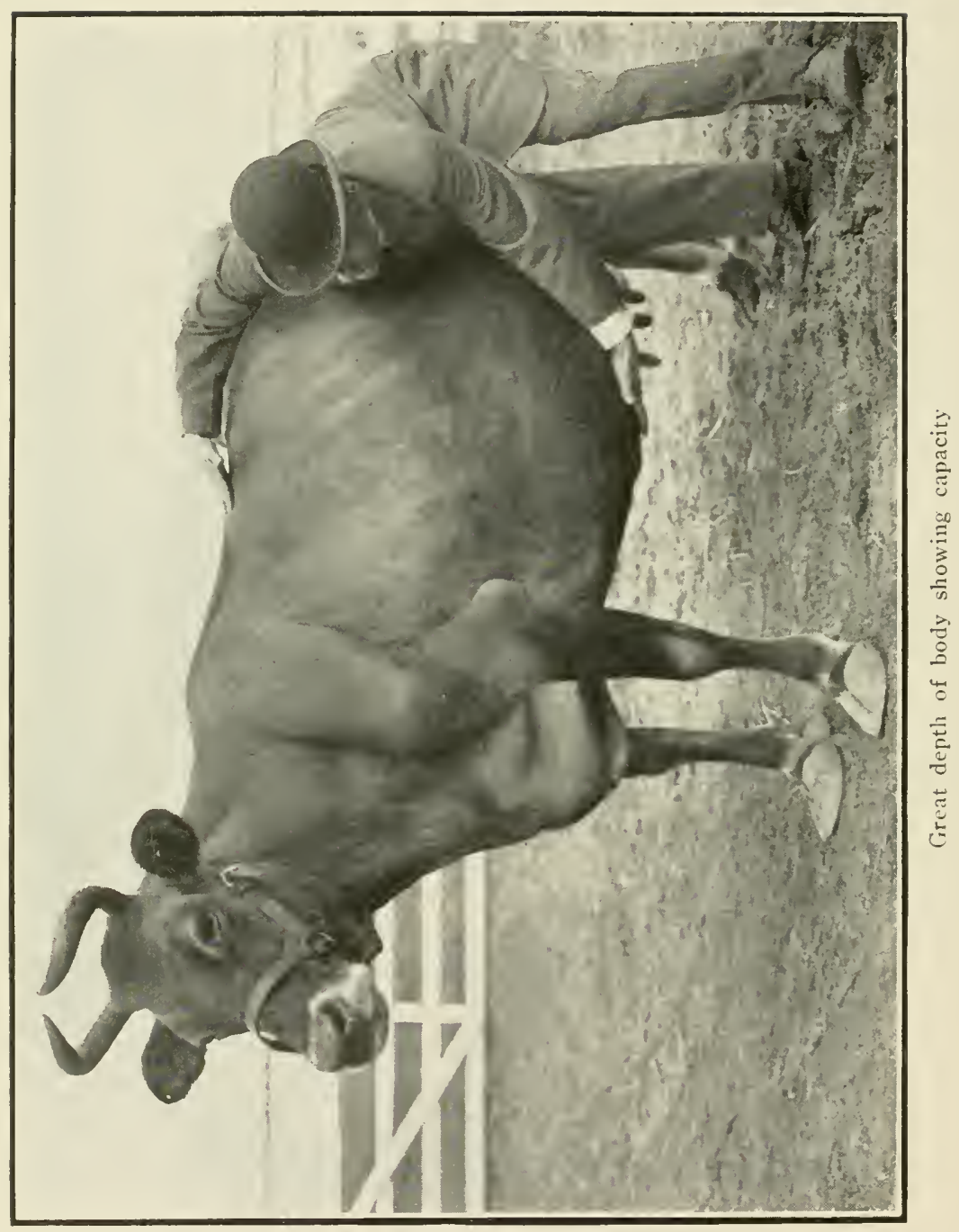




\section{VAN PELT'S COW DEMONSTRATION}

from feeding. Even though there is a short time each year when the cow gives little or no milk, she must maintain her own body and nourish the offspring with which she is soon to present her owner. These functions establish an additional demand upon her to consume heavily of food at this time for she must build up the tissues of her own body and that of the unborn calf so she may freshen strong and in good condition for the next year's butter producing campaign in which she must make good.

\section{Large Mouth Indicates a Good Feeder}

So well do experienced feeders of all classes of farm animals realize that the animal with the large mouth is a good feeder that this qualification has come to be one of the recognized indications of capacity. The animal with a small pointed mouth and a small muzzle is always difficult to feed, being dainty and indifferent to the efforts of the feeder to tempt its appetite. Associated with the small mouth is a corresponding smallness of nostril; a detraction from the desired facial features.

Thorough mastication of the food is very necessary for it is not only the action of grinding the food but it is during mastication that the first process of digestion takes place. It is when the cow chews her cud that the saliva secreted by glands entering the mouth is mixed with the food, changing starches to sugar and beginning the many chemical changes that take place before the food can be assimilated. For these reasons strong jaws of well defined width and depth are desirable. Weakness in these parts indicates poor feeding qualities to quite as great an extent as does a small mouth and is to be guarded against.

A careful study of the different processes and the many organs involved in digesting the food after it has left the mouth as well as a consideration of the great amount of food nutrients necessary for the maintenance of the animal and for great milk production points to the significance of an adequate and roomy space where the foods may be stored and digestion carried on.

\section{Large Barrel}

This entails a large barrel, one that is long, broad and deep. These specifications are insured by length from the shoulder to the hip bone, broad, flat, well sprung, deep ribs.

On the other hand it often occurs that close coupled cows, those with short bodies that are broad and deep are 


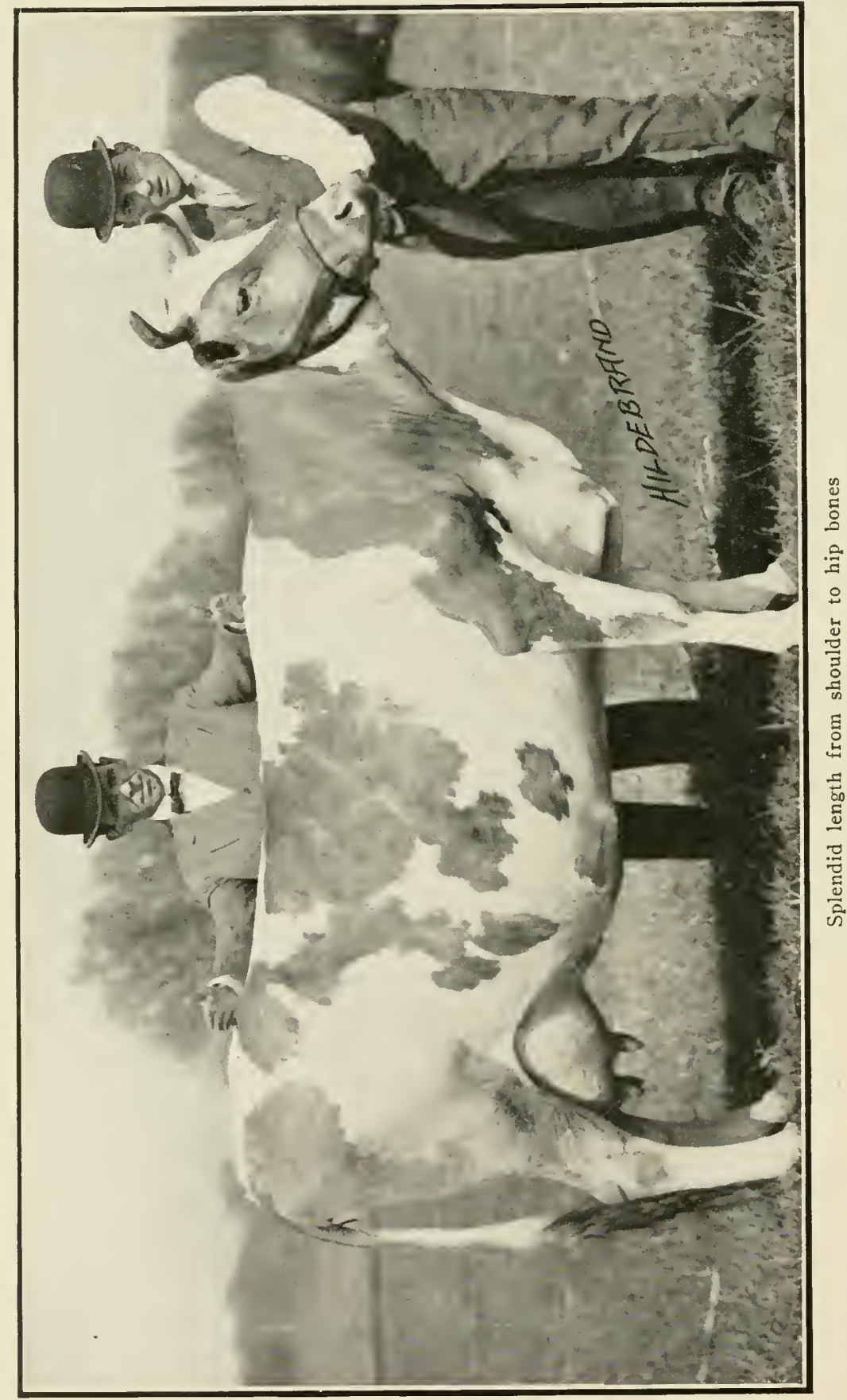


excellent feeders and good producers and if there is to be any sacrifice made in the dimensions of the barrel it is better that length rather than any of the other proportions be overlooked.

The cow that is long of body, slab-sided and shallow ribbed is seldom, if ever, satisfactory either as a feeder or as a great and economical producer of milk products or of offspring. Even though she may yield well for a short time she is not persistent and she soon declines in her milk flow. Any efforts to stimulate greater production result in her leaving her food or sickening with indigestion of one kind or another because of insufficient capacity.

Not only is it important that the cow be capable of consuming a great amount of food at one time but it is very important that every possible ounce of the food she takes into her body be digested and assimilated. No portion of the food is used for any purpose except the nutrients which the digestive apparatus liberates in a form suitable for the blood to absorb. All other portions pass on and are wasted. wasted.

It may be that some cows although voracious feeders and large of barrel do not utilize the food they eat in the efficient manner necessary for economy of production.

\section{Efficiency as Important as Size}

Strength, power and efficiency of the digestive apparatus are factors quite as important as size. They may be, and quite likely are, of more importance.

The condition and efficiency of the organs of digestion may be determined by the handling qualities of the animal. By carefully lifting the hide from the body there is at once conveyed to the touch one of two sets of conditions; either the hide is soft, pliable and elastic and the hair covering it soft and silky-or the hide is hard, stiff and so tightly drawn over the body that it is impossible to lift it away from the ribs. Such hide is usually covered with hair that is coarse, harsh and wiry: standing out from the body rather than $1 \mathrm{y}$ ing smoothly. When the former condition exists, not only quality of all parts of the body is indicated but an efficient digestive tract is also assured. The animal will consume its food, digest it quickly and be ready for more. But when the hide is covered with harsh, wiry hair there is something wrong with the digestive apparatus either temporarily or permanently and even though the animal is a gross feeder the best use will not be made of the food. 


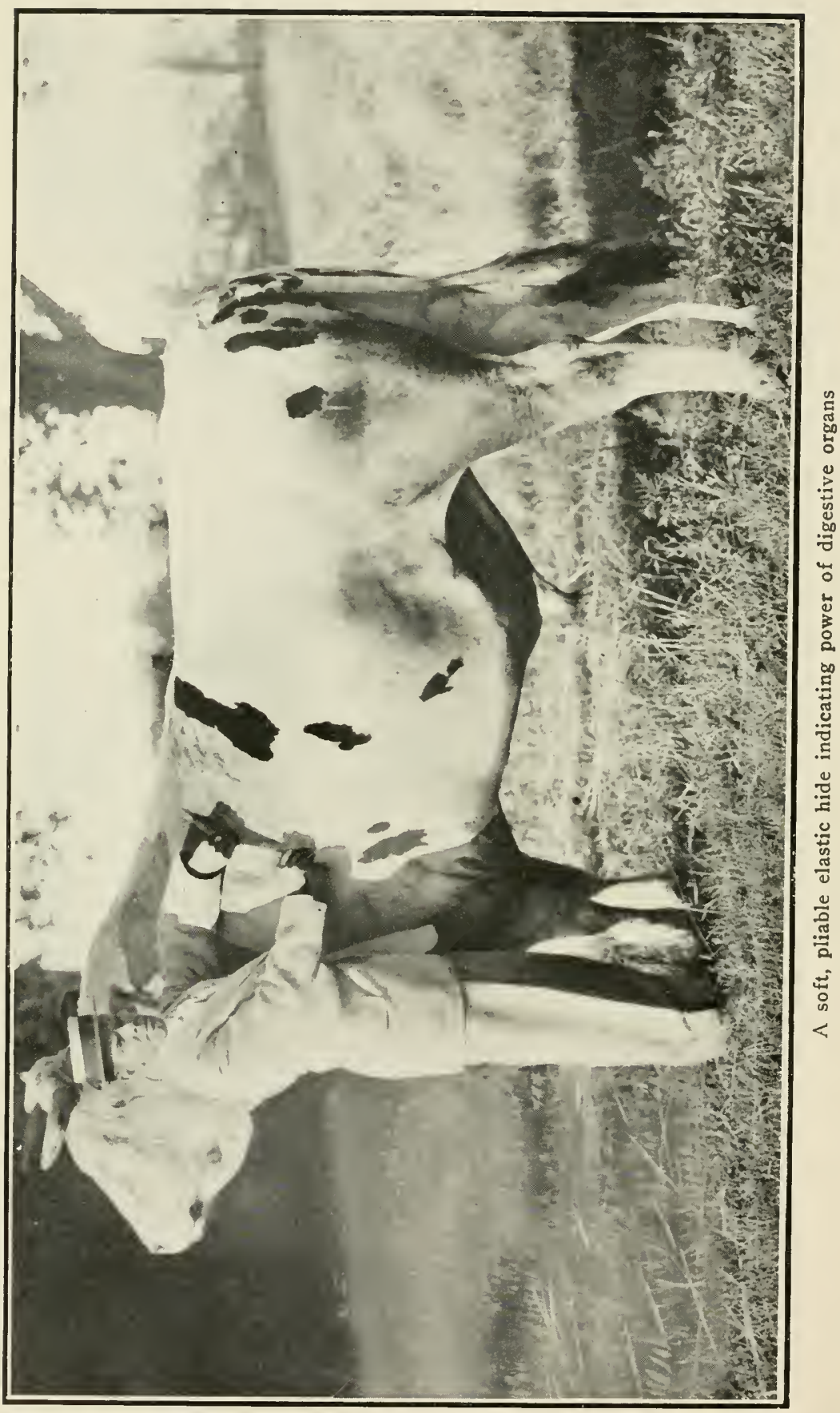




\section{Texture of the Hide}

The expert show yard judge during the course of his examination of the animals before him always lifts the hide from each and by the sense of touch studies the quality of the animal and determines by the texture of the hide and hair that which he cannot see with his eyes; the strength, power and efficiency of the digestive organs. Ie realizes that the skin of the animal is a continuation of the inner and vital organs the condition of which is reflected through the outer medium. That these indications are more practical than theoretical any successful feeder will assert for he has noticed that the first indication that a cow is reaching the limit of her feeding capacity is not when she begins leaving feed in her manger or when her voidings assume an unnatural condition but when the eye gets dull and the hair begins standing out from the body and becomes harsh to the touch. If these first warnings are not heeded then it is that the cow begins leaving her food and soon the softness and pliability have left her hide and it becomes tight, hard and stiff.

True it is that care and feeding have much to do with the condition of the hide and hair and likewise they have much to do with affecting the digestive organs and the method of care and feeding that adds tone to the vital organs makes itself known to the touch of the jurlge. In other words those parts that can be seen and felt indicate the condition of the invisible organs rather than vice versa.

It is, of course, well to secure in one and the same animal both size and power of digestion but if the necessity presents itself of sacrificing a portion of one or the other, then digestive power should have preference. The large barreled cow of poor quality will consume a large amount of food at one time but because of her sluggishness will waste a portion of it but the cow active in digestive traits eating less at a time, but oftener, will eat fully as much if not more on the whole, only recpuiring longer to do so and she will make better use of it in keeping up the condition of her own body and in yielding milk products. 


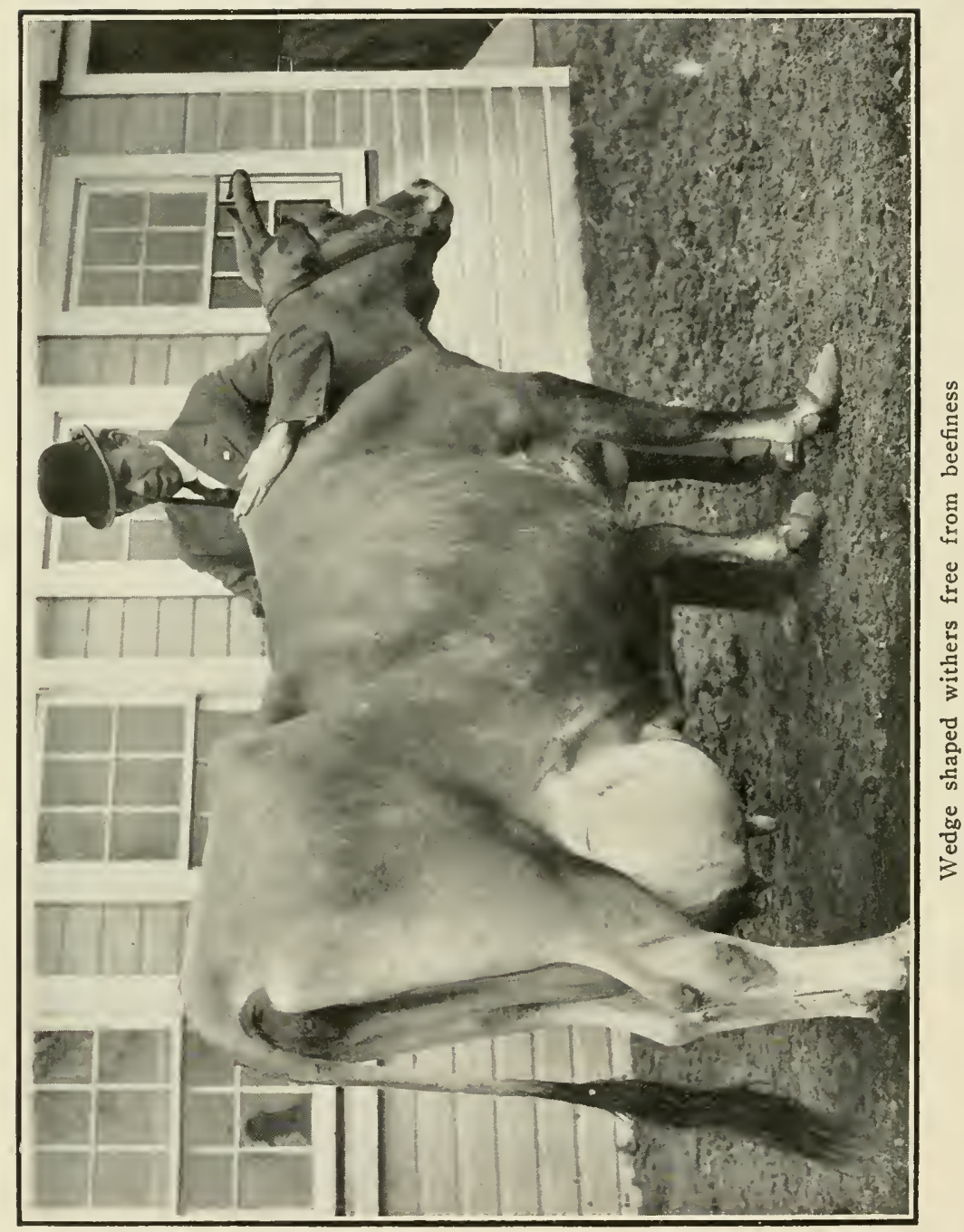




\section{CHAPTER IV}

\section{Nervous Temperament}

The term nervous temperament used in referring to the disposition of the cow means the inherent propensity to work, to eat food, digest it and convert every available ounce of it not required for maintenance into milk products. Nervous temperament does not imply that the cow is nervous in the generally accepted meaning of the term nor does it mean that she is excitable, fretful or hard to manage, but that she is especially strong in the development of the nervous system. It naturally follows that such an animal is always alert, active and responds readily to all surroundings whether they be favorable or adverse.

It is this nervous temperament that enables the dairy cow to endure for a long period greater work than her form, appearance and size would indicate. It is the quality that gives the Arabian horse the endurance which enables him to make long journeys with little food and water and the same characteristic is termed stamina when found in the horse bred for speed. In the dairy cow this trait stimulates the function of milk making.

\section{Lymphatic Temperament}

There is another temperament that is found in beef breeds-and often-in fact too often-in individuals of the dairy breeds, termed the lymphatic temperament. Such an animal is sluggish in disposition, inclined toward laziness, with an inborn tendency to convert its food into fat and selfishly distribute it over its body. This temperament is one of the essentials to look for in selecting profitable feeding steers and is a point well recognized by experienced cattle feeders for they know that the steer which fattens readily is the one that gorges himself at the feed bunk, lies down and chews his cud contentedly with absolutely no consideration for what goes on around him until another feeding time rolls around and he hears the nubbins being broken over the side of the feed bunk when he arises, stretches himself and lazily and deliberately walks over to his source of food supply.

Cows of this disposition are an unprofitable kind indeed when compared with the one that at feeding time stands at the gate or in her stall and bawls for her feed or at the 


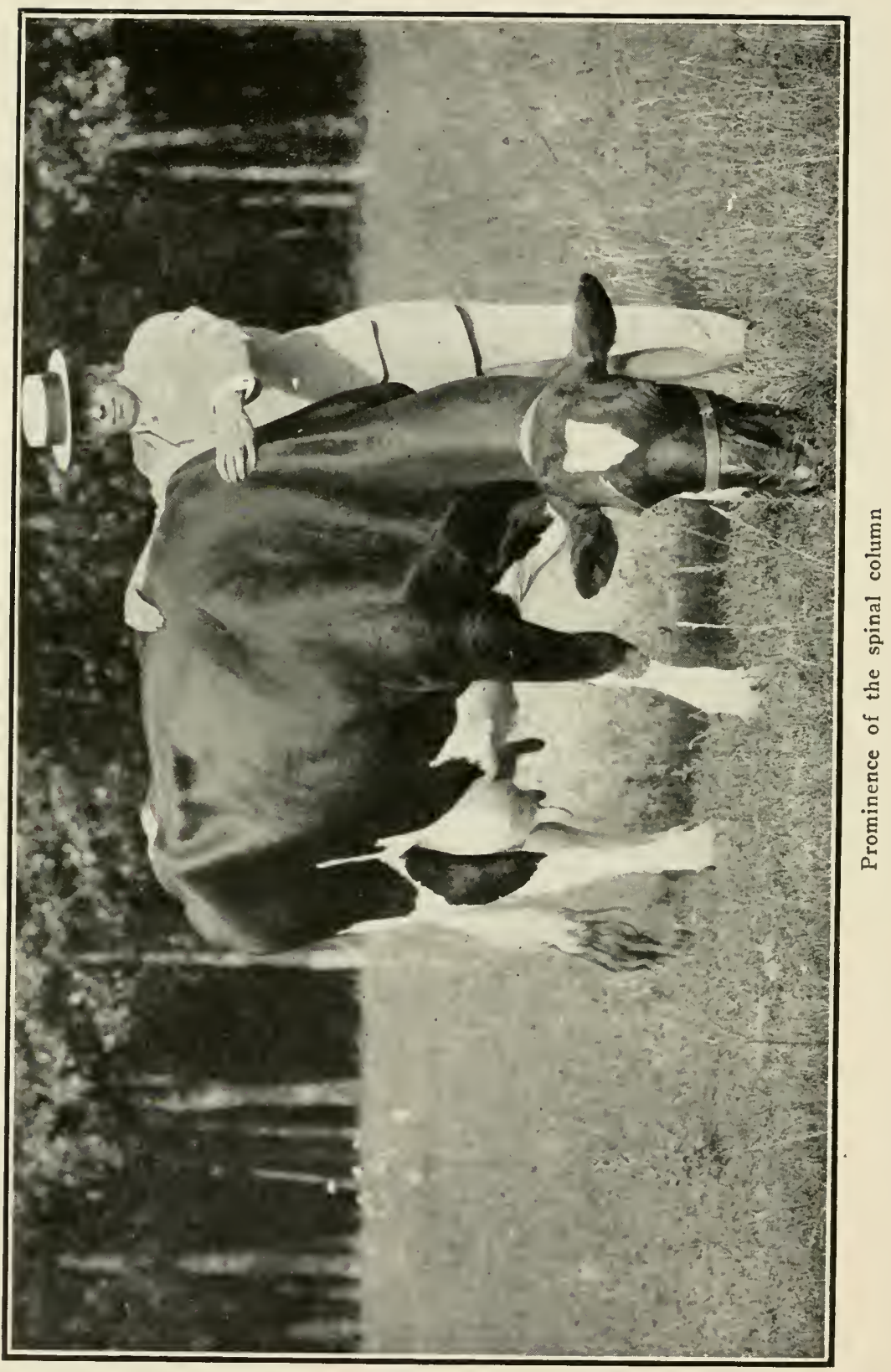


call of her master breaks into a run in her haste to reach the feed and fill the milk pail and when her meal is finished shakes her head and wishes for more.

\section{Loafers}

From the dairy standpoint cows with lymphatic temperament are loafers and as a rule do not produce enough milk and butter-fat to pay for the feed they eat, for it must be remembered that all food converted into fat that is distributed over the cow's body when she should be giving milk is wasted from the dairyman's standpoint. The great need of the American dairyman is to sort ont and get rid of these low producers. In the borine family as in the human family they never pay for their own board. Some friend or relative must do that for them.

There are many indications of nervous temperament. Chief among these is a face that is broad between the eyes and a long broad forehead which may taper to the poll. It is in this region that the brain is located. It is the brain that controls the nervous system which in turn governs all functions of the cow: among these are digestion, blood circulation and milk secretion. If the face and forehead of the cow are narrow there is sufficient indication that the brain capacity is limited and that the brain itself is small and the control over the nervous system is limited. Nervousness more likely results than nervous temperament.

\section{Temperament Reflected by the Eye}

Temperament is always reflected in the eye of an animal. A large, bright, prominent, placid, alert eye with an intelligent expression gives assurance of nervous temperament. In the same manner the dull, sluggish, receding eye even though it may or may not have an intelligent expression denotes the sluggish temperament. No experienced judge of human or bovine nature overlooks the story the eye tells. It is well for the feeder and breeder of cattle to be observing at all times of the lessons that may be learned from the eyes of his animals.

From the brain the spinal cord passes backward through the spinal vertebra or back bone Open jointedness and freedom from fat indicate nervous temperament as represented by these parts. The statement is often made that the spinal processes should be large and rugged indicating good development of spinal cord. Anatomists of authority, however, assert that the higher the position an animal occupies 


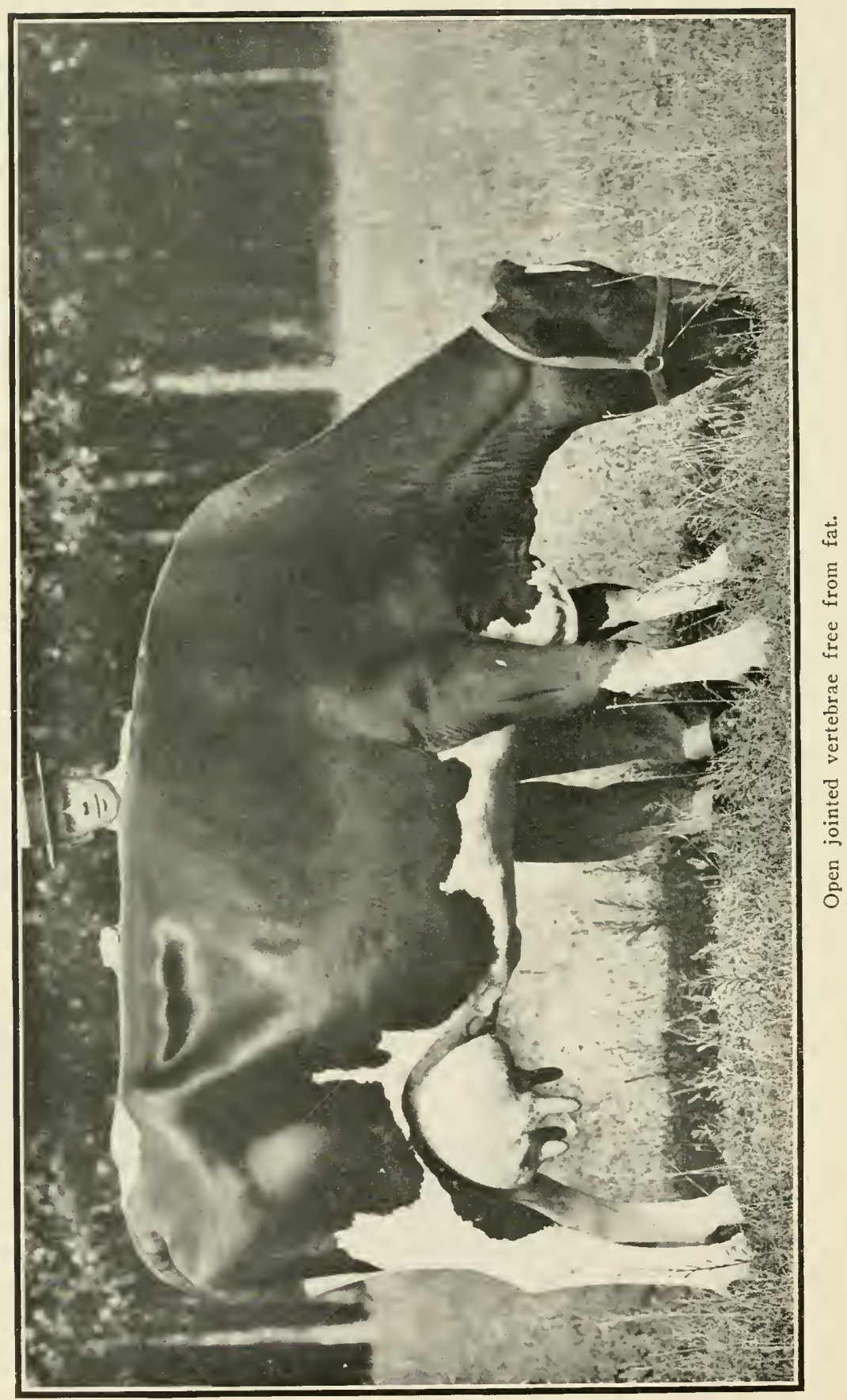


in the scale of intelligence the smaller and lighter the cord relatively. It is therefore true that if the size of the spinal processes are an indication of the size and weight of the spinal cord they likewise indicate a lack of size and weight of the brain and less intelligence. Judging from this, smaller and more refined spinal vertebrae would seem to be more desirable as indicative of greater brain power and nervous temperament.

\section{Freedom from Fat}

Prominent hips and ribs that are apparent to the eye and freedom from beefiness or superfluous fat over the entire body are all important indications for they denote that the nervous temperament has stimulated the conversion of the food into milk and butter-fat rather than into beef which would be the case if the animal was endowed with a lymphatic temperament. Add to these points style, activity and freedom of carriage, alertness and consciousness of all surroundings and you may guarantee that the cow possessing these is a worker and if the other four essential points are present she will, when given an opportunity, be a source of profit to her owner.

To the great development of nervous temperament possessed by Dairymaid of Pinehurst, whose butter record is 1,003 pounds as a three year-old, her owner attributed to a large degree her marvelous production.

Not only does she possess all the points referred to, indicating that she is a worker, but see her when you will, if she is not feeding she is chewing her cud which is merely the act of masticating and mixing with saliva the food she has gathered and has just found time to chew. So thoroughly does her owner believe that nervous temperament or disposition to work continuously is one of the great attributes of a great cow that when he attempts to select a cow for phenomenal production, he takes his time after considering other points, sits around and watches the actions of the anmal. He learns whether she is a worker or a loafer by noting whether she works or loafs. Perhaps this is one of the valuable lessons Dairymaid has taught. Certainly it is true that the most valuable lessons that can be learned about selecting cows are taught by the cows themselves or by a close comparison of good and poor individuals. 


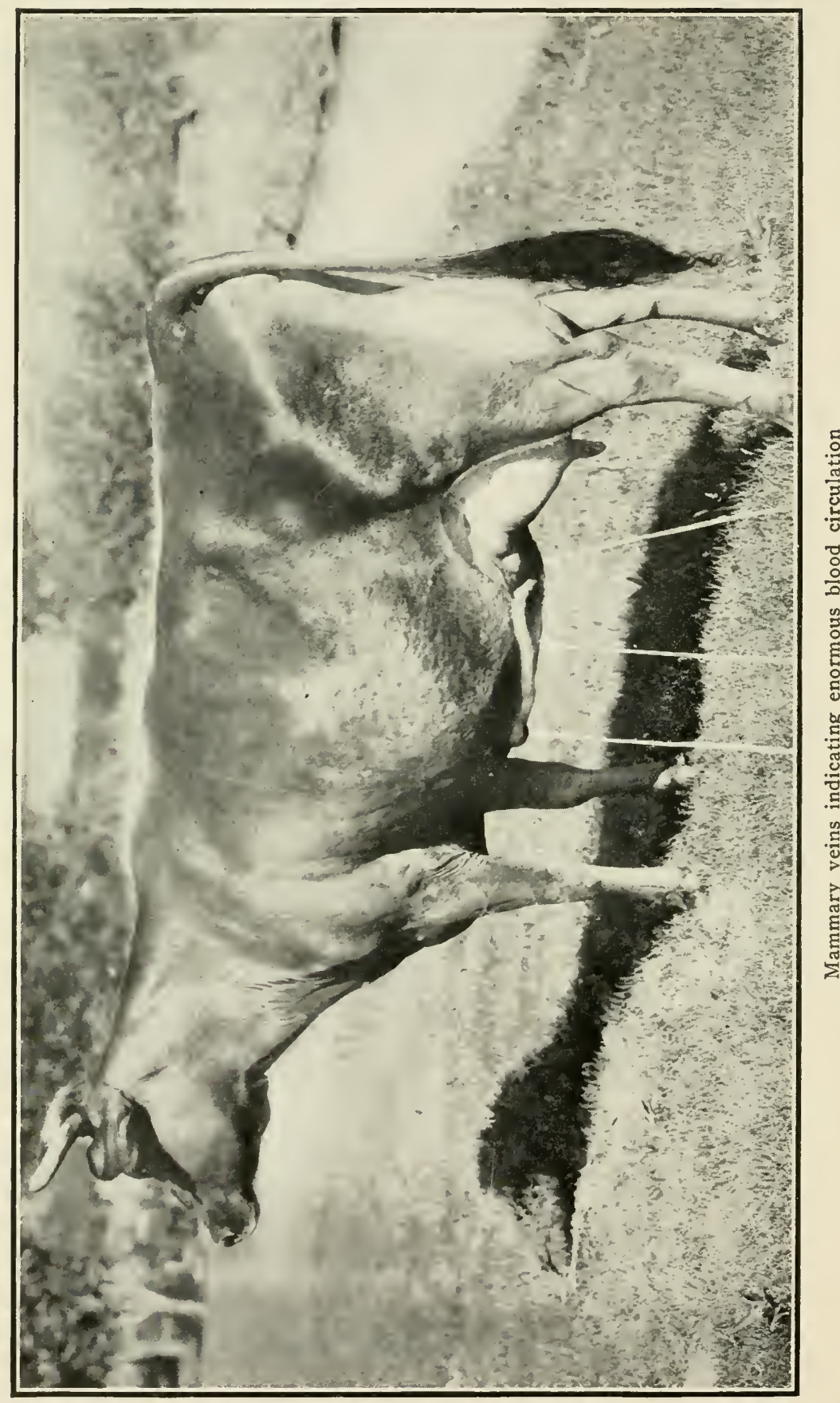




\section{CHAPTER V \\ Blood Circulation}

After the cow has eaten and digested her food the next process is that of absorption or the picking up of the nutrients, carrying and distributing them over the body where they belong according to the function of the animal.

In this respect the blood circulating to all parts of the body plays no small part in the great general plan the cow adheres to in making milk.

It is interesting to study the manner in which cattle accomplish the purpose for which they are kept. At feeding time or during the day when the cow is on pasture she first gathers her food and bolts or swallows it, because she is too busy at that time to masticate it. The food in this condition passes into the first stomach which serves largely in the ruminant as a storehouse for the food. When the cow finds time she regurgitates the feed she has secured during her busier hours and masticates it which is usually termed, "the chewing of the cud." Then it is re-swallowed, further moistened, softened and refined, finally reaching the fourth stomach and later the intestines. During this course it comes in contact with different digestive fluids such as the gastric juice, the bile, the pancreatic juice and the intestinal juices which have the power of taking from the food those nutrients that are digestible and converting them into a form to be picked up by the blood for absorption. It is then the the importance of the blood circulation asserts itself, picking up and transporting, so to speak, the nutrients which have been digested from the food. The blood acts as a carrier and a distributer of these nutrients.

Every feeder of farm animals should be conversant with the entire process of digestion, assimilation and the distribution of food nutrients. The subject is of great importance and complete discussion of it would make a book in itself.

Up to the time when the blood of the animal starts on its course of transporting the digested nutrients, the work of the beef animal and the dairy animal are largely the same, but at this point their paths divide and the remaining uses of the food greatly differ. In the beef animal the blood for the most part carries the digested nutrients, after utilizing those necessary for the maintenance of the body, to the: top 


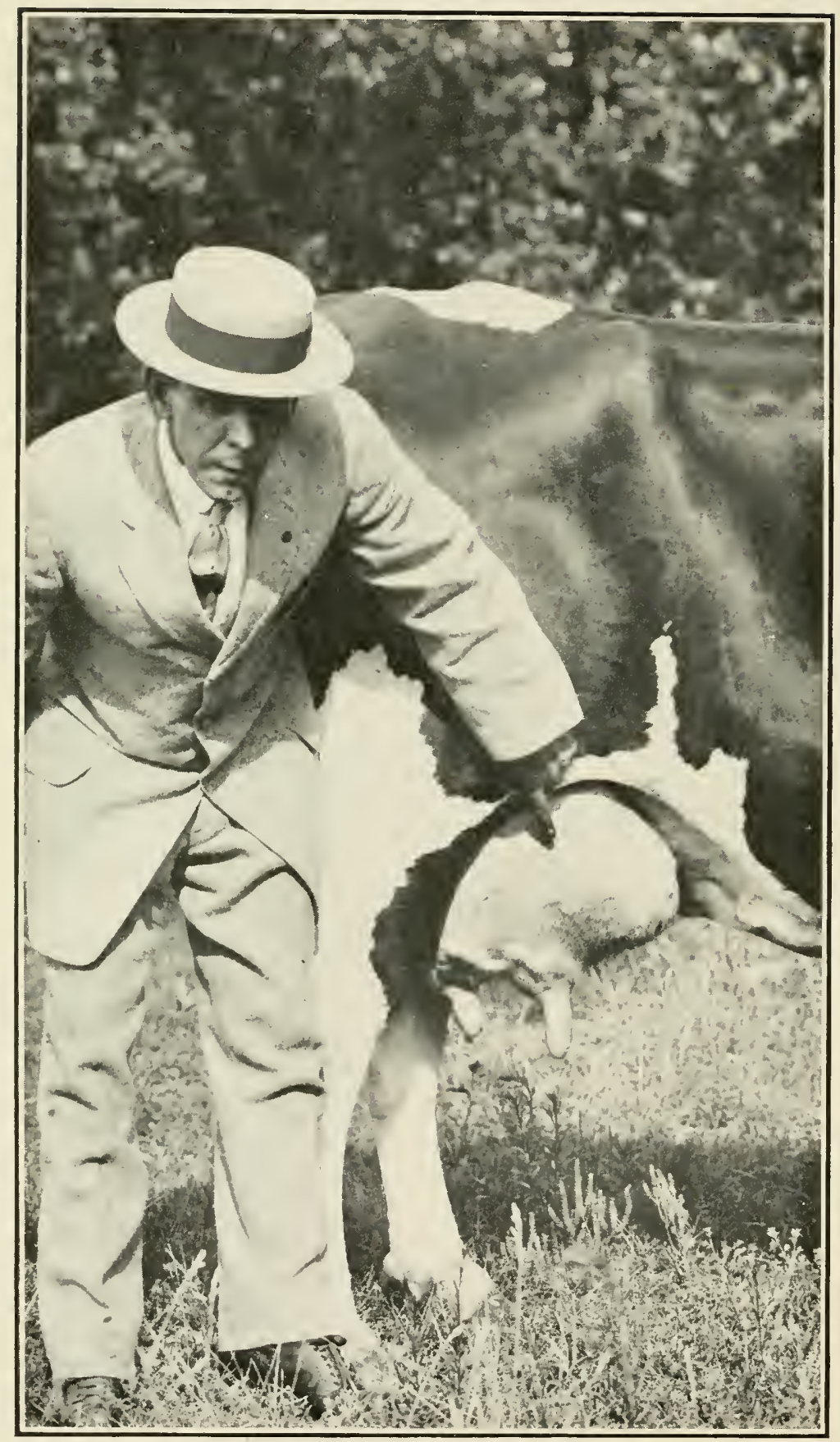

A net work of veins on the udder 
regions of the animal. Here they are distributed in the form of beef and fat over the shoulders, chin, back, loin, ribs, rump, thighs and twist. There is a reason for this. For hundreds of years there have been successful breeders of beef cattle who have striven to create an animal that would consume a great volume of food, digest and carry it to those portions of the body where it is assimilated and manufactured into beef. They have bred animals for this purpose because they have been advised that the aim of all their efforts in creating pure bred beef cattle is the steer and his end is the block. Through the packer they have learned that the most valuable cuts of the beef animal are to be secured from the portion of the animal above a line drawn through the longitudinal middle of the body. This the packer has learned from the retailer who, in turn, has learned that the consumer appreciates and is willing to pay larger prices for cuts secured from these parts than for those frons the underline known as chuck and flank steaks.

\section{Milk Production Sacrificed}

The breeder of beef cattle has been very successful in his operations and the market toppers and prize winning show steers and other beef animals of the present day show yards have been the result. Milk has been sacrificed because the milk making nutrients which are largely the same as beef making nutrients have been carried to other parts of the body than that where milk is manufactured, for a cow never made a pound of milk in any part of the body except the udder.

On the other hand, over in Holland and on the Jersey Isles, the Guernsey Isles and in the County of Ayr, Scotland there have been breeders equally intelligent who for even a greater length of time have striven to create an animal that would consume a great volume of food, digest and assimilate it and send the digested nutrients around to the udder where the manufacturing process of milk and butterfat production are carried on. That they have been successful in their operations is evidenced by such cows as Colantha 4th's Johanna, Pietertje Maid Ormsby, Jacoba Irene, Olga 4th's Pride, Adelaide of Beechlands, Yeksa Sunbeam, Dairymaid of Pinehurst, Dolly Dimple, Rosaire's Olga and Netherhall Brownic 9th. This, of course, has been accomplished by sacrificing the production of beef in the same manner as the successful creator of beef animals has sacrificed the production of milk. Experiments that have been conducted show that the dairy bred steer will 


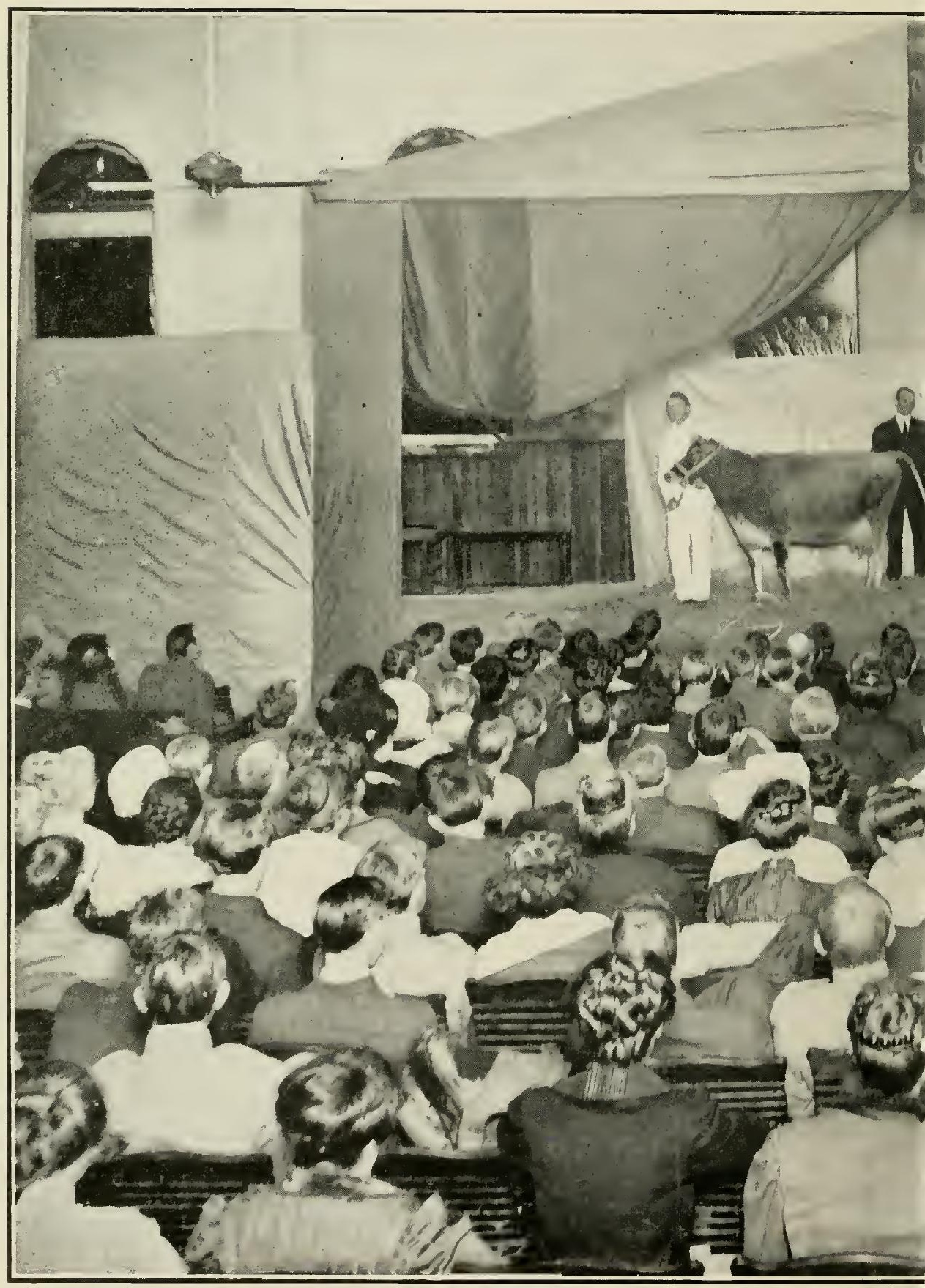

Prof. Hugh G. Van Pelt giving his dairy cow demo 


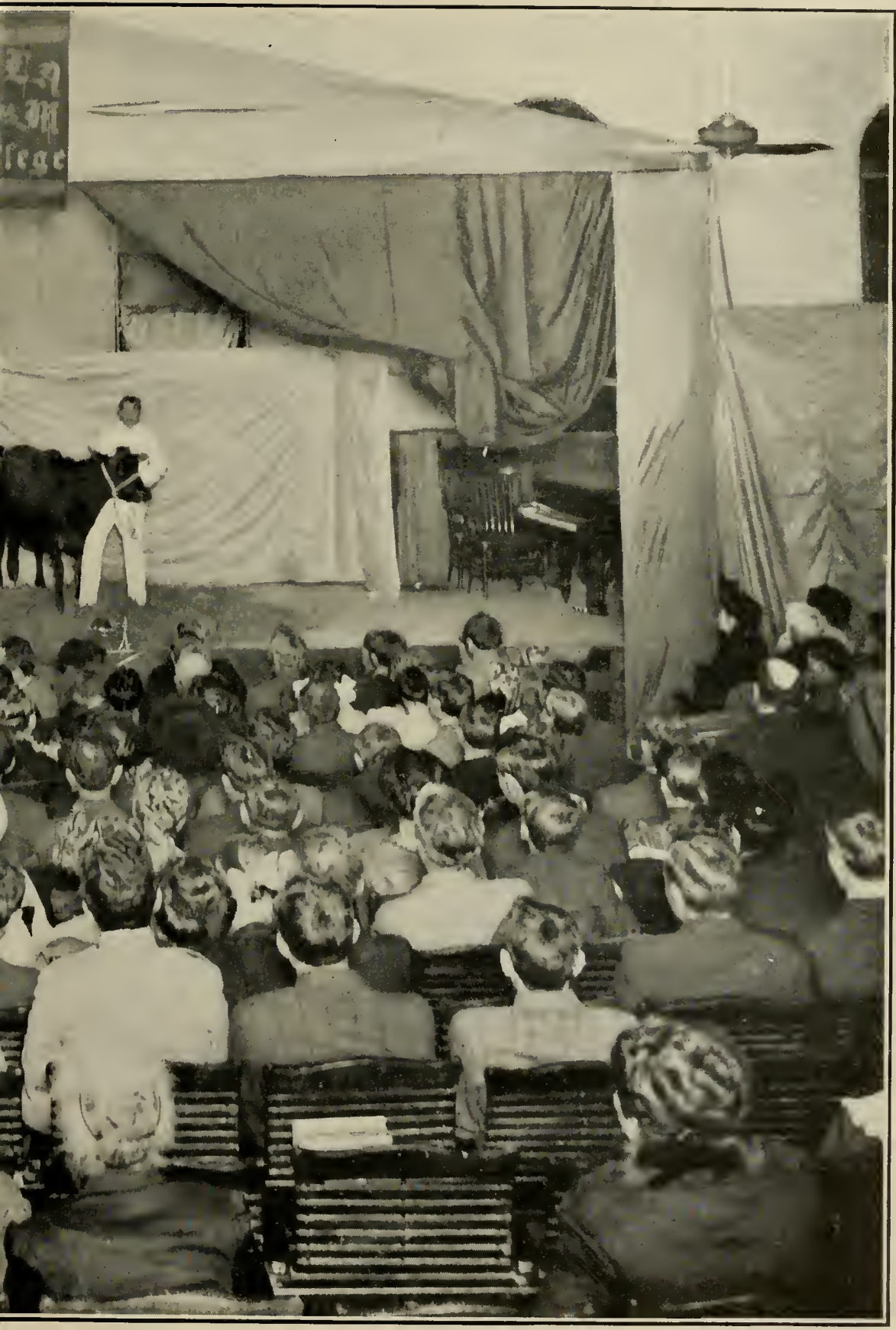

tion at the Oklahoma College of Agriculture 


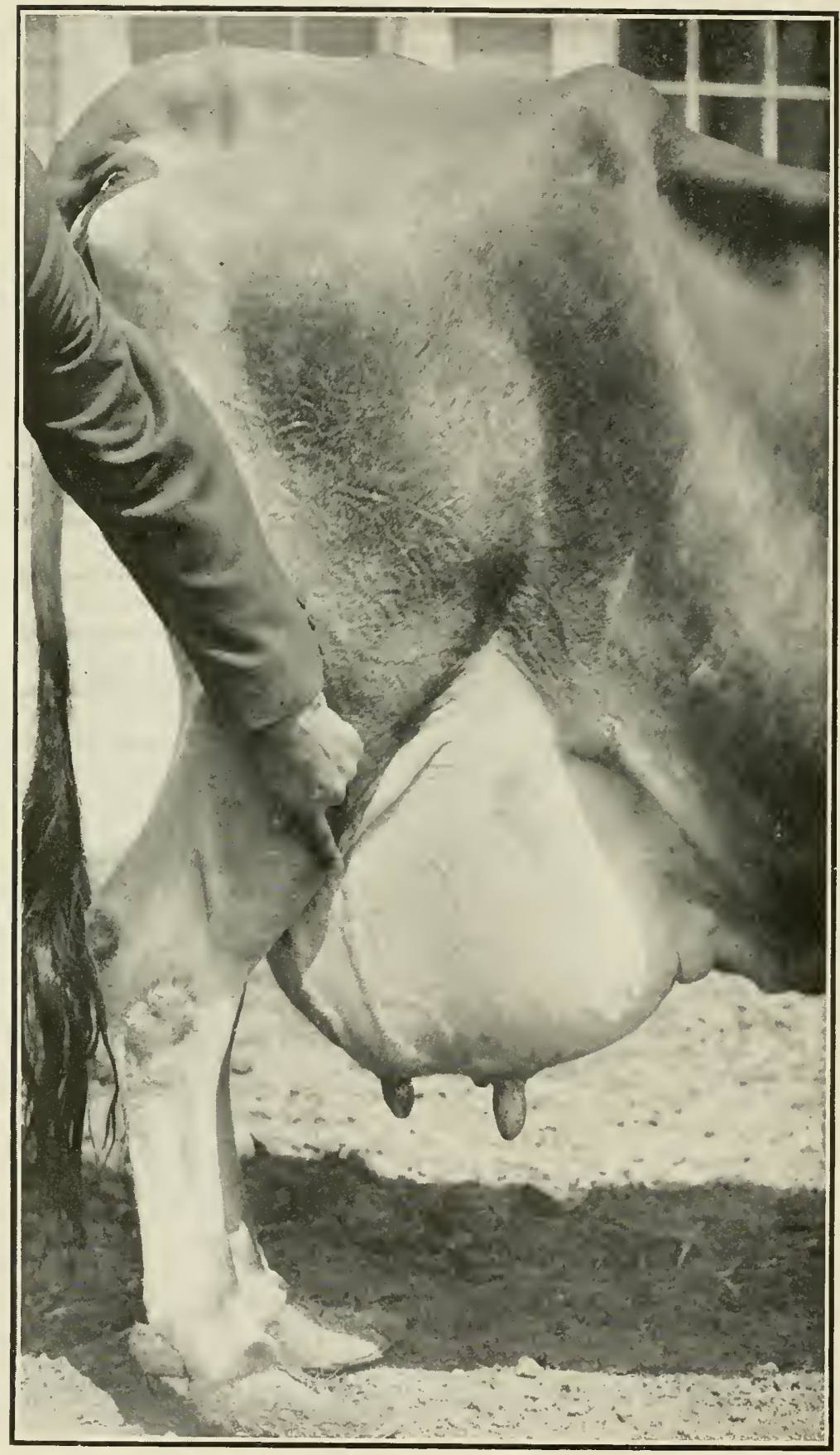

Large veins carrying a plentiful flow of blood through the udder 
make as great an amount of gain from a given amount of feed as will a beef bred animal, and to this extent, from the standpoint of making beef, the dairy bred animal is quite as profitable as the beef bred animal: but owing to the fact that for generation after generation his ancestors have been bred for the purpose of sending digested food nutrients to the underline of the body rather than to the top line, when he reaches the market he is found to be profitless. He is therefore discriminated against to the extent of several cents per pound by the packer who knows that choice steaks are not and never will be secured from the underline of the steer or from the inside fat and tallow. But the steer is not to blame. He did just what his inherent characteristics compelled him to do. Too many generations had the blood of his ancestors flowed to the underline of the body for him or his master to change the course.

\section{The Cow Not a Mysterious Being}

Neither can the cow whose ancestors for hundreds of years have been selected and bred for the special purpose of beef production be blamed because she does not produce milk as profitably as dairy cows. If the dairyman will permit himself to consider for a moment he will realize that the cow is really not a mysterious being and it is absolutely impossible for her to manufacture out of a given amount of feed both milk and beef at the same time. True it is that a portion of her food may be manufactured into beef and a portion of it into milk but it is certain that every pound of feed which is manufactured into beef while the cow is milking is absolutely lost and wasted from the standpoint of milk and butter-fat production and every pound of feed that is manufactured into milk and butter-fat is absolutely lost and wasted from the standpoint of beef production.

Thus it is that the direction in which the blood flows after picking up the milk making nutrients is of important consideration for the feeder of dairy cows. Likewise the volume of blood which circulates past the digestive apparatus and, in turn, through the udder or milk making factory has much to do with the amount of milk and butter-fat produced. For if the volume of blood be great and the cow well fed, the volume of nutrients will be great; and, in turu, if the milk making cells are efficient and numerous, the volume of milk will be large.

The volume of circulating blood and the direction in which it flows are indicated by the escutcheon, mammary veins and milk wells. 


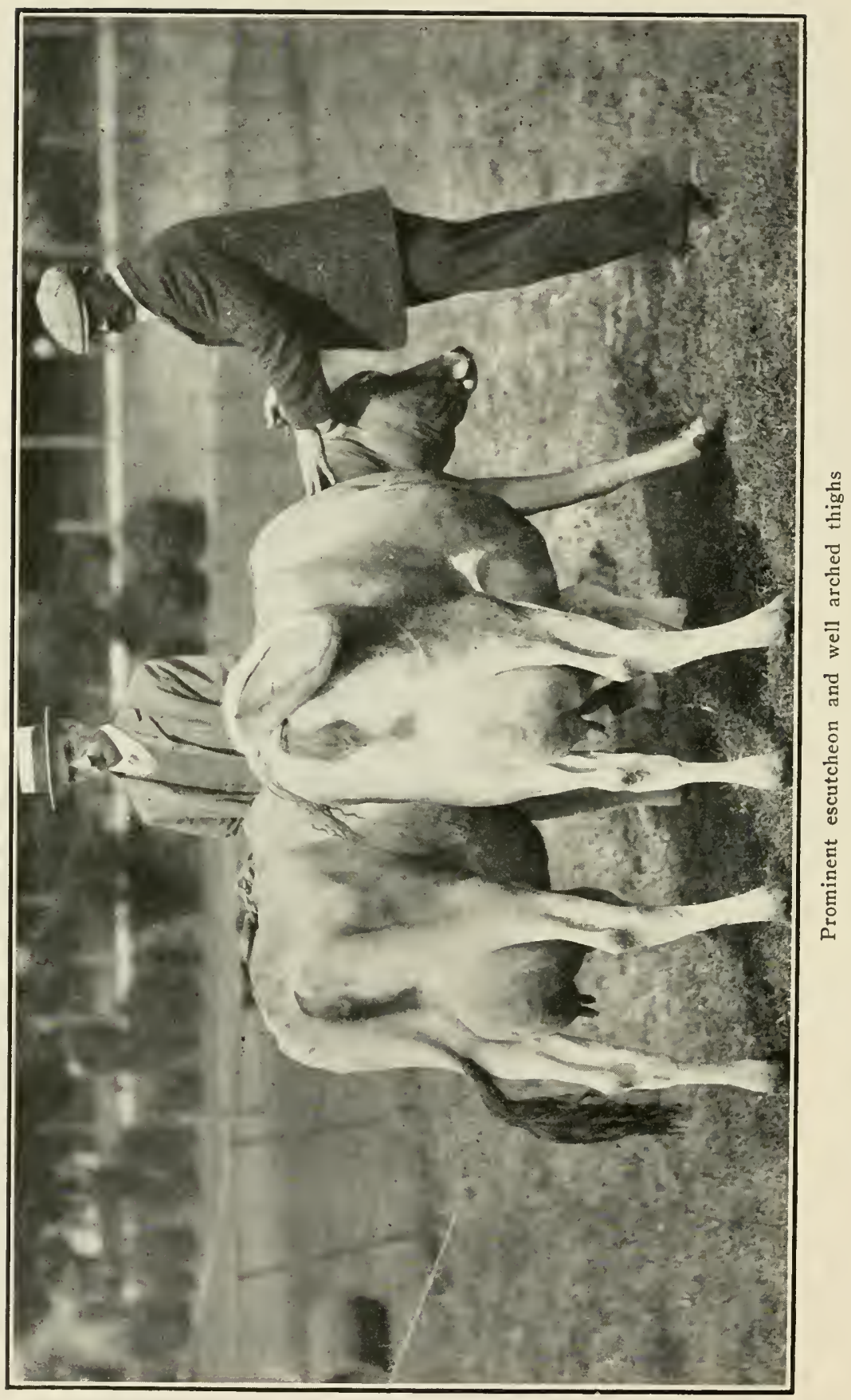




\section{The Escutcheon}

The escutcheon is that portion of the hind quarters above the udder where the hair grows upward. At each side of the escutcheon the hair grows in the opposite direction. It is a theory, and probably true, that the reason why the hair on this portion of the body grows in the opposite direction is because it is nourished by the large arteries passing into the udder while the hair on each side is nourished by other blood vessels in the same manner as the hair on other parts of the body. There was a time when judges of dairy cattle paid a great deal more attention to the size and shape of the escutcheon than they do at the present, because they probably had not yet realized that a much simpler and perhaps a truer method of determining the volume of blood passing through the udder was by the mammary veins.

The escutcheon that is long and wide, extending down over a portion of the urlder, is an indication of a large amount of blood passing into the udder, taking with it large amounts of nutrients. The mammary veins are found passing forward along the underline of the cow from the udder toward the shoulder pits. Every cow has two of these veins, one on each side. On some cows these veins are short, straight and small. On others they are large, long. tortuous and branched. In one case only a small amount of blood is passing through the udder while in the other instance the indication is that there has been an extremely large volume of blood flowing in the proper direction for milk production.

\section{Mammary Veins}

Cows differ very greatly in development of mammary veins. Some have a third vein termed a center extension passing forward along the center of the belly. At the end of each of these veins there is a hole in the abdomen through which the blood passes back on its way to the heart and lungs for purification and to be pumped back again on its former route past the digestive apparatus and around through the udder to other portions of the body where it carries nutrients for the maintenance of the animal. These small holes in the abdomen are called milk wells. If the vein is small, only a small milk well will be found at the end. If the flow of blood is sufficiently great the mammary veins become developed to greater proportions and in turn the milk wells are large. Oftentimes one well is not enough for each vein and then a portion of the blood passes into the first milk well, the 


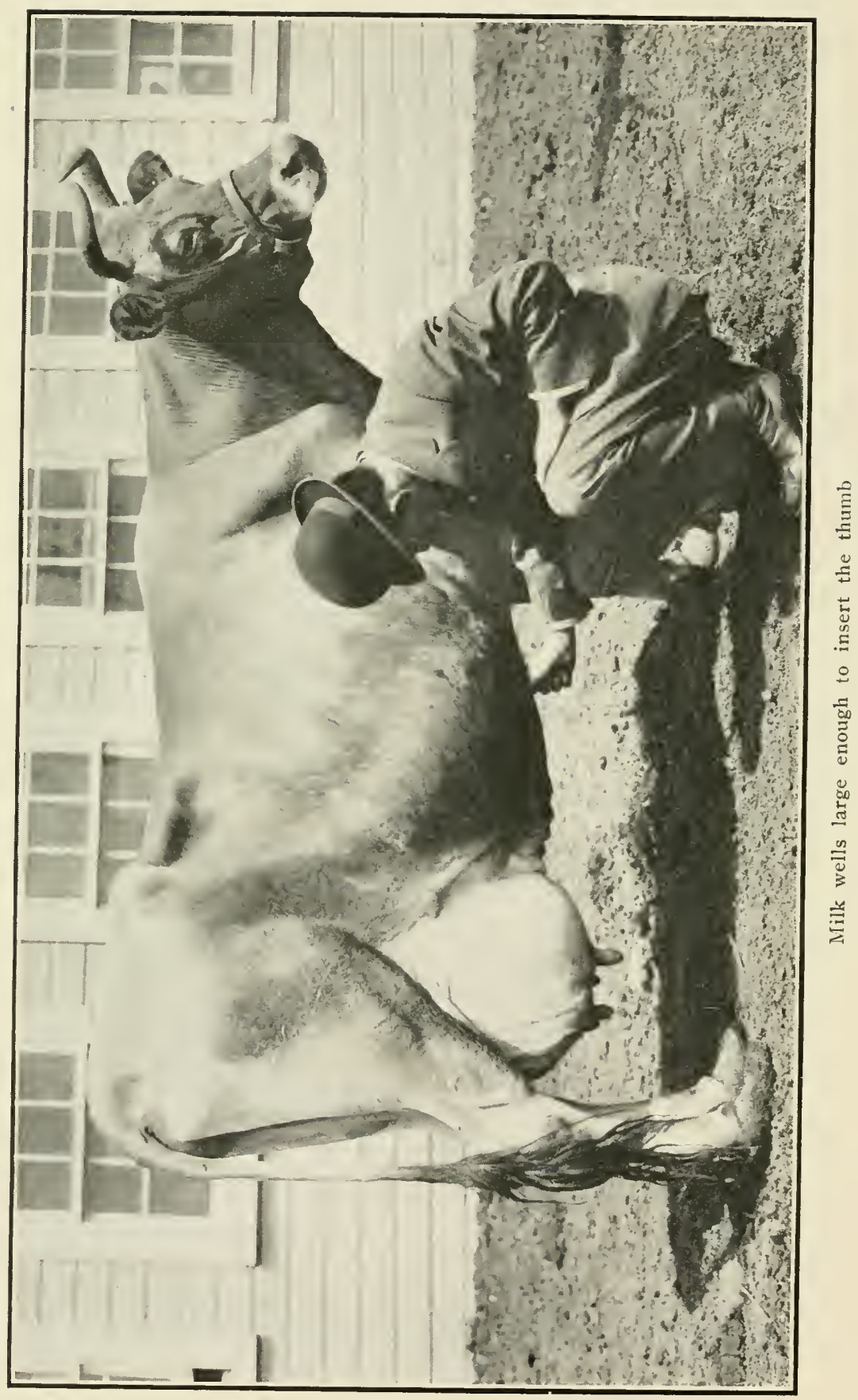


overflow passing to a second well, sometimes a third and occasionally a fourth or a fifth well. Such veins are known as double extension veins. It is quite often that cows have double extension veins on one side of the animal and occasionally they are found on both sides. Many times the veins branch, running back and forth across the abdomen and extending upward on her sides and forward in certain cases even as far as the shoulder pits. Invariably the greater the development of the mammary veins designated by their length, size and tortuousness, the larger and more numerous the milk wells, the more productive the cow. There are a few who disagree with this opinion but it is only necessary to examine the ablomen of every cow that has been largely productive as compared with those that are unproductive to agree that much importance should be based upon the mammary veins and milk wells, circulation of blood and production. I have never seen an extremely good cow whose system of mammary veins and wells was not extremely well developed and I have never seen a really poor cow with a great mammary system. It has been my pleasure to examine such cows as Colantha 4th's Johanna, Jacoba Irene, Dairymaid of Pinehurst and Financial Countess and without exception their veining is tremendous.

\section{Milk Wells}

In the instance of Colantha 4th's Johanna the entire abdomen is covered with veins ranging in size from that of a man's thumb to that of his wrist, terminating in numerous wells which, in turn, range in size sufficiently large for the insertion of a man's thumb to those only large enough for the insertion of the small finger. These indices point to the fact that a wonderful volume of blood has passed through the udder. Common sense bespeaks the necessity. when it is remembered that in the case of Colantha 4th's Johanna there was a yield in one year of $27,432.5$ pounds of milk containing $1,247.95$ pounds of butter. In her case, as in the case of every other good cow, it would matter little how great her constitution, how capacious her digestive apparatus or how strenuous a worker she might have been, had the greater percentage of her blood flowed to the top of her back, carrying with it the nutrients extracted from her food she would never have produced the wonderful volume of milk and butter-fat which she did; and although she might have been a profitable animal for the butcher she would have been worth little in the dairy. 


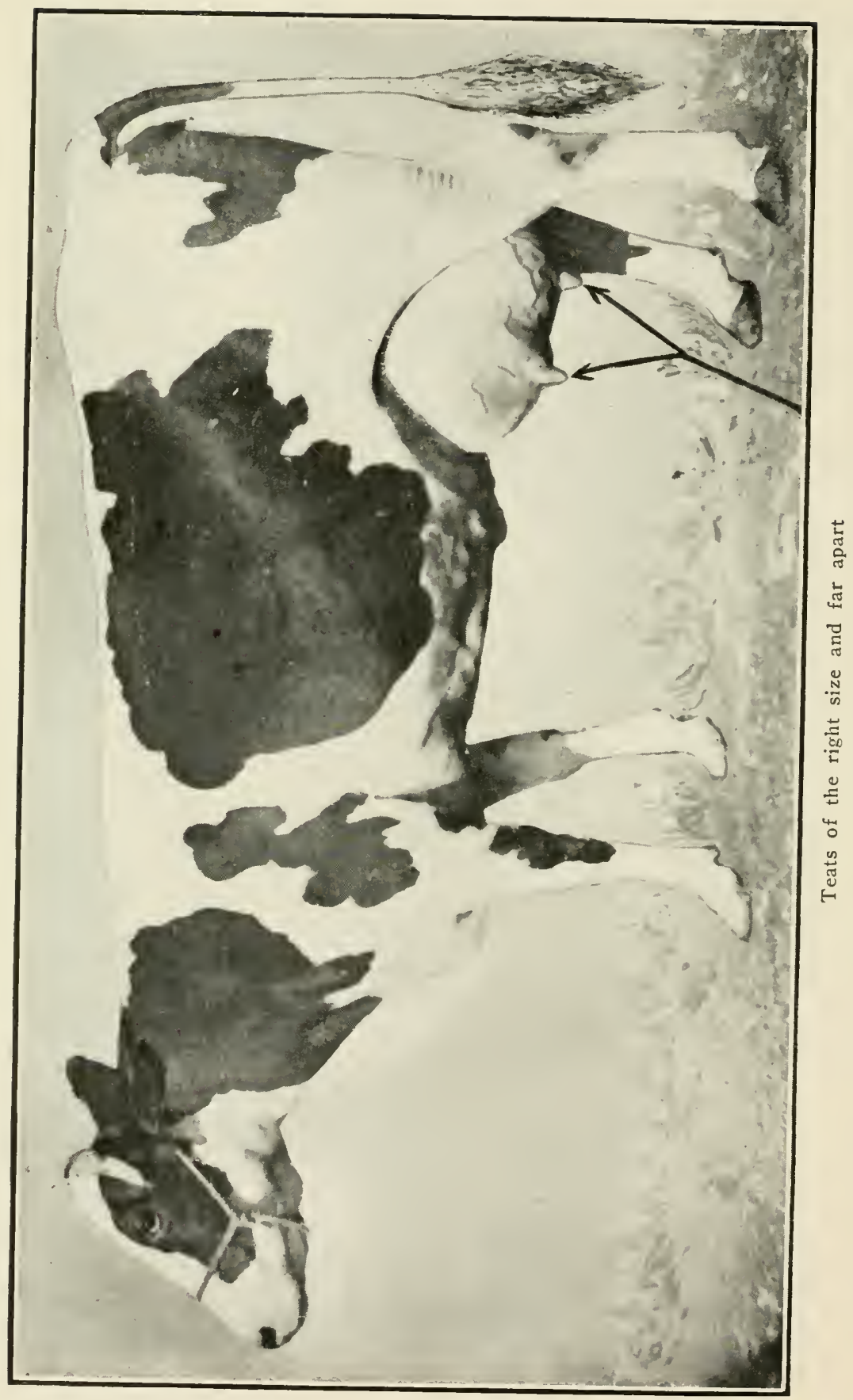




\section{CHAPTER VI \\ Ability}

Ability, used in describing the cow, refers to her powers of performing her required function of milk giving. Although ability is synonymous with capacity their difference in meaning is great enough to justify their use in differentiating between the cow's receptiveness for food and her power for manufacturing the nutrient from the food into milk products.

Given vigorous constitution, large capacity, nervous temperament and copious blood flow to the lower regions and the discription might apply equally as well to some other animal as to the cow. It is the fifth point, ability to produce milk that is the great distinctive maternal trait with which nature has endowed all mothers to a degree great enough to supply their babes with sustenance. This trait has been developed in the cow by man to such abnormal proportions that she has almost become an artificial being.

\section{Milk Making}

In all nature there is no demonstration of ability so interesting to the dairyman as that exhibited by the udder in taking from the blood, feed nutrients and, by a process $111-$ fathomable by man, manufacturing them into butter-fat, casein and milk sugar, which are combined in certain well regulated proportions with water and given off to supply the necessities of her infant offspring and to add her mite to the world's great milk supply.

Any indications, therefore, that denote efficiency in the cow's specialty of milk giving must not be ignored. As the whole of this important work is carried on in the udder, this organ, with its accessories alone, remains as indication of ability.

Size, form and texture of udder development are the principal indices. Size should be sought in length and breadth of udder rather than in depth, for several reasons. Largeness of udder gained by depth results in a pendent udder, one that hangs from the body and dangles or swings between the legs. Such udders are disagreeable to mill. When the cow lies down on the cold ground or cement floor almost the whole of the appendage comes in contact witli the cold surface and garget or inflamed udders and spoiled 


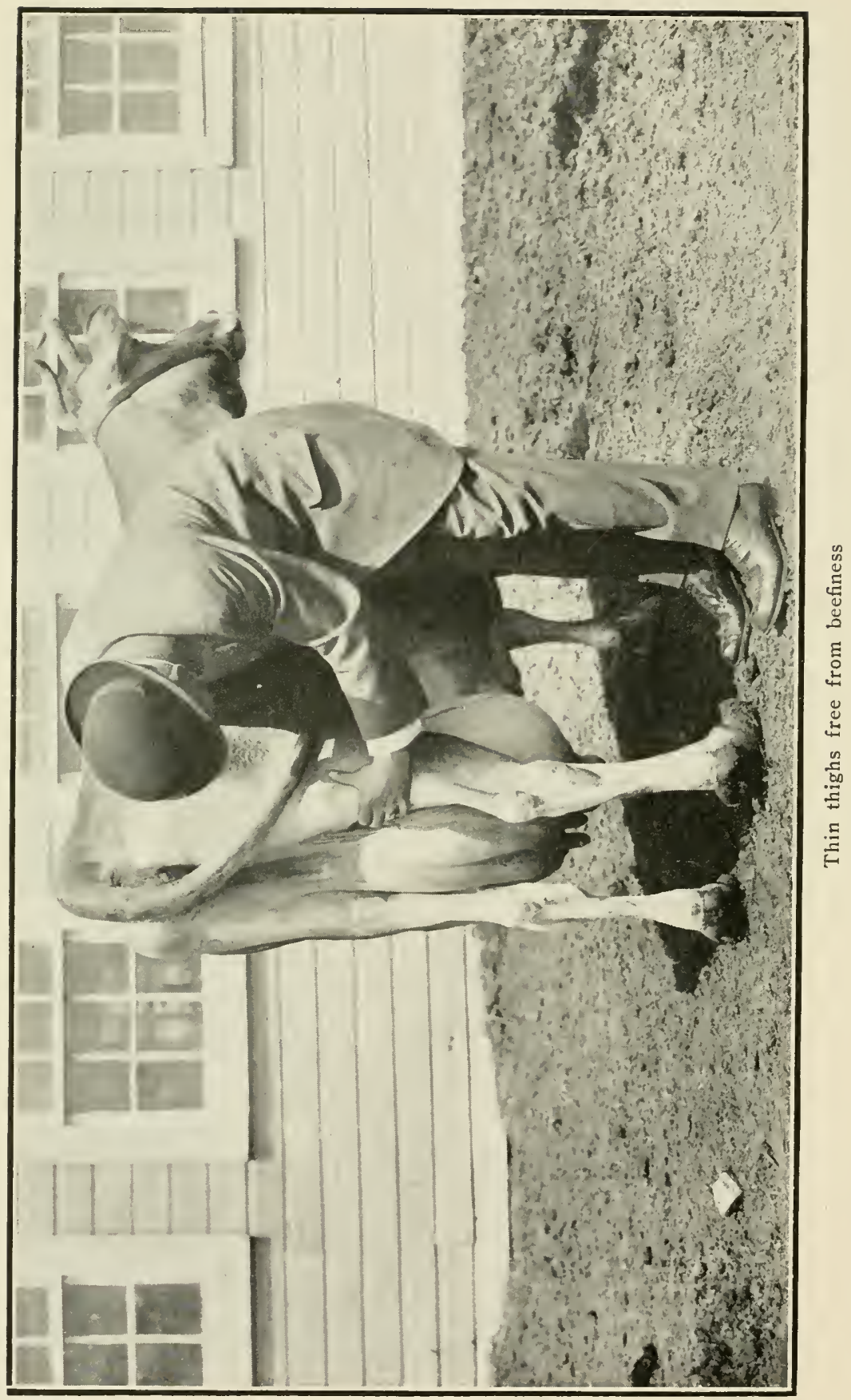


quarters are more liable to occur. When the cow stands in or walks through muddy places the udder and teats get wet and muddy and the least of the troubles that follow if the weather is cold is that much of the mud finds its way into the milk pail.

\section{Deep Udder Objectionable}

These difficulties can largely be overcome by good care but the real vital disadvantage of the udder that is large, because of its depth only, is that its joining surface with the borly is limited. Along the body pass the large arteries through which is carried the materials for milk manufacture and from these many small arteries pass downward into and all through the udder. If the size is obtained by length and breadth, a greater area of the udder comes in contact with the large arteries and opportunity is presented for a greater nimber of small arterial branches to be given off carrying in them the blood laden with milk making nutrients to be distributed among the numberless cells that form the working parts of the udder.

To be long the udcler must be attached high belinind and carried far forward. There is no danger of the rear attachment being too high nor the front attachment too far forward. Cows with uddlers the front and rear attachments of which are both to be found in between the hind legs are never known as great producers of either milk or profits.

Width of udder development is determined by the conformation of the thighs. If encouraged by thin thighs that are free from all signs of beefiness, they must curve outward forming a broad well defined arch, which has its beginning high, insuring breadth at the highest point where the udder attaches.

\section{Thin Thighs}

Beefiness in the thighs as in any other part of the body is to be guarded against so that in instances of cows with well formed hind quarters the thigh can be measured with the thumb and inclex finger. To recognize the importance of this conformation one needs only to investigate the size and form of the udder liung between beefy hind quarters. Especially is this true with such pronounced beef making proclivities as would excite the pride of the breeder of beef cattie or give assurance that she was capable of winning prizes in the show yard. Such a cow approaches the fulfillment of the beef cattle breeder's slogan, "beef to the hocks." Instead of being able to measure her thighs with the thumb 


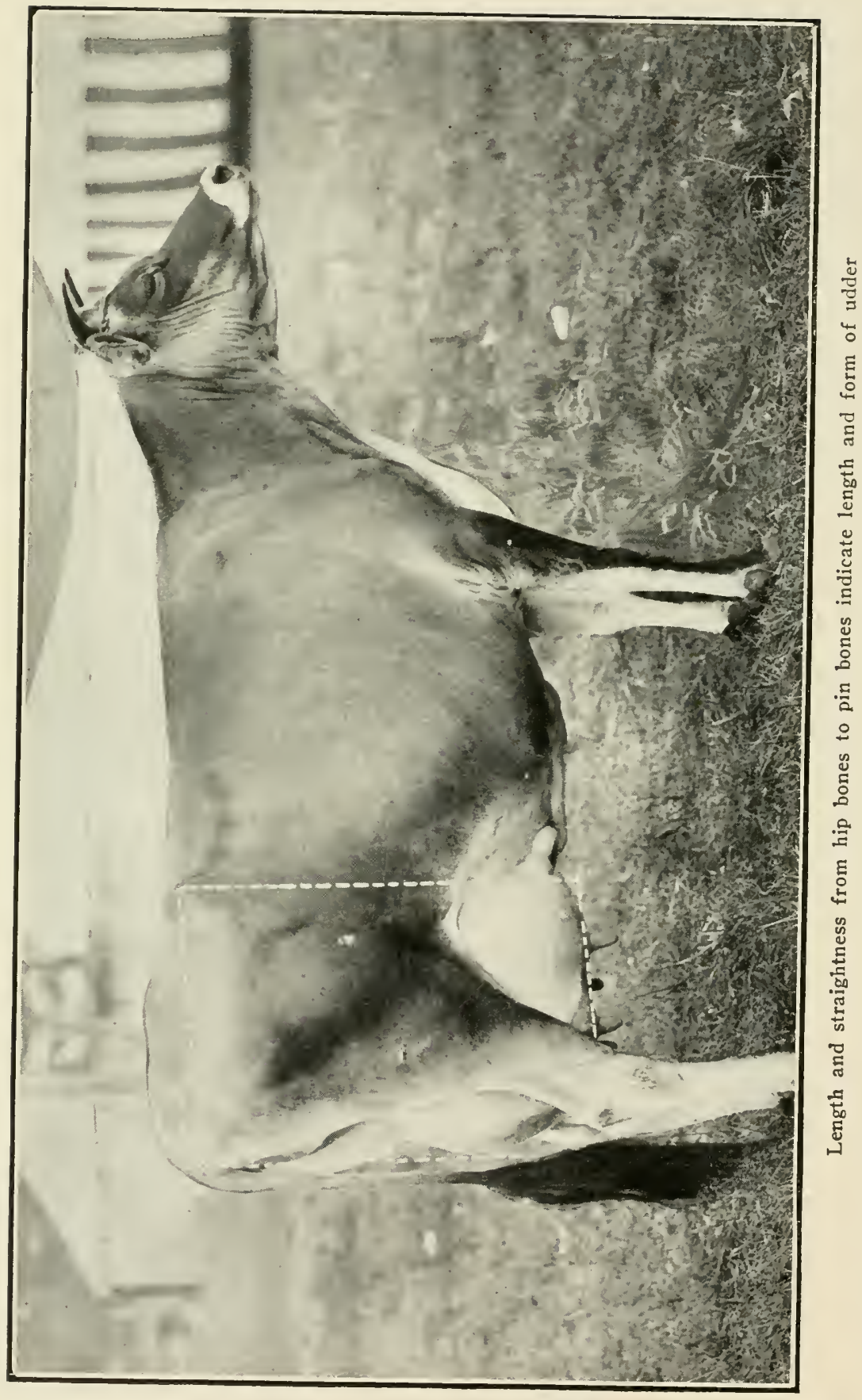


and finger both hands ontstretched are required because of the fleshy filling termed the twist that quite completely occupies the arch where the rear udder appears on the true dairy cow. Were such a cow endowed with a well developed rear udder she would be at a loss to find a place to lang it.

\section{Misshapen Udders}

Many cows have what are termed tilted udders-those that are fully developed in the rear portions but greatly lacking in the fore quarters. Slanting as such udders are from the hind teats to the abdomen there is no suitable place for the attachment of the front teats and they are set either very close to the hind teats or on the slanting edge of the udder. Such cows very often give from three-fiftlis to fourfifths of their total volume of milk out of the rear quarters and it is reasonable to believe that if the fore quarters of the udder were equally developed much capacity would be added to the udder and greater milk production result.

Pointed udders are even more objectionable for they are more lacking in capacity. Such udders may be described as being short in their rear attachment, extending downward to a point from all sides where all four teats are placed so close together that they have the appearance of originating or springing from the same hole. Cows of this character are disagreeable to milk and seldom yield profitably.

The quartered udder is the one that is divided by deep fissures into apparent halves or quarters and is neither sightly nor indicative of great production.

Cows of the Ayrshire breed are generally recognized as having udders very nearly approaching perfection of form and extremities of attachment.

\section{The Desirable Form of Udder}

Of all forms the udder most desirable is the one symmetrical and uniform in the development of each portion. Each quarter and half should correspond with the other and be so closely connected as to make the juncture almost invisible. With size added to the udder of this form there is ample room for the placement of four easily milked teats of medium size set far apart, one on each corner.

Those who have had extensive experience with dairy cows can call to mind some that had udders complying quite closely with this description both in size and shape but they were light producers and unprofitable. A careful examination would have revealed that their udders lacked quality 


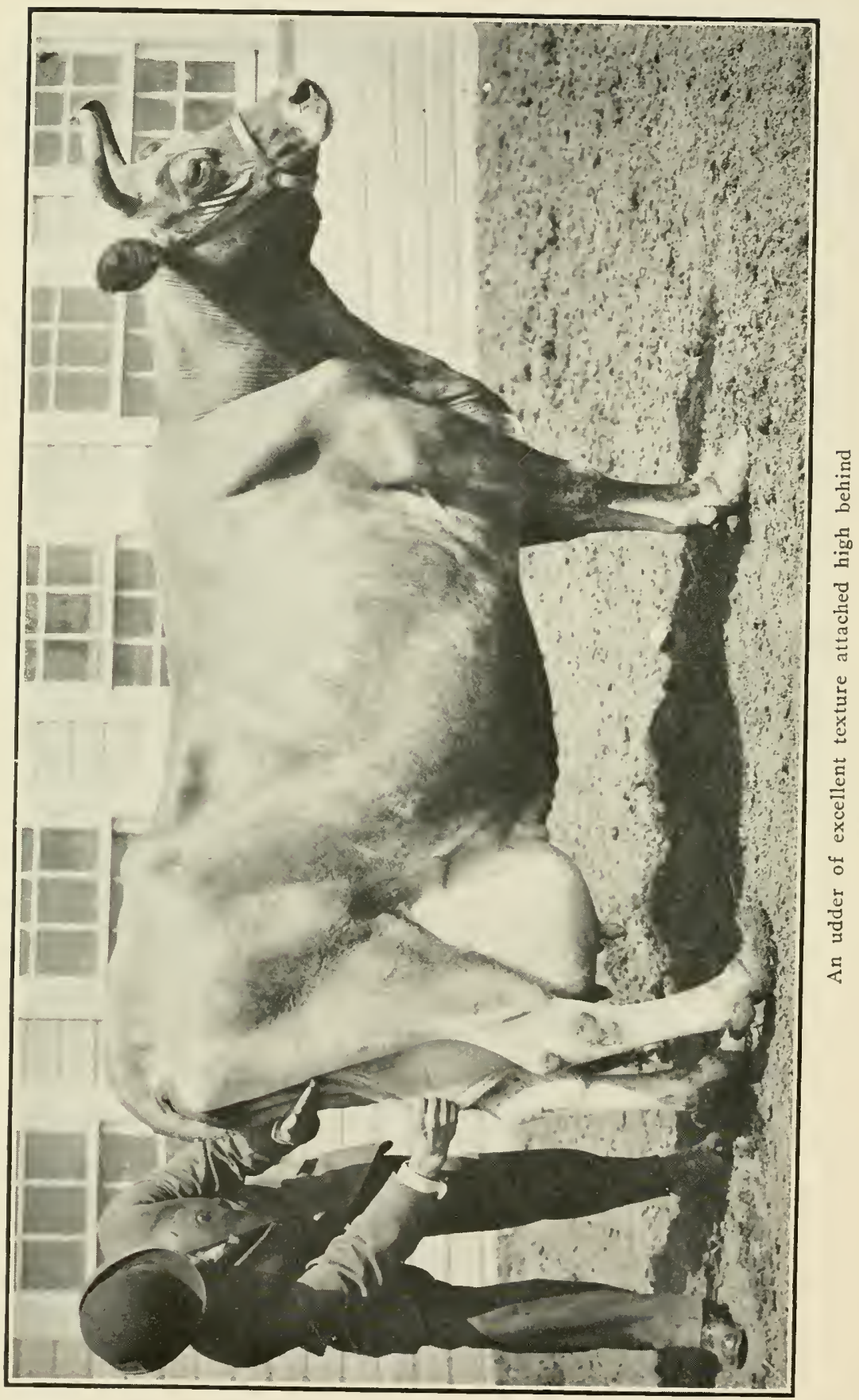


and texture. Instead of being made up of milk making celis they were composed of fatty tissues, hard and resistant to the touch and equally as large and well formed after milking as before. Udders of this character always point to a worthless beast. As an indication of ability to yield largely and economically the presence of quality and texture is ail important. Desirable as are all the qualities, size, shape, texture and quality if any of them must for any reason be sacrificed in the selection of a cow the two latter should be retained at the expense of the former.

\section{Quality of Udder}

Texture is indicated by the handling qualities of the udder and the hide and hair covering it and by the comparative appearance of the udder before and after milking. The udder pliable and soft, yet firm to the touch, covered with hide that is soft, unctuous and elastic, covered with short, fine silky hair is usually of proper quality. Then if large in the beginning it collapses during the process of milking and the covering falls together in folds that are plentiful, loose, soft and oily, all quarters of equal size and shape there is no indication of poor quality.

Often cows are selected when they are dry and then it is difficult to determine definitely the size and shape that the udder will assume when the animal freshens. The height of attachment behind can be discovered but only approximately how far it is carried forward. By the manner in which the thighs are arched and curved the width of udder development can be estimated but the examination of the udder does not truly indicate the length and form that will appear when the cow freshens As for the true length of udder the best indication is the length from the hip bone to the pin bones. When the cow is fresh and her udder is full a plumb bob dropped downward from the point of the hip bone falls immediately in front of the udder. Another dropped from the pin bones falls immediately behind the udder. Consequently, if the length from the hip bones to the pin bone is great, the length of the udder will be correspondingly great.

\section{Short and Drooping Rump Undesirable}

Cows short from the hip bone to the pin bone invariably have short, pendent udders and likewise those long in. these dimensions have udders that are attached high behind, extending far forward which are conditions always to be desired. Many cows, though long in the rump, droop from the 


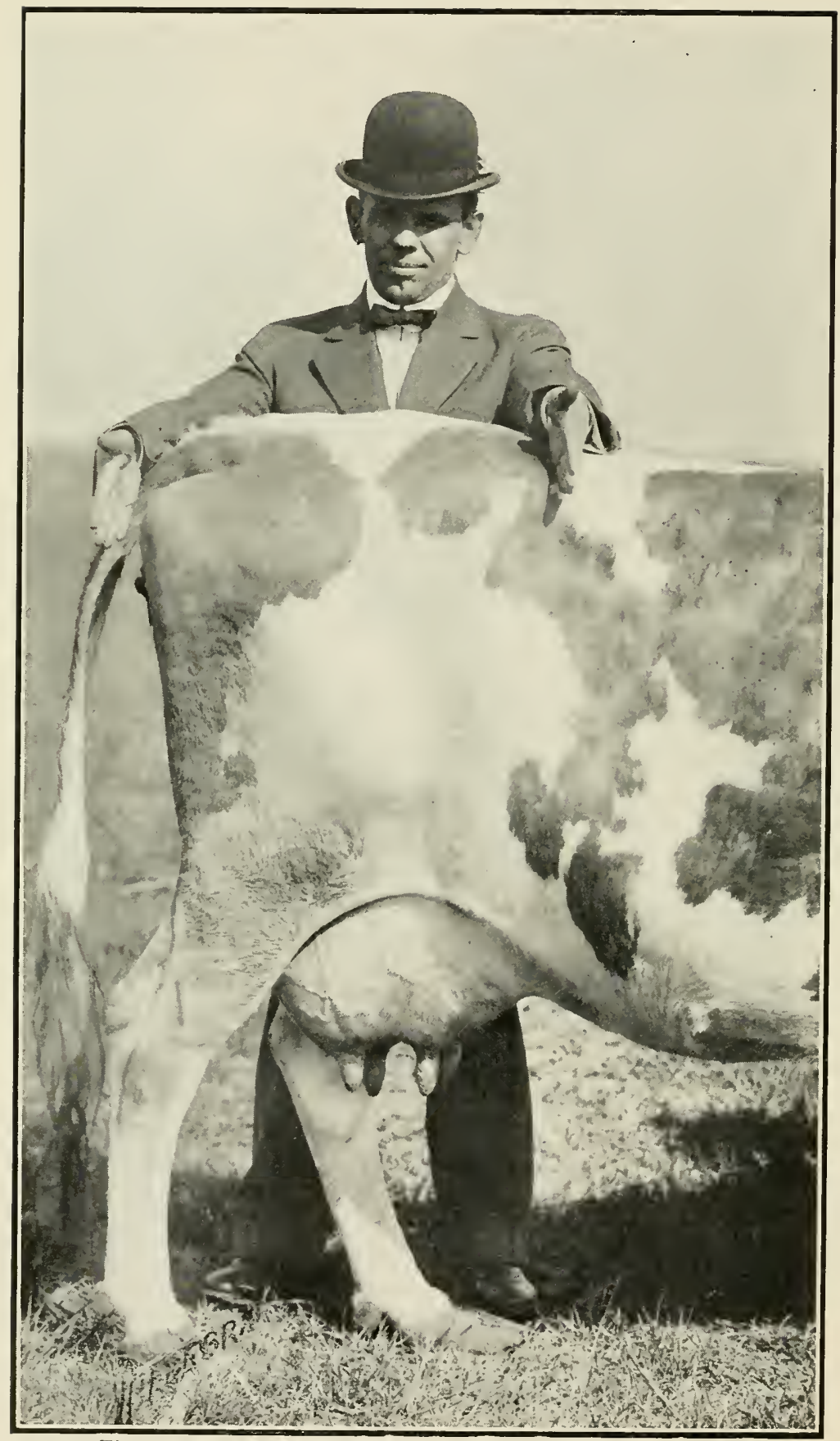

The rump is a valuable index to follow in selecting dry cows 
hip bones to the pin bones and are described by the expression "drooping rumperl." This conformation not only detracts from the beauty of the cow but as a rule those cows which droop at the rump also have tilted or slanting udders a portion of which seems to have been cut away and this naturally detracts from the ability of the cow.

On the other hand those cows which carry out straight from the hip bones to the pin bones have udders that are straight on the bottom, symmetrical and carry well forward with each quarter large and uniform in size. The fact that the length of udder can be determined by the length from the hip bones to the pin bone, and the shape of the udder by the manner in which the rump is carried out, is likely due to the law of correlation of parts which enables the anatomist when he finds a bone to determine from its dimensions the dimensions of every other bone in the animal's body from which it came.

The association of the drooping rump and the tilted udder appears with more certainty in families than in indiviclwal animals. In some of the dairy breels there are families of cows that have been bred for many generations without regard to the length and straightness of tailhead and invariably in these families a large percentage of animals are found that are at once miserable appearing "critters" and at the same time are handicapped in their ability to yield profitably becanse part of their udder is gone. Even though in certain indiviluals that lroop at the rump the udder is not very perceptibly faulty it may be taken as a rule that if offspring are continuously bred from animals of this conformation the associated characteristics will in time follow. 


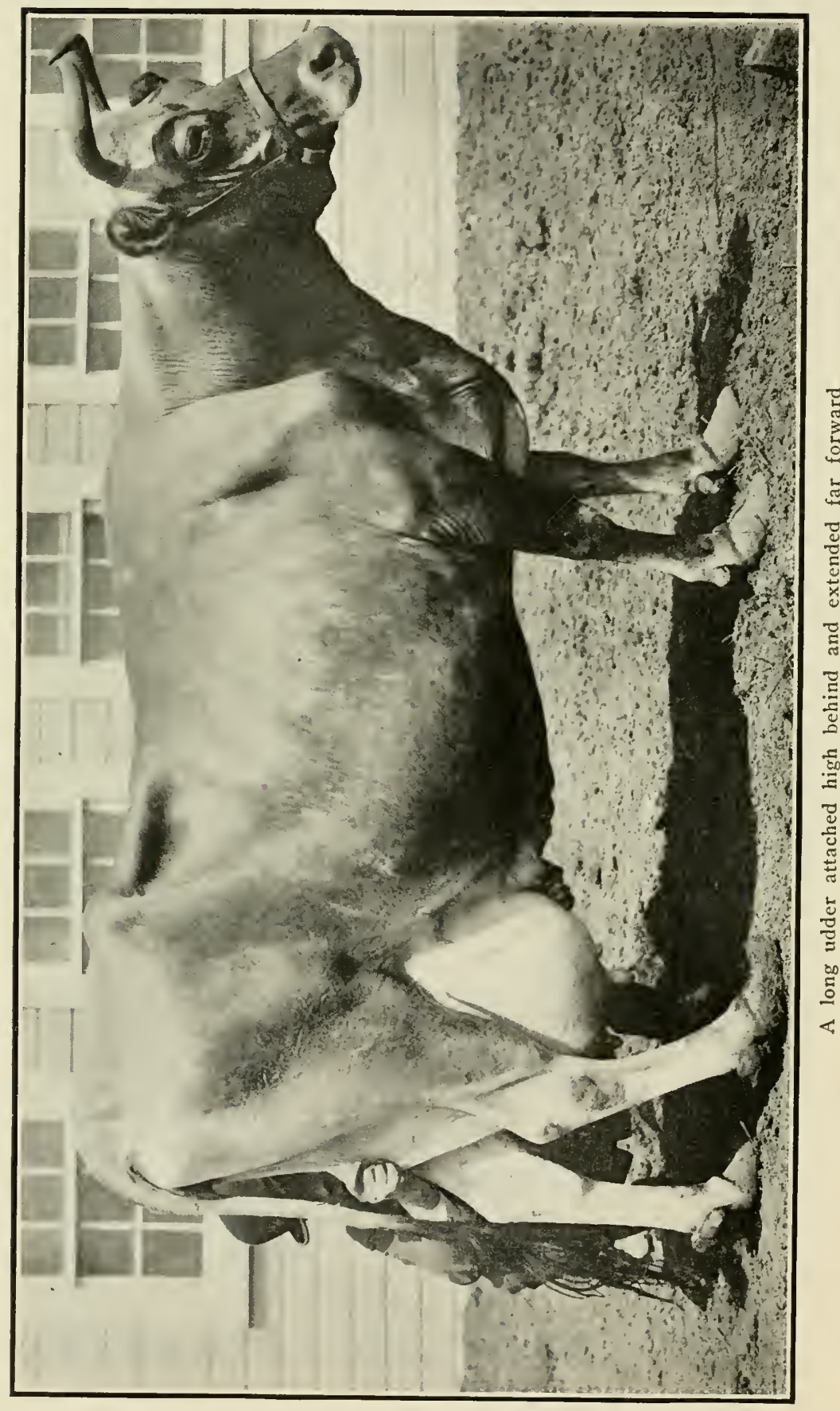




\section{CHAPTER VII \\ Other Desirable Points \\ Form}

General form of the dairy cow is a point that has received much consideration and has been the topic of extensive discussion. It has not been considered as one of the real essential points in this book because it is doubtful if by securing the accepted form of the present day authorities the points that are really essential to great and economical production will follow or if by securing in the animal the essential points for production the most desirable form will result. Whichever is the case the great improvement needed on every farm in America is not only an increase in the yield of the cow but also a decrease in the cost of production.

By selecting and breeding cows that show marked indications of the five points discussed great progress will result in these directions and as a further result the dairy form as called for in score cards and admired by breeders of dairy cattle will be much more prevalent among, the general rank and file of herds than it is at the present.

\section{Beauty}

Attractiveness of appearance, though hardly an essential to great production, should never be lost sight of, for, other things being equal, the handsome cow will command the greatest respect when placed upon the market and will invariably sell for the highest price. If beauty were an indication of small or costly production, then it might be well to overlook its importance. Who, after seeing such cows as those that stand at the head of each dairy breed today because of their great yearly records, will stake his reputation for good judgment on the assertion that it is only the brokenbacked, drooping rumped, tilted-uddered, homely creatures that yield well.

On the other hand it is safe to say that the breeder of dairy cattle who will be most successful in the future will be the one who because of the perfection of form and conformation and beauty of contour of his animals is able to win laurels in the show yard and with the same animals produce records that are large enough to prove beyond a 


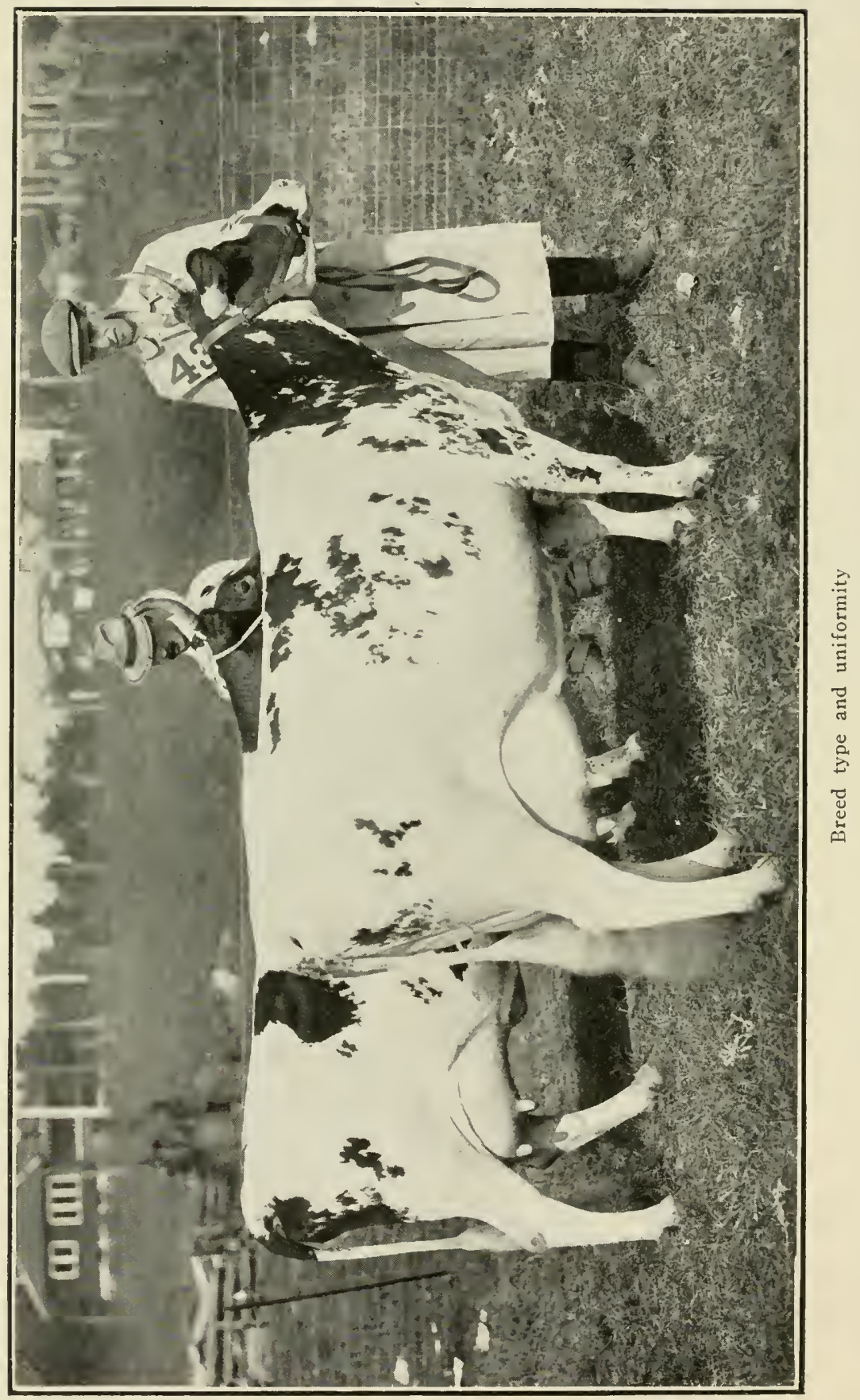




\section{VAN PELT'S COW DEMONSTRATION}

doubt that the handsome cows are the profitable kind to keep on the farm and in the clairy. Working the show animals and showing the working animals is the great necessity that is now being recognized by breeders of dairy cattle for making popular the breeds and stimulating demand for the blocd.

\section{Breed Type}

Dairy breeds differ greatly in color markings, size, yield and quality of milk and in several other ninor ways. However, having been bred for so many generations with the same real purpose in view, yielding butter-fat profitably, they do not differ greatly in this particular. There is at this time more difference between the productive ability of varions animals in any particular breed than there is betiveen the different breeds.

It is not the purpose to go into a discussion of breed type further than to call attention to the fact that those characteristics peculiar to the breed are distinguishing features and must be given due consideration by the breeders of pure bred dairy cattle and by the show ring judge. These features are important in that they clenote that the animal carries the blood lines of the particular breed she resembles and her production may be estimated accordingly. It is therefore reasonable to expect that with given form and conformation she will yield milk in quantity and quality much like the breed from which she is a descendant.

\section{Color}

Color is a breed characteristic rather than a factor in the determination of the value of the cow. It has had much to do in making the history of some breeds and many herds. Many a great animal has been sacrificed because its color markings did not meet the approval of its breeder. Color has much to do in giving miformity of appearance to a breed or to a herd but should never be the controlling factor in selecting cows for production.

Like many other of the less important yet desirable characteristics it is an excellent plan to seek them through the sire, special care being taken that other and more important requirements are not sacrificed.

\section{Size}

Considered from the standpoint of the beginner in the dairy business or the breeding of dairy cattle, size is the one great controlling factor. He selects cows that are large, re- 


\section{VAN PELT'S COW DEMONSTRATION}

gardless of all other considerations. This is probably because his earlier training has been with beef breeds of cattle and his past experience leads him to believe that small cows are delicate, small producers and unprofitable.

Size is an admirable feature when it can be secured without a loss of quality but all experience proves that in making a choice between two cows, one excellent in quality but small and the other large but coarse and lacking a symmetrical development of the essential parts the former is always to be chosen.

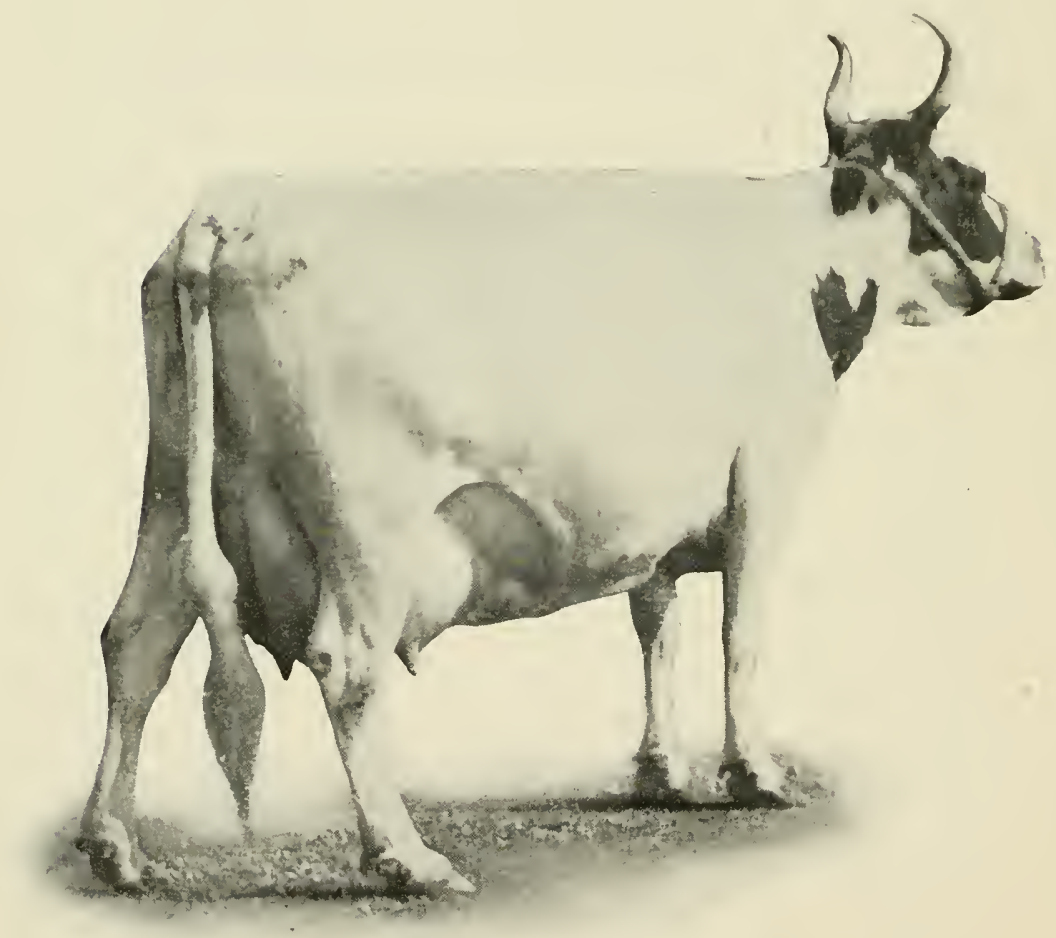

Great producers are economical producers 


\section{How to Secure Cows Combining the Five Essential Points}

Although there are millions of cows being milked on the farms of the United States, there are comparatively few that are not markedly deficient in one or more of the points that denote real worth. It is a well recognized fact that a great majority of the coivs milked today are no better than the cows that were being milked 50 years ago, although there are many breeders and dairymen that have made great advancement. They have improved their herds by selection and breeding and have pointed out to the world not only the possibilities that rest with the dairy cow but also the manner in which great couvs can be produced.

Those who own cows well developed in all of the five essential points are not desirous of parting with them because such a cow is always recognized by the intelligent owner as a most profitable animal. She returns annually more net profit than any other animal on the farm and in many instances more profit than her selling price would amount to were she to be offered for sale. For this reason although cows excellent in productive characteristics can be bought by the hundreds, they are very high priced as compared with common cow values. Nevertheless, they are worth many times as much and, rather than to milk a lot of cows that range from a loss to only a few dollars profit annually, it is advisable to bear in mind the points of a good cow. Secure in all events those that will return annual profits ranging from $\$ 50$ upward for such an increase will pay interest on a greatly advanced cost price and at the same time pay for the cow in a short time.

\section{More Good Cows Needed}

Such cows should be numerous on every farm in America and no doubt the time is close at hand when they will be. With land increasing rapidly in value, food stuffs and labor becoming expensive and scarce, he who milks is soon going to realize that it is a costly luxury to keep cows that do not pay a profit on the feed and labor expended upon them even 


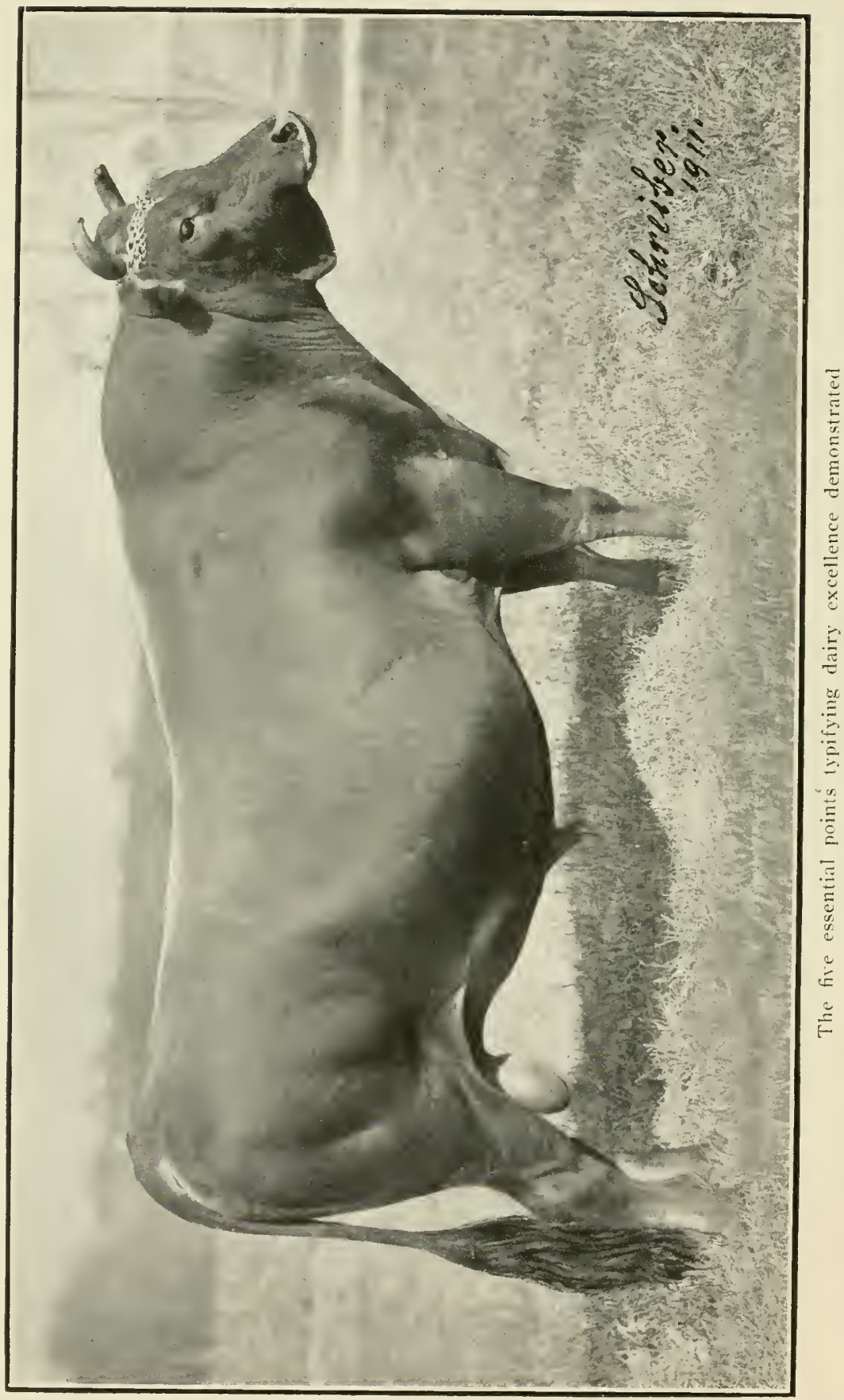


though they do prove themselves extremely valuable in keeping up the fertility of the farm.

The scarcity and high price of good cows renciers it impossible for everyone or even a large proportion of those who milk cows to clispose of the animals they are now milking and fill their places with the more desirable type. There is a method, however, of superseding the common cow with sood individuals that is practical and advisable. That is by selection and breeding.

Every breed of improved live stock known today has been developed by following well known laws of breeding and selection. The greatest of these laws is "Like begets like or the likeness of some ancestor." Never was there a law more true and he who is satisfied to milk and breed offspring from nonproductive cows with the same sort of ancestry may rest assured that he will never secure a great cow during the life time of drudgery that milking scrub cows assures.

\section{Improved Sires}

The solution of the problen of stocking farms ivith good cows rests largely upon the use of improved sires. The first consideration in selecting a sire should be the productive records of his maternal ancestry, that of his dam being the most important but dependant upon the records and individuality of the granddlams, great-granddams and back through the pedigree for at least six generations.

There are many who would not think of using other than a pure bred recorded sire and still in making the selection no consideration is given except the question of whether or not "papers" accompany the bull. These papers are always raluable, not so much because they indicate that the animal is pure bred, as because they teil the history of the animal's ancestry. Thousands of pure bred bulls are in use at this time whose purity of blood is boasted by their owners yet whose pedigrees say, "This bull's ancestors back for six generations were all veritable scrubs from the standpoint of milk and butter-fat production for there never has been a cow in the whole fanily that would give enough milk to raise her calf respectably." "Like produces like or the likeness of some ancestor." It makes no difference how good the cows in the present generation, the use of such a bull means retrogression and accounts for the fact that, on the general farm, cows are becoming poorer every generation. Bulls are being sold to thoughtless farmers at ligh prices under the cloak of registration papers regardless of the story 


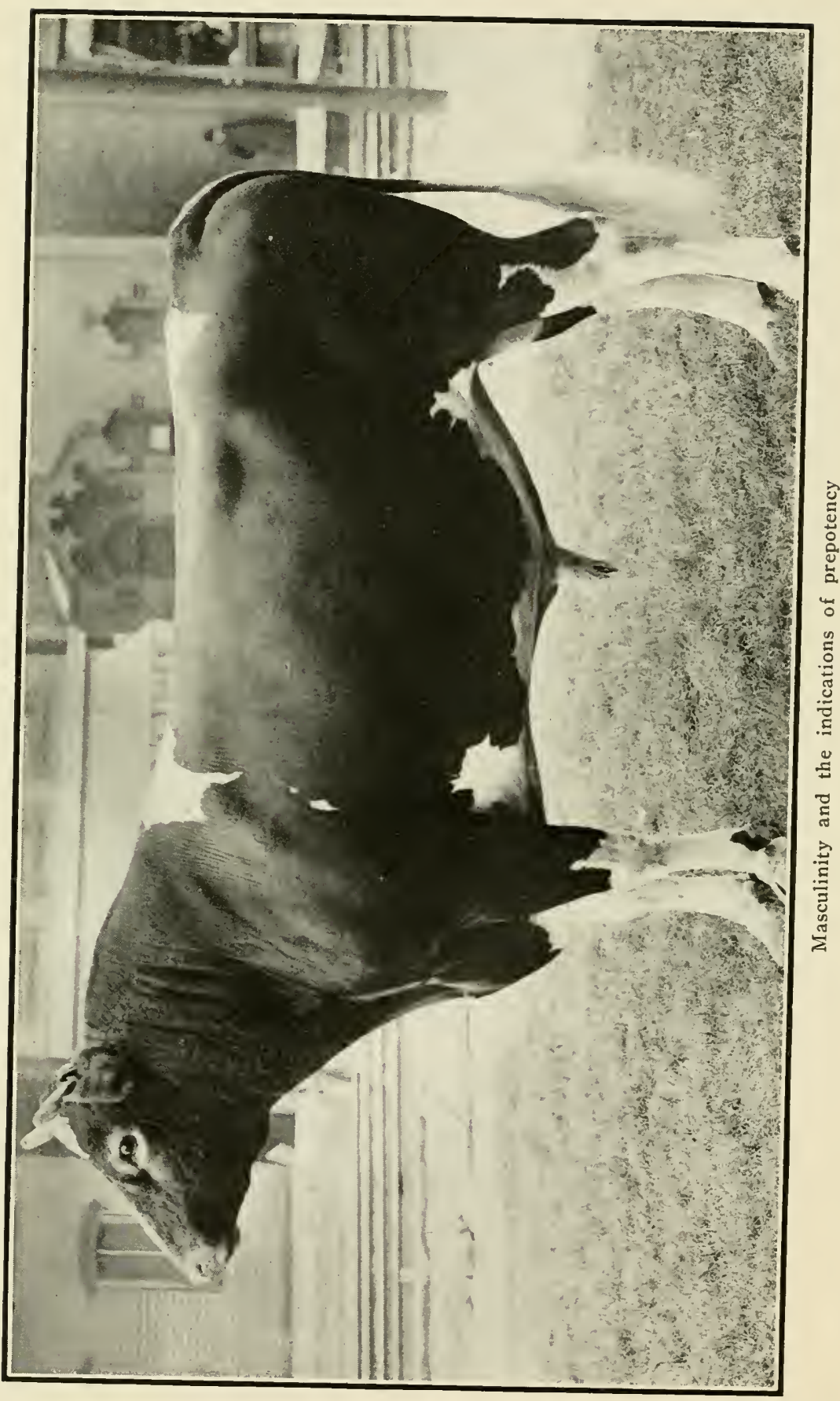


the papers tell. It is the same old story of the signature on the contrace reappearing as the signature of a note because the indorser did not read the contract which contained the information.

\section{The Valuable Pedigree}

The pedigree that foretells improvement in future generations is the one that points out that the females whose names and records compose it have all been great yielders of milk, butter-fat and profits. As surely as like produces like or the likeness of some ancestor such a sire will produce offspring that are an improvement over their mothers from the standpoint of production. This is the great value of a bull. Worthless indeed and an expensive possession is the bull whose daughters at the same age and under the same conditions produce less butter in a given time than their mothers did.

After a careful consideration of the information imparted by the pedigree, the individuality of the animal should be considered. Perhaps the first consideration should be whether or not he has the prepotency necessary for the reproduction of the valuable traits of his ancestors. This is indicated by masculinity and character. If present the animal will have the appearance and instincts of a bull expressed in his every characteristic.

\section{Essential Points of the Bull}

In addition every point indicative of production in the cow should be present in the contour of the bull. He should be outstanding in all indications of constitution, capacity, nervous temperament, bloorl circulation and ability.

To determine the presence or detect the absence of any of these essentials, the examination should begin at the head and end at the tip of the tail. The following description should be complied with:

The nostrils should be large and open; the mouth large; the jaws broad, wide and strong; the face long and clean cut from the eye to the nose and extremely broad between eyes that are large, prominent yet placid and expressive. The horns, though heavy at the base, should be of reasonable size and not coarse: the ear of medium size, rather than coarse, and covered with short fine hair instead of that which is long, coarse and wiry. The neck should be long, clean cut in the throat latch, well developed in the region of the windpipe and well crested on top denoting masculinity. A 


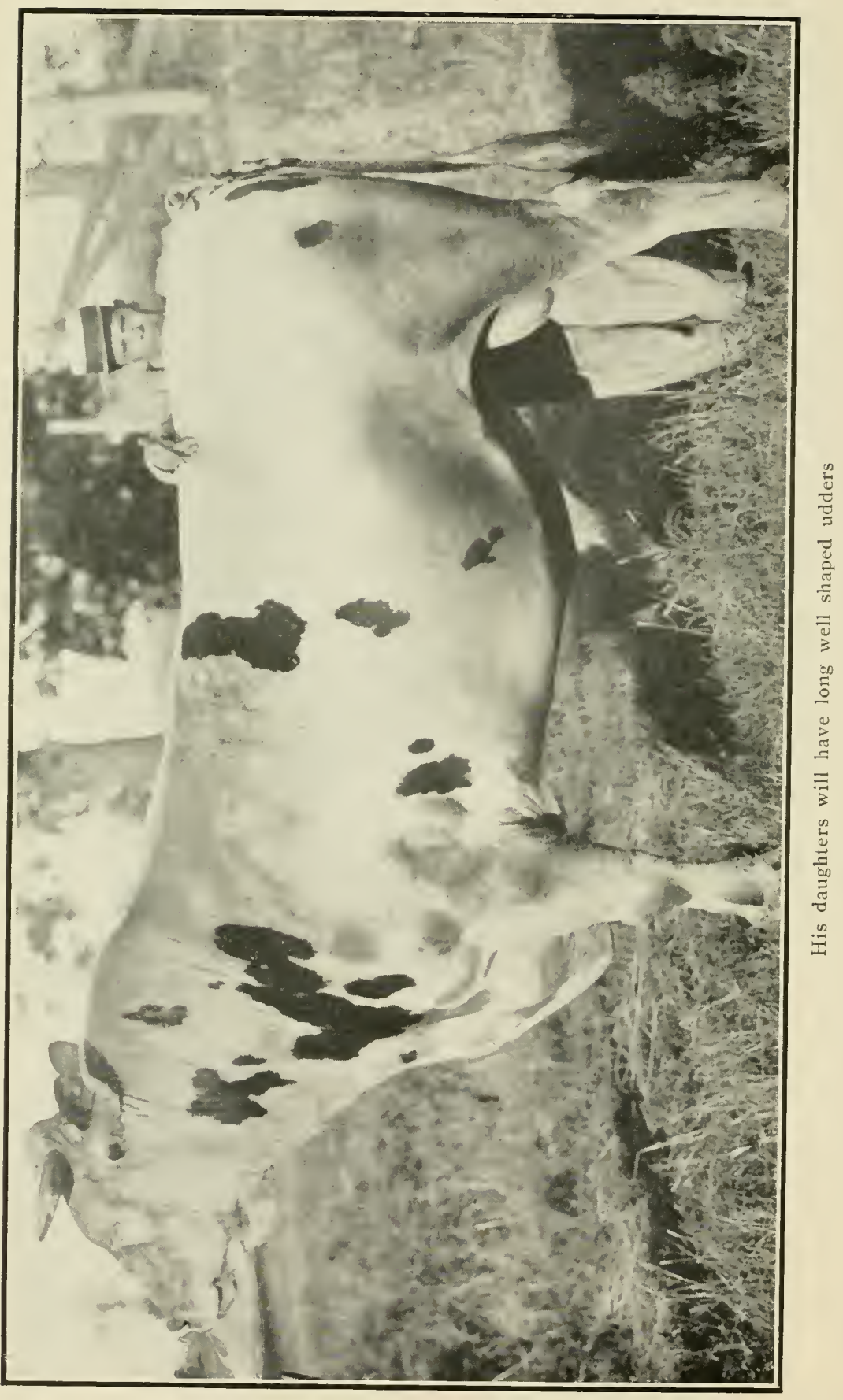




\section{VAN PELT'S COW' DEMONSTRATION}

head and neck of this description go far toward indicating constitution, capacity, nervous temperament, character and prepotency, all of which are desirable points to be transmitted to the offspring.

The shoulders should be oblique and not coarse, although masculinity encourages coarseness to some extent and bulls are always heavier. comparatively, in the front quarters than cows. Depth of chest and obliqueness of shoulders tend toward narrowness at the withers. There being no reason for width at this point, it is a mark of excellency for the top of the shomlders to be pointed giving the animal a wedge shaped appearance when viewed from in front.

As further inclications of constitution, capacity and quality, the heart girth and barrel should be long and deep, the ribs deep and well sprung, and the body covered with hide that is soft, pliable, elastic and oily, and hair fine and silky. These points with the exception of the character of the hicle and hair are more evident in the male than in the female and therefore more readily distinguished. Furthermore. in the well bred sire of proper form the back bone shows greater development, is more open jointed and larger, and, like the well bred cow of desirable conformation, there is an absolute freediom from beefiness in these regions and over the entire body.

Inch consideration should be given the hind quarters of the animal, for these parts indicate the ability he is liable to transmit to his female offspring. Reasonable width between prominent hip bones, great length and straightness from the hip to the pin bones and width through the thurls indicate that there will be a like conformation in the calves. In the case of heifer calves these points indicate that when they have grown to cowhood they will have roomy productive nrgans and long well balanced udders. If the rump is short and drooping. and there is narrowness between the thurls, it is quite likely that the calves will be of the same conformation and few if any well formed and balanced udders will result from his use.

Viewed from behind, the thighs should be thin, well curved and free from fat and beef, forming an arch that is at once high and broad. By conveying the same peculiarity to his effeminate offspring suitable provision is made for the placement of an udder that may be wide and hung well up behind. Bulls beefy in the hind quarters and not cut well up behind should be guarded against as their heifers are seldom of a desirable sort.

As an indication of the size of the udders and the place- 


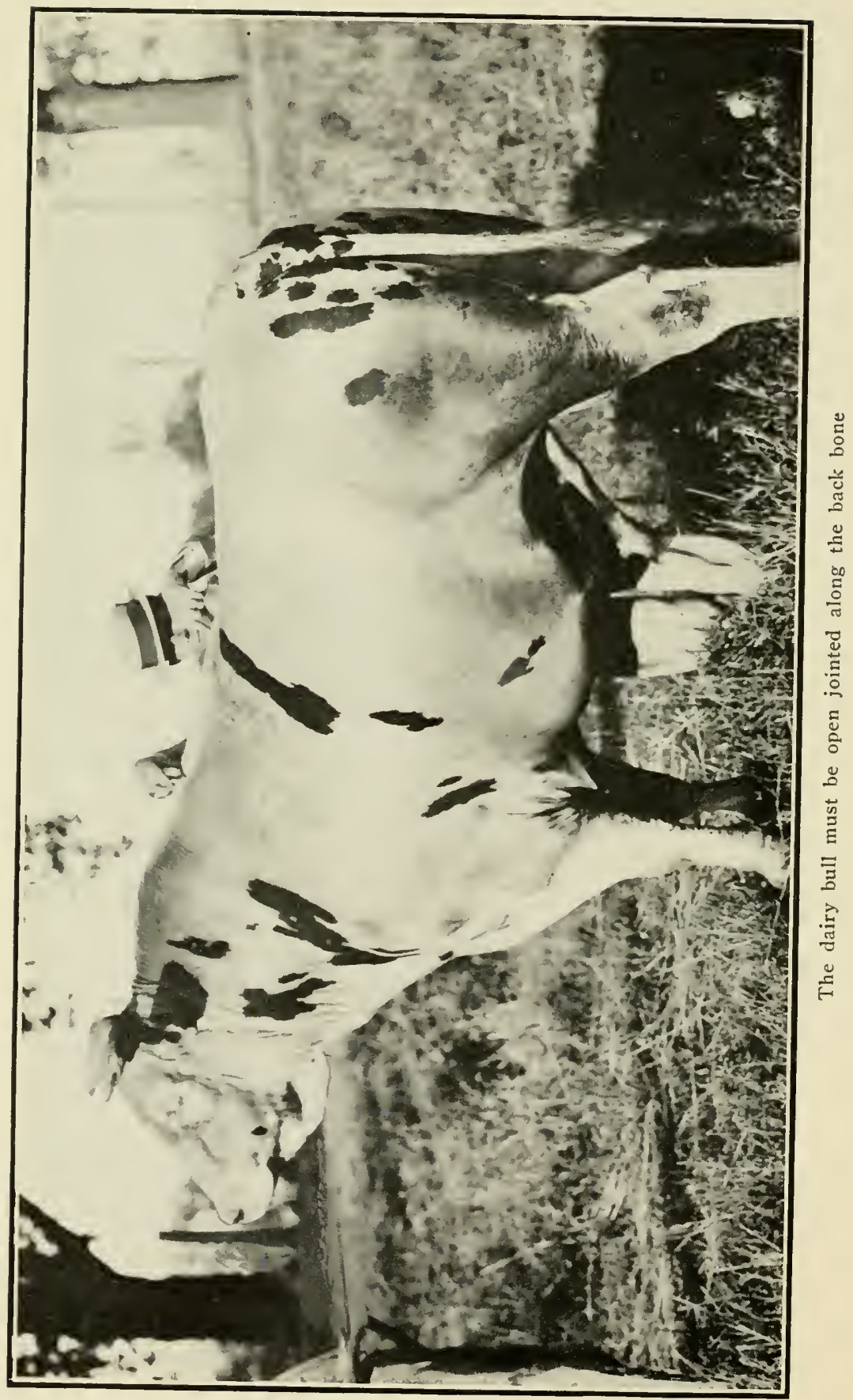


ment of the teats on the progeny of the bull the rudimentary teats which should be found forward on the scrotum, should be recognized as an index. It is believed that if these teats are large the teats of the female progeny will be large and if the rudimentaries are placed far apart the teats on his daughters will be placed far apart. In addition to being a desirable trait, this is an indication that the udder will be both long and wide.

Mammary veins and milk wells are important points to observe in selecting sires, for, as in the cow, they indicate the volume of blood flowing to the lower parts of the body. In so much as it is so important that there be a great flow of blood through the udder of the cowv, it is necessary that the characteristics of the bull indicate that he will transmit that trait to his descendants.

Bulls differ greatly in size, length and development of mammary veins much as do cows. Some of them have large veins that pass as far forward as the shoulder pits and others veins that are small and short with no signs of branches and ending in milk wells that are so small that they are difficult to find. It is not to be expected that these veins and wells will be as large as those of the cow for the same reason that the veins of a young heifer or a cow far advanced in the period of lactation ivill not be as large as those of an older cow or one that is giving a large flow of milk. Heavy production develops the size and it is noticeable that cows well fed and forced to yield large amounts of milk for a long period exhibit greater veins and wells than those that have never been stimulated to do their best. Nevertheless the presence of large, tortuous, long branching veins and large, numerous milk wells on the sire indicate that his heifers will have correspondingly desirable veins and wells. When they come into milk they may be developed by good care and feeding. Other things being equal they will be more productive than the descendants of a bull less developed in these respects.

\section{Good vs. Poor Sires}

Pointing to the great value of a good sire and to the utter worthlessness of a poor one, are the experiments that were carried on at the Missouri experiment station by Prof. Eckles, who says :

"In 1884 the Missouri Agricultural College bought four registered Jersey cows and the entire herd we have on hand today is descended from these corvs. Of course, herd bulls have been purchased from outside but no female has been bought. Since 1892 complete milk and butter-fat records have 


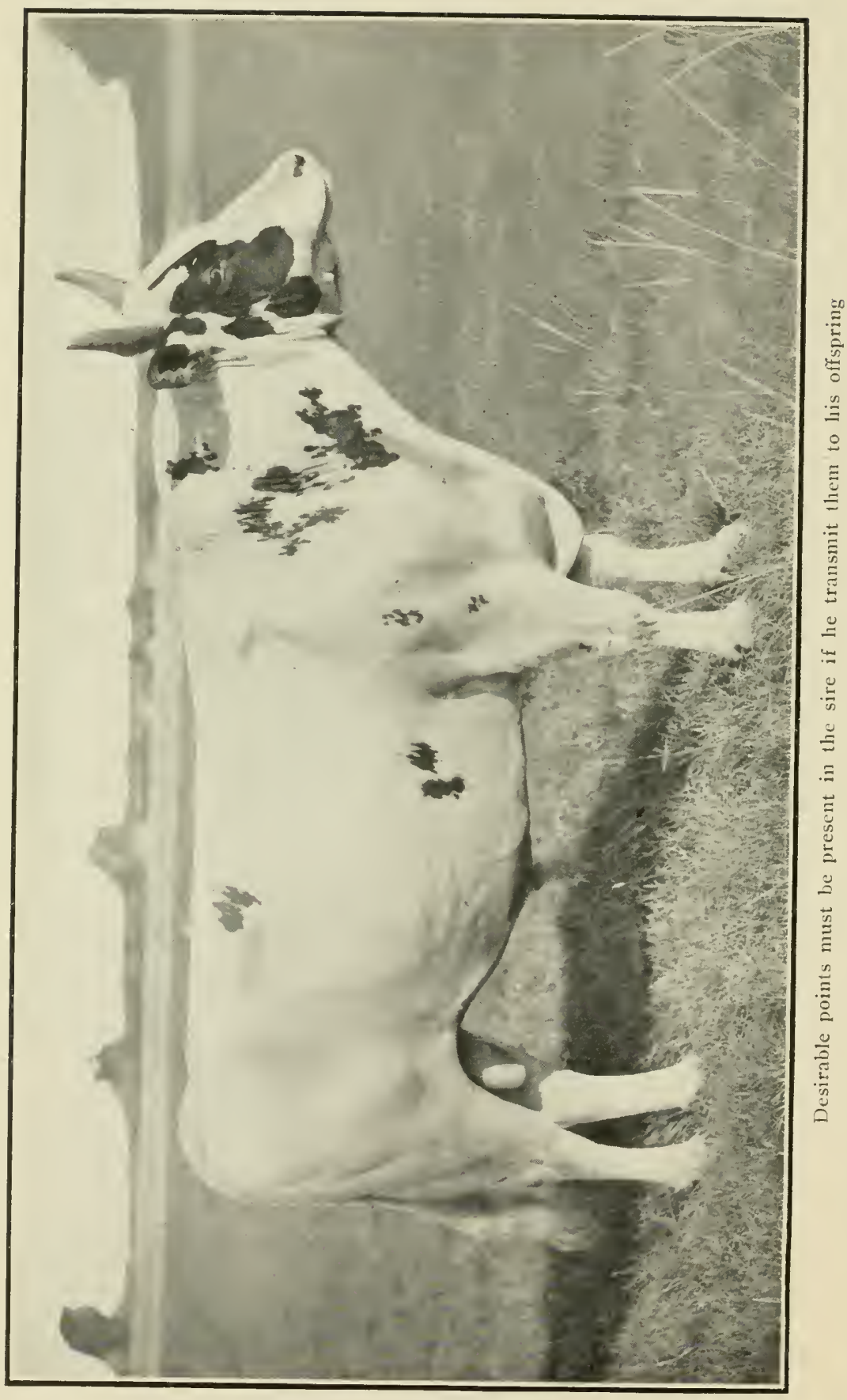


been kept of every cow. Up until 1901 practically every female was retained in the herd regardless of her dairy qualities. These conditions give an opportunity to study the effect of sires which can hardly be duplicated anywhere. The first bull used was Missouri Rioter, a son of Bachelor of St. Lambert. There is no record indicating the dairy quality of his dam. In fact his sire is the only animal in his pedigree known to be a strong breecler. This bull was a very weak breeder. His danghters averaged 4,336 pounds of mitk per vear while their dams averaged 5,380, a decline on the average of 1,044 pounds of milk per year each. The average fat production of the dams was 234 while the daughters everaged only 216, a decline of 18 pounds per cow from the dams to the daughters.

\section{Hugorotus}

"The next bull used in this herd was Hugorotus. He was a cheap bull without any high testing animals in his pedigree. His mother, however, is said to have been a good cow. The daughters of this bull were inferior to their dams in milk production, but on account of a higher per cent of fat they gained slightly in fat production.

"Ten daughters fell a total of 3,770 pounds of milk per year behind their dams but gained 100 pounds of fat. The general results of using this bull were disastrous. In fact, the poorest animals ever in the herd were his offspring. The averages shown are made as good as they are only by the fact that two full sisters sired by this bull, through some 'nick,' proved first-class animals.

"When the herd was culled on milk records alone, nine out of the 11 daughters of this bull, then in the herd, were sold to the butcher. The two remaining were the full sisters mentioned. As long as this bull was in the herd, the general tendency was backward.

\section{Lorne of Meridale}

"The next bull at the head of the herd was Lorne of Meridale. This bull had a splendid pedigree from the standpoint of records and his offspring show the results. His daughters, with one exception, were all superior to the dams. The average milk production was raised from 4.542 pounds per year to 5.751; the fat production from 220 to 280 pounds per year. At butter-fat prices the 10 daughters of Lorne of Meridale returned each year $\$ 150$ more than their clams. What a difference from the results from Missouri Rioter. ***** 


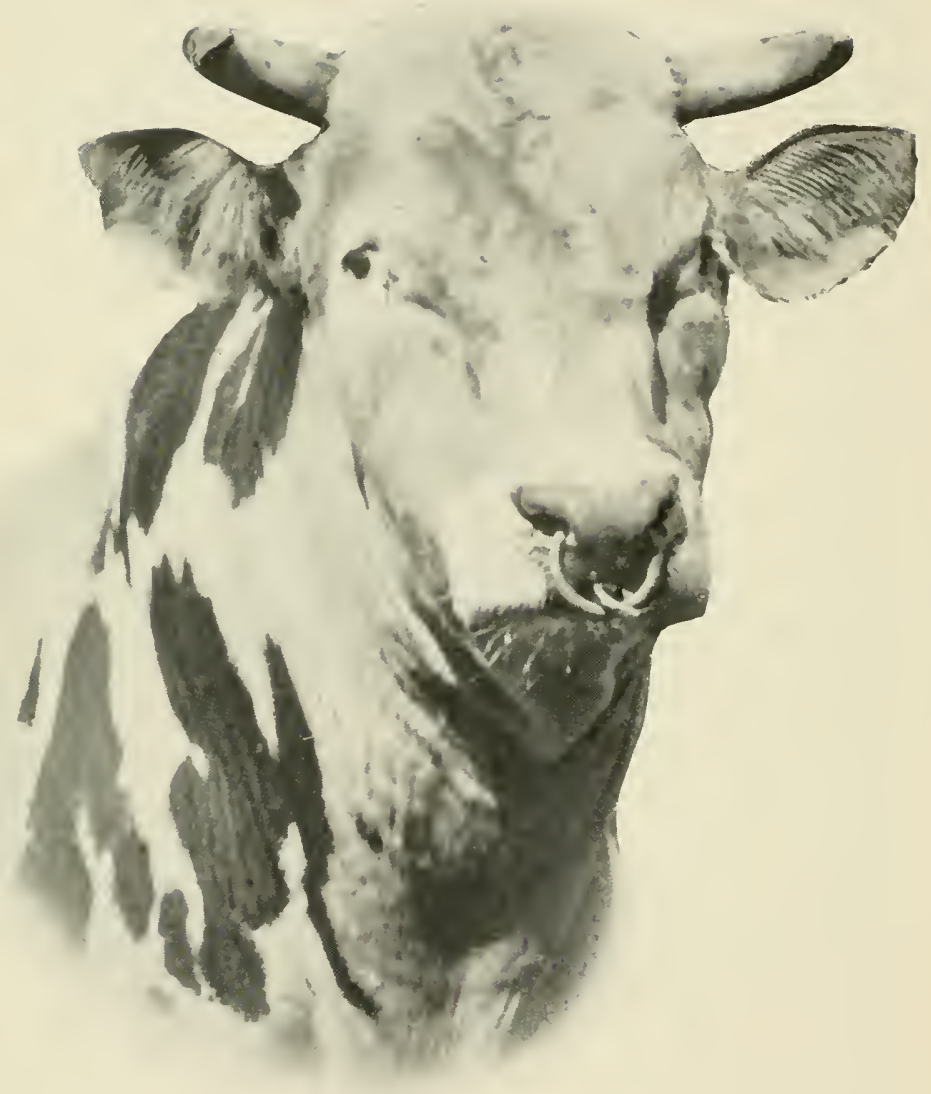

All the desirable points of the head are here 


\section{Missouri Rioter 3d}

"The next herd bull was Missouri Rioter $3 \mathrm{~d}$. This bull was the son of Missouri Rioter and was the only real good thing this latter sire left in the herd. The remarkable qualities of Missouri Rioter $3 \mathrm{~d}$ may come in part from his dam, which was the best cow in the herd up to that time. She, like the sire, was the offspring of Bachelor of St. Lambert.

"The best cows ever in our herd were sired by Missouri Rioteer 3d. From dams with average records of 4,609 pounds of milk he sired daughters whose records average 7.154 pounds. The dams averaged 238 pounds fat per year and the daughters raised this to 348 . Ten daughters of this bull produced $\$ 275$ worth of fat per year more than their dams. **** This bull was raised on the college farm and, as is often the case, because he was a home product instead of coming from a distant state, he was not counted of any special value, and was sold from the herd without any record ever being made as to his purchaser and was never transferred. His remarkable breeding value was recognized when it was too late and now we would like the chance of giving $\$ 1,000$ to have him back.

\section{Minnette's Pedro}

"Minnette's Pedro is the last herd bull with a sufficient number of daughters to give figures of any value. The herd remained practically at a standstill while he was at its head. In general this was not a very prepotent bull since we have wide variations and a lack of uniformity in his offspring. Among them are some excellent cows and some worthless. From the good dams we secured good daughters; from ininferior dams the same quality of daughters."

\section{Summing Up}

Of the five sires used in the history of the herd two increased the production, two lessened it and by the use of the fifth, the herd remained at a standstill. Were records kept of results attained on all farms they would not in many cases be found to be better and in many herds much worse.

By the use of one bull 110 pounds of butter-fat, worth at least $\$ 30$ is added to the average annual production per cow. If in his lifetime he sires 100 daughters, each of which work for 10 years he has proven his value. By the use of another bull 18 pounds of butter-fat worth over $\$ 4$ is lost from the average annual production per cow. If in this bull's life time he sires 100 daughters each of which works for 10 years his absolute worthlessness is proven. 


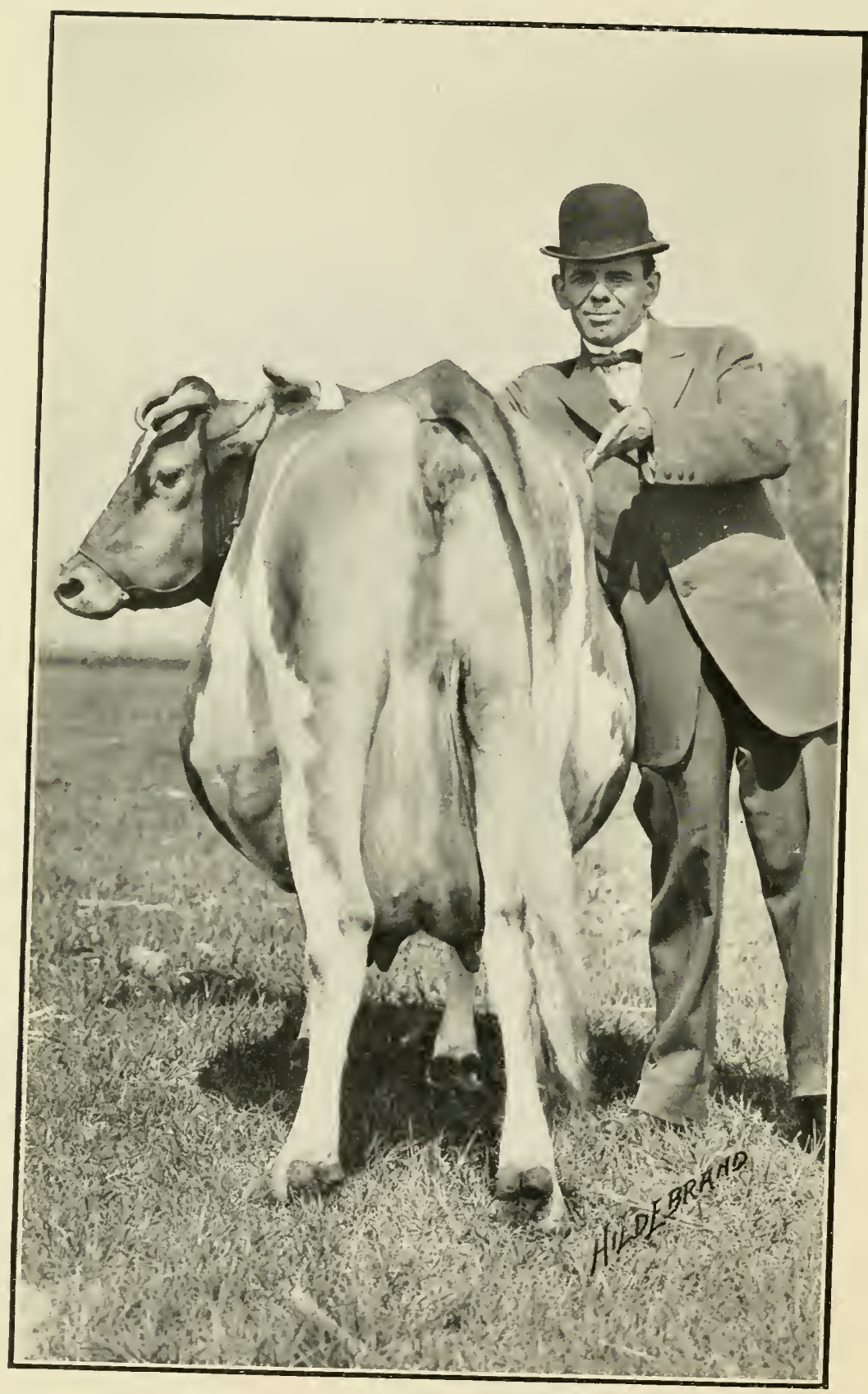

Width of hip essential to reproduction 


\section{The Accurate Proof of the Cow's Value}

Experience, care and good judgment exercised in examining cows soon lead to efficiency in detecting the points, the presence or absence of which indicates production. Especially valuable is the knowledge gained by a close study of the world's greatest cows and fixing thoroughly in mind the peculiar characteristics that account for their great work. In fact it is possible and advisable to study them so carefully that a distinct picture becomes impressed upon the mind's eye and then it is always possible to use them as models by which to measure other cows.

Mistakes in the selection of animals should not be a cause for discouragement. The best of judges make plenty of them and few are the herds indeed in which there are not counterfeits when judged by the pail and churn. Accurate as may be the ability of selecting good cows and discriminating against poor ones no judge has ever yet become sufficiently accomplished to prophesy the true productivity of the individual cow. A careful consideration of the points to be observed in selecting cows will invariably enable one to choose a good cow but, after he has chosen, he knows not just how good the cow may or may not be. The eye is not accurate enough to determine within a few pounds or sometimes within a few thousand pounds of how much milk a certain cow has the power of producing in a year. Neither is it possible to know within one or two per cent how rich her milk may be. So long as it is true that a careful consideration of the outward appearance of the cow is no more accurate than this, although being a valuable and absolutely necessary guide in selecting animals to add to the herd, it is well, in learning which ones to keep and which ones to dispose of, to supplement it with additional information. This will give the accurate worth of the herd since its future character depends largely upon the merit of the individuals in it.

The most accurate method of learning the cow's real productive power is the simplest and yet the mere suggestion of it seems such a bugbear to many that it is the least used. This fact is not only true of the farmer and dairyman but ap- 


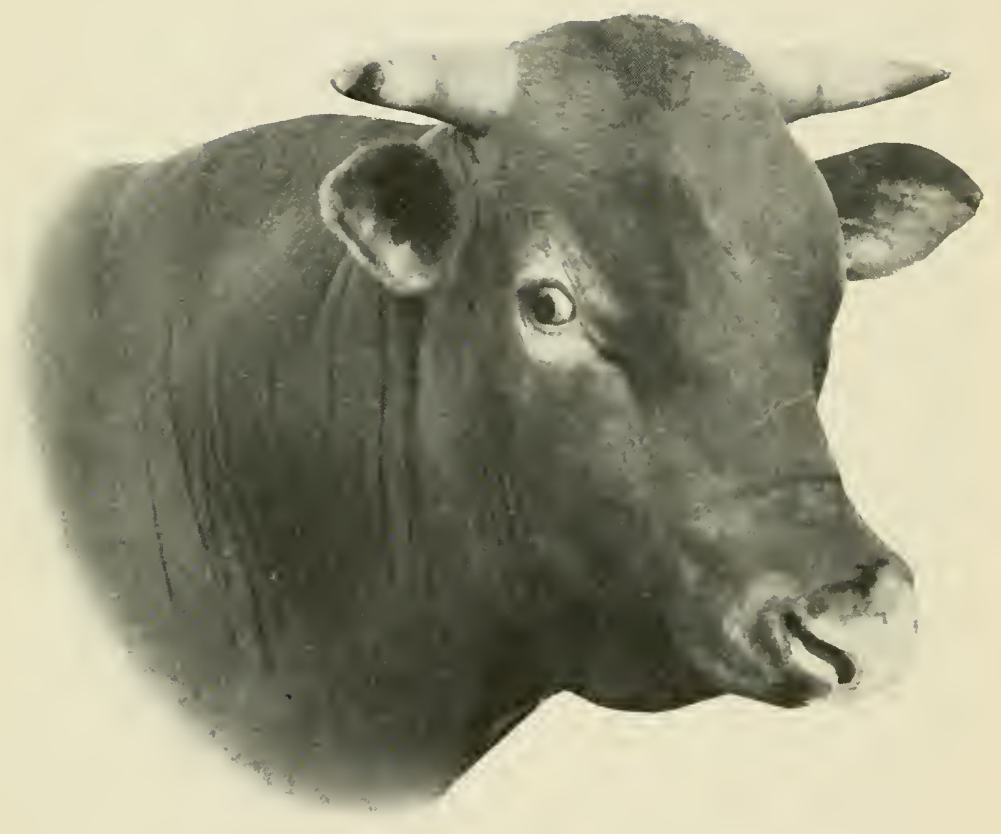

Masculinity and character 
plies also to a large percentage of breeders of no small reputation. Great changes have taken place in most breeds during the past few years and greater changes are yet to follow. In the future the famous breeder will be the one who knows his cows to a certainty, liaving learned them through the only accurate manner, that of weighing and testing the milk and keeping the records up to date and prizing them as he now does that which the pedigree and conformation implies. Then and not until then, will the greatest advancement ensue, for few indeed are the breeders who can boast of the fact that they never sold their best cow without knowing how really great she was.

\section{Keeping Records}

Furthermore, when all who term themselves breeders of pure bred dairy cattle weigh and test the milk of their cows, the general farmer will soon do likewise and it is then that he will appreciate the blood that the breeder has to dispose of through his bull calves. Not more than one year of record keeping is necessary to convince the most skeptical that blood will tell and that like produces like and records will point conclusively to the fact that certain breeds and certain families are decidedly more productive than others and that a still greater difference exists between individuals.

Continuous weighing and testing of milk, keeping in touch with the records, and by their use selecting the best cows to keep and those to sell to the man who has not time to keep records; the use of good sires from productive ancestry and raising the best calves from the best cows will result in time in a wonderful herd.

In fact it matters little how poor the herd being milked today, careful and accurate selection of cows and sires to mate with them will insure in a few generations a herd so great that if properly fed and cared for will have few superiors even including the breeder's herd.

Establishing records for individual cows with the scales and Babcock test demonstrates and proves the successes and failures in selecting cows. There is no better source of information for establishing knowledge pertaining to the types, breeds and families of cows that are desirable. By learning the mistakes once made one is in a position to guard against the same mistakes the second time while great as may be the mistake, if the maker never learns of it, he will readily make the same mistake a second, third and indefinite number of times. On the other hand it matters little how great the success once made, if the maker never learns of it, he is not in a position to repeat it with certainty. 


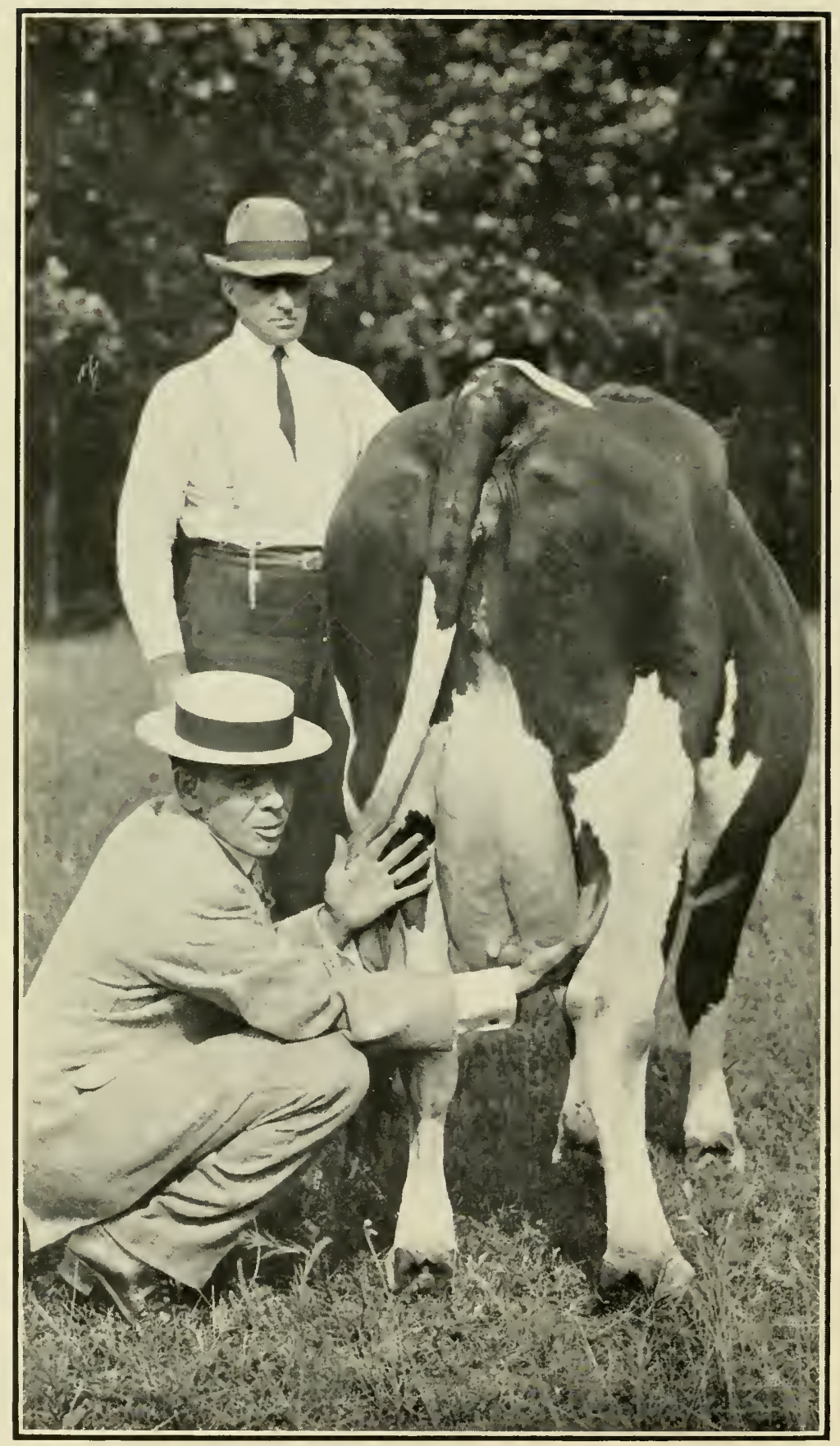

Width of udder. 


\section{Cost of Production}

Greatness of production as proven by weighing and testing the milk is not the complete record of the greatness of the cow for the question still remains as to the cost of production. And, after all, this is the vital question and the one that is growing in importance contintally. It is the rule that the coiv which yields largely of milk and butter-fat is the economical producer but it often occurs that of two cows producing the same amounts of milk and butter-fat in a given time one of them does so at a much less cost for feed. True it is that the difference in profits is not so largely governed by the cost of feed as in the yield but as conditions change, land becomes higher in price, feeds and labor scarcer and more expensive this difference will widen. Many dairymen even now weigh the food consumed by their individual cows and by doing so they reduce their business to the same commercial basis considered absolutely necessary in other lines of business. It pays, and pays well, for if in no other way it teaches the feeder the capacity and the ability of each cow. It enables him to exact the best work from her. Practical lessons of this sort are the valuable ones in rendering reliable the opinions relative to both the selection and feeding of cows for great and economical records.

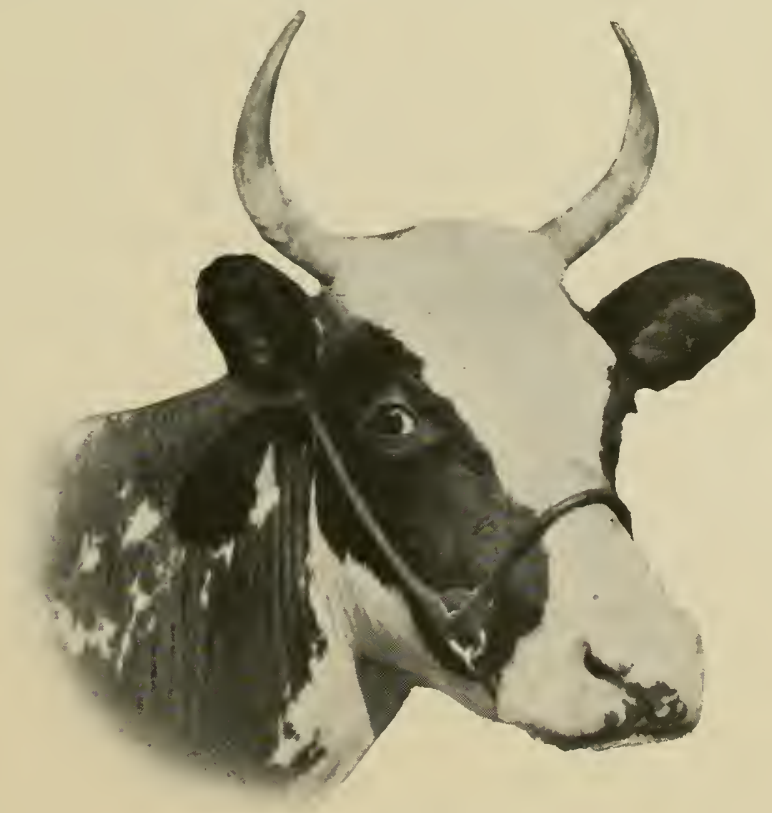



One copy del. to Cat. Div. 
